\title{
From Cellular Transport to Synthetic Biomimetic Transport using Carbon Nanotube - Actin Hybrid Assemblies
}

\author{
Zahra Ronaghi \\ West Virginia University
}

Follow this and additional works at: https://researchrepository.wvu.edu/etd

\section{Recommended Citation}

Ronaghi, Zahra, "From Cellular Transport to Synthetic Biomimetic Transport using Carbon Nanotube Actin Hybrid Assemblies" (2013). Graduate Theses, Dissertations, and Problem Reports. 4997. https://researchrepository.wvu.edu/etd/4997

This Thesis is protected by copyright and/or related rights. It has been brought to you by the The Research Repository @ WVU with permission from the rights-holder(s). You are free to use this Thesis in any way that is permitted by the copyright and related rights legislation that applies to your use. For other uses you must obtain permission from the rights-holder(s) directly, unless additional rights are indicated by a Creative Commons license in the record and/ or on the work itself. This Thesis has been accepted for inclusion in WVU Graduate Theses, Dissertations, and Problem Reports collection by an authorized administrator of The Research Repository @ WVU. For more information, please contact researchrepository@mail.wvu.edu. 


\title{
From Cellular Transport to Synthetic Biomimetic Transport using Carbon Nanotube - Actin Hybrid Assemblies
}

\author{
Zahra Ronaghi \\ Thesis submitted to the \\ at West Virginia University \\ in partial fulfillment of the requirements \\ for the degree of \\ Master of Science \\ in \\ Electrical Engineering \\ Parviz Famouri, Ph.D., Chair \\ Cerasela Zoica Dinu, Ph.D. \\ Dimitris Korakakis, Ph.D.
}

Benjamin M. Statler College of Engineering and Mineral Resources

Lane Department of Computer Science and Electrical Engineering Morgantown, West Virginia 2013

Keywords: Carbon Nanotubes, Actin, Hybrid Assembly

Copyright 2013 Zahra Ronaghi 


\begin{abstract}
From Cellular Transport to Synthetic Biomimetic Transport

using Carbon nanotube - Actin Hybrid Assemblies
\end{abstract}

Zahra Ronaghi

One of the many interesting materials that have emerged in the field of nanotechnology in the last quarter century is Carbon Nanotube (CNT). CNTs have been explored in a broad range of fields from electronic devices and biosensors, to bioimaging and tissue engineering. However, as stand-alone materials CNTs have limited capabilities in the field of biology and medicine unless they are combined with biological agents. Due to the similarity in diameters, CNTs can be combined with biomolecules such as enzymes, antibodies, antigens, DNA, etc. These "hybrid" assemblies will combine the properties of the CNTs with the recognition characteristics and functions of the biomolecules.

In our work we utilize one such biomolecule - actin, which is present in almost all eukaryotic cells and serves as scaffold for molecular motor myosin. The results of the research indicate that actin monomers (G-actins) were able to attach to Multi-Walled Carbon Nanotubes (MWCNTs). The MWCNTs exhibited close to full coverage by the Gactin proteins. Moreover, the G-actins remained functional and were able to polymerize into actin filaments (F-actin) onto the MWCNT scaffolds. Furthermore, the functionality of actin filaments on the surface of the MWCNTs was also investigated. The CNT-Factin hybrid assemblies showed limited movement in synthetic environment. This may be partially due to the inability of the myosin motors to recognize the polarity of the actin filaments, or due to steric hindrance and orientation of actin-based hybrids. The results of our work indicate that these hybrid assemblies can be useful for future biosensor applications with the protein acting as an agent for specific detection. 
To My Family 


\section{ACKNOWLEDGEMENTS}

I would like to sincerely thank my committee chair and advisor Dr. Parviz Famouri for his guidance, support and encouragement throughout my Masters' studies. I will always appreciate all his efforts towards my thesis as well as opening many doors for my future academic career. I would also like to thank my committee members Dr. Cerasela Zoica Dinu for her invaluable guidance and mentoring, and Dr. Dimitris Korakakis for his insight and suggestions.

My gratitude extends to Dr. John Zondlo for his invaluable support, enthusiasm and inspiration throughout my graduate studies. His wisdom will forever influence my current and future academic career, in particular making me understand the value of outreach and community activities that help build future engineers.

I would like to thank Yongkuk Lee and Chenbo Dong for their help with my project. I would like to acknowledge the help of everyone in the Lane Department of Computer Science and Electrical Engineering. I wish to thank the Shared Research Facility staff, especially Dr. Marcela Redigolo, for their help with my project and valuable training.

Lastly, and most importantly, I would like to thank my parents, my brother, my sister and my grandparents. They have always supported me throughout my life with their guidance, encouragement and unconditional love. I dedicate this thesis to them. 


\section{Table of Contents}

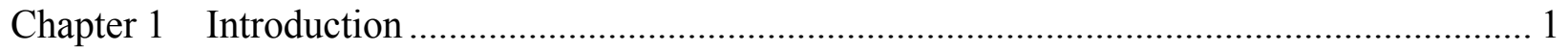

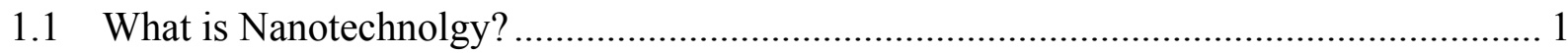

1.2 Motivation and Proposed Work ………………......................................................... 3

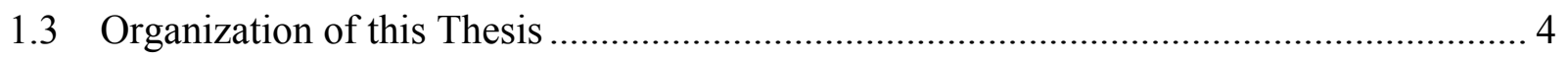

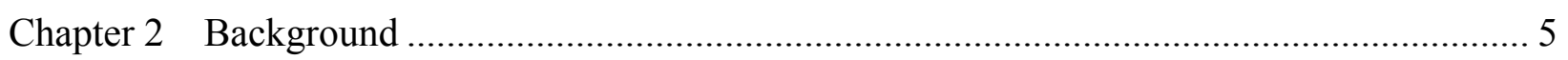

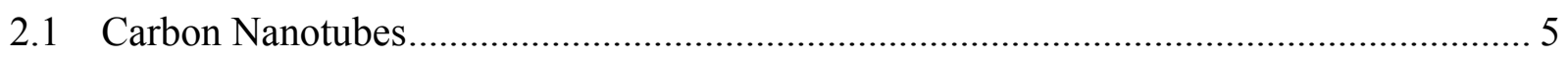

2.1.1 Carbon Nanotube History and Properties ……………………………………...... 5

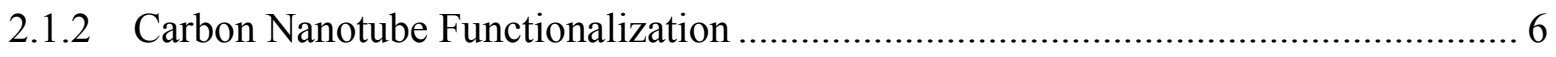

2.2 Structure and Function of Actin and Myosin .................................................................. 9

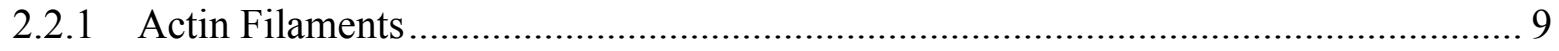

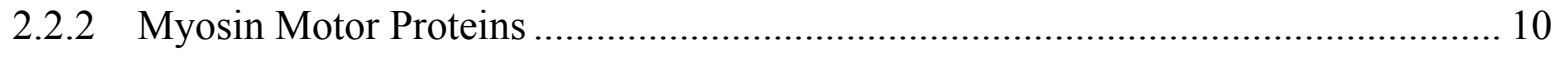

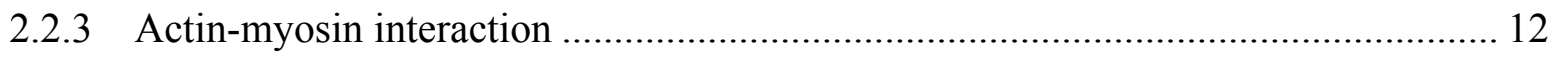

2.3 Structure and Function of Primary and Secondary Antibodies ...................................... 14

2.4 Structure and Function of Streptavidin and Biotin ....................................................... 16

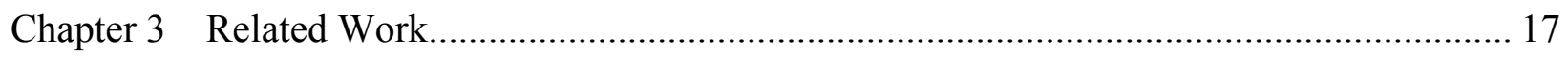

3.1 Carbon Nanotube- Microtubule Hybrid Assemblies ..................................................... 17

3.2 In Vitro Sliding of Actin Labeled Quantum dots.......................................................... 19

3.3 Transportation of Cargo using Actin Bundles ……........................................................ 19

3.4 Transportation of Actin-coated liposomes .................................................................. 20

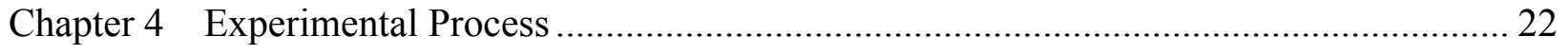

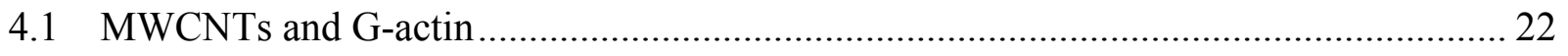

4.1.1 Experiment: Investigate the effect of DI water and G-buffer on MWCNTs........... 22

4.1.2 Experiment: Investigate the attachment of actin monomers onto MWCNTs.......... 22

4.1.3 Experiment: Investigate the functionality of MWCNT-G-actin conjugates............. 22 
4.2 MWCNTs and F-actin.

4.2.1 Experiment: Investigate the functionality of the MWCNT-F-actin assemblies using antibody recognition.

4.2.2 Experiment: Investigate the functionality of the MWCNT-F-actin assemblies using

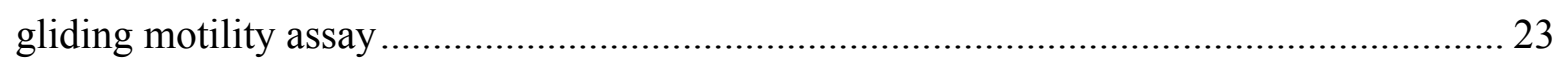

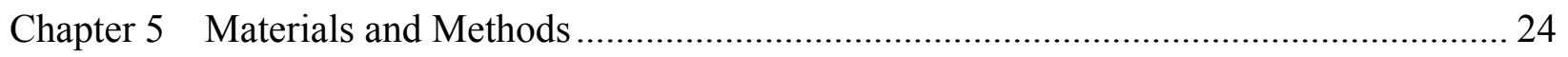

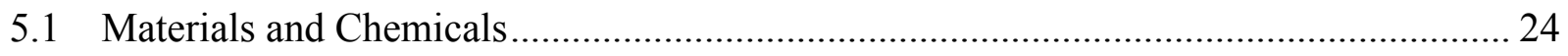

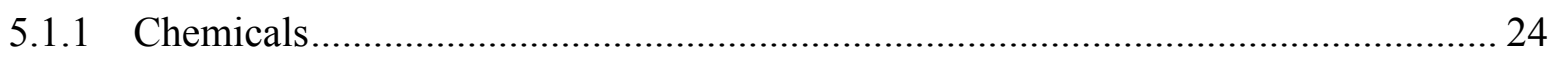

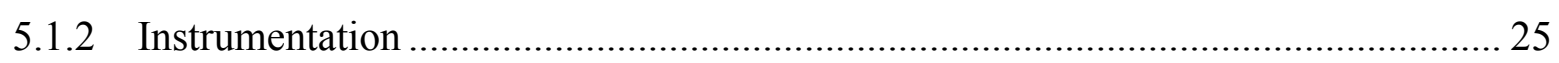

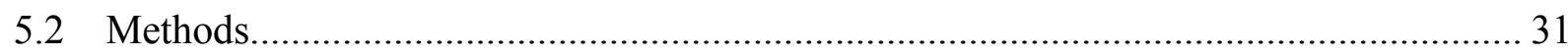

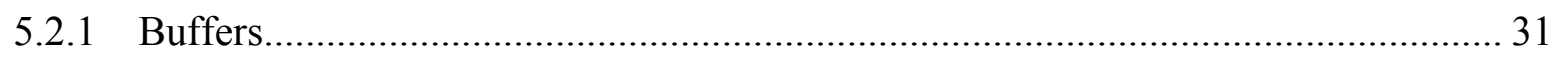

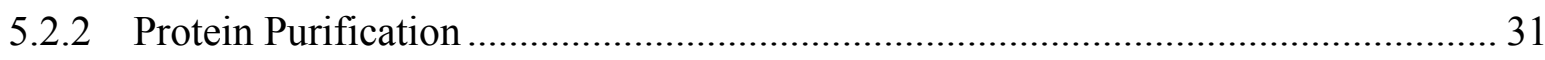

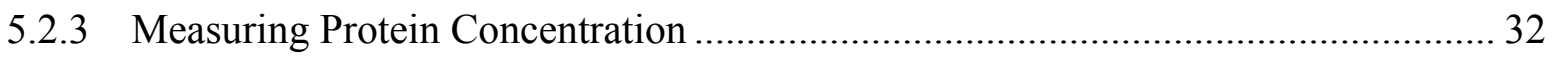

5.2.4 G-actin to F-actin polymerization ............................................................... 33

5.2.5 F-actin Labeling and observation.............................................................. 34

5.2.6 Antibody and bead attachment onto F-actins............................................... 34

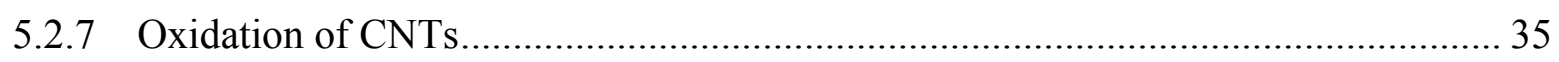

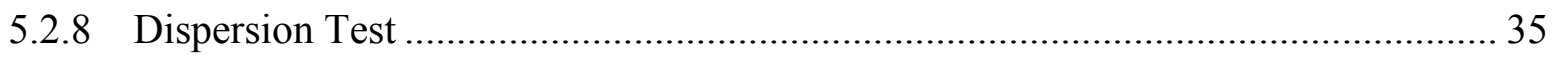

5.2.9 G-actin immobilization onto MWCNTs .................................................... 35

5.2.10 Calculation of G-actin loading onto MWCNTs ............................................. 36

5.2.11 Polymerization of G-actin on MWCNTs to F-actin ......................................... 36

5.2.12 Antibody and bead attachment onto CNT/F-actins ..................................... 37

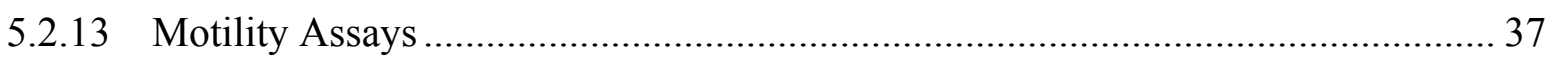

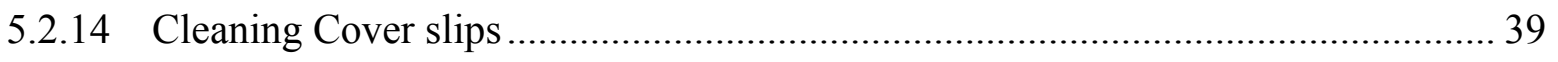

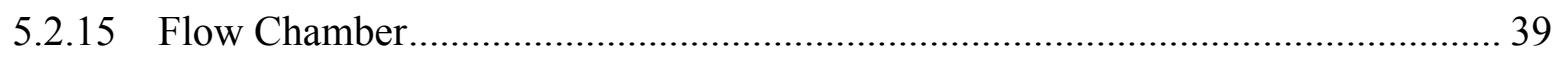

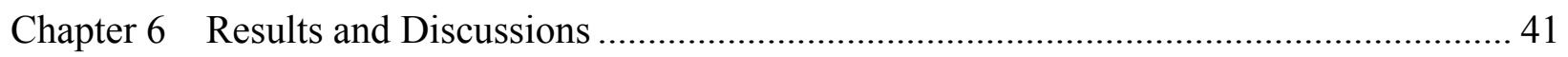




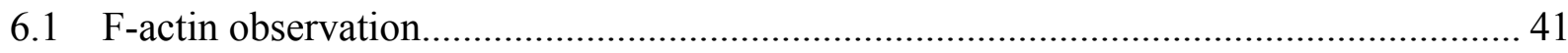

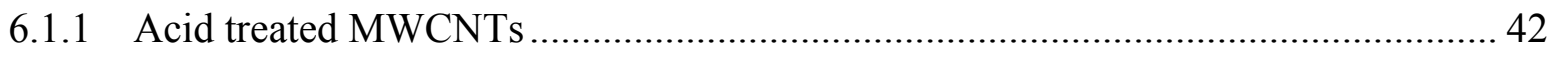

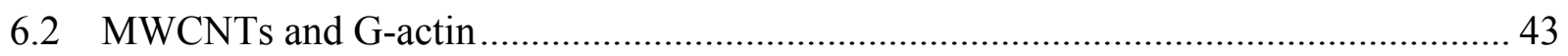

6.2.1 MWCNTs in G-actin Buffer (G-buffer) ………….............................................. 43

6.2.2 Attachment of G-actin to MWCNTs......................................................................... 43

6.2.3 Observing MWCNTS using DIC and fluorescent microscopy ................................ 44

6.2.4 Atomic Force Microscopy (AFM) for observation of G-actin ................................. 46

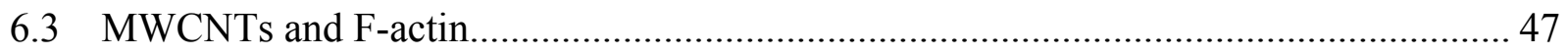

6.3.1 Functionality of MWCNT-G-actin conjugates ..................................................... 47

6.3.2 Functionality of MWCNT-F-actin hybrid assemblies ............................................. 48

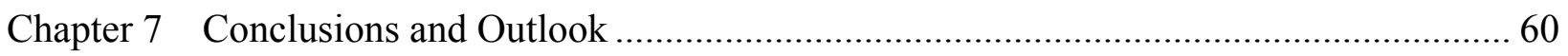

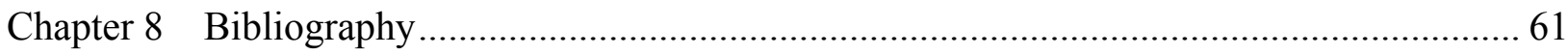




\section{List of Figures}

Figure 1.1 - Nanometer Scale, National Institutes of Health (NIH) .......................................... 1

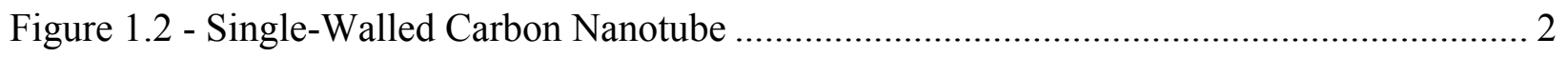

Figure 2.1 - Single-walled on the left and Multi-walled carbon nanotube on the right [22] .......... 5

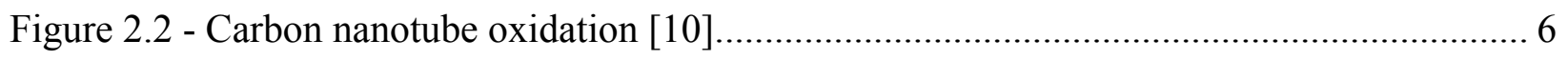

Figure $2.3-[2+1]$ cycloaddion of carbon nanotube [10] .................................................... 6

Figure 2.4 - Non-covalent coating of SWCNT with DNA [41] …………………………....... 7

Figure 2.5 - Carbon nanotubes encapsulating drugs and fullerene [44] f...................................... 8

Figure 2.6 - Left: Actin filament, Right: Actin molecule, yellow represents a single molecule of

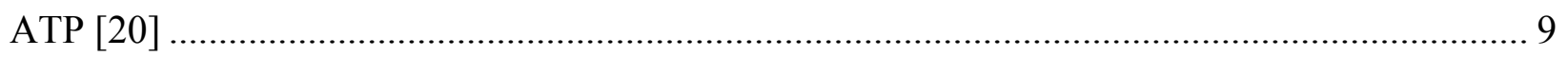

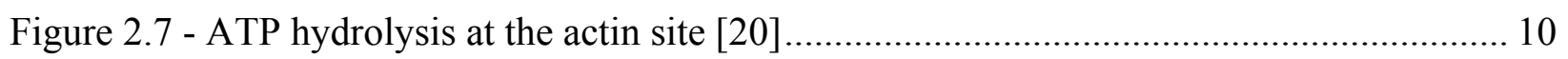

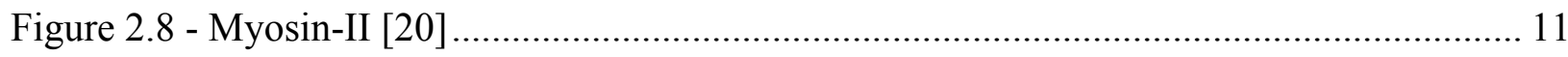

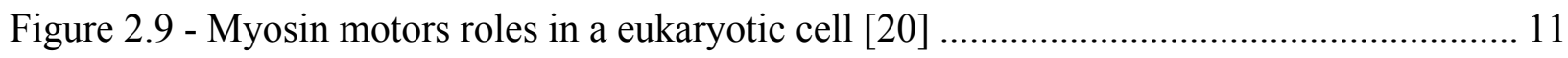

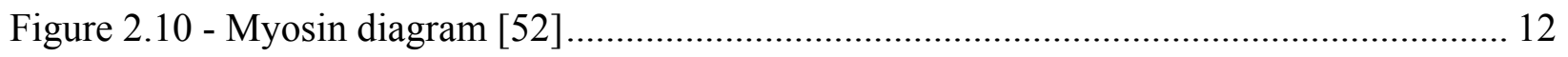

Figure 2.11 - Attachment of myosin and movement along actin [20] ....................................... 13

Figure 2.12 - Displacement of myosin along actin [20] ....................................................... 13

Figure 2.13 - Antibody and antigens, Wikimedia Common ...................................................... 14

Figure 2.14 - Structure of an antibody, Wikimedia Commons....................................................... 14

Figure 2.15 - Primary and secondary antibodies, Wikimedia Commons ..................................... 15

Figure 2.16 - Streptavidin (ribbon) bound to biotin (sphere), Wikimedia Common ...................... 16

Figure 3.1 - TEM images of a) Microtubule-MWCNTs b) MWCNTS without tubulin [58] ...... 17

Figure 3.2 - Schematic of microtubule vs. microtubule-MWCNT biohybrid motility [58] ......... 18

Figure 3.3 - Streptavidin-coated MWCNT and biotinylated microtubule hybrid [59]................. 18

Figure 3.4 - a) biotinylated liposome attached to actin bundle b) E. Coli attached to actin bundle

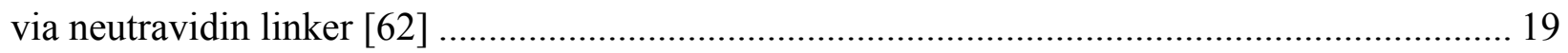

Figure 3.5 - Transmission electron microscopy of liposome attached to actin bundle [62] ......... 20

Figure 3.6 - Liposome coated actin filaments on HMM motor proteins [63]................................ 21

Figure 3.7 - Actin-coated liposomes at 6-second intervals on HMM-coated surface using phase-

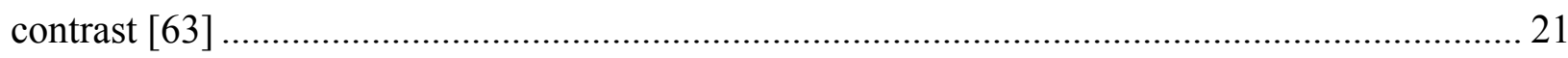


Figure 5.1 - Fluorescent Microscope, Wikimedia Commons …………………….......................... 26

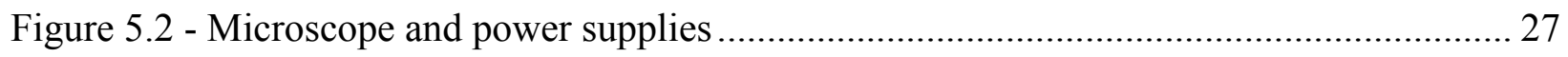

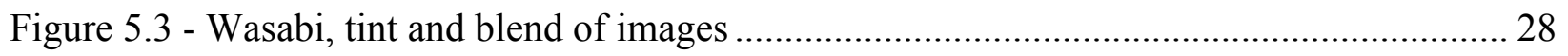

Figure 5.4 - Image J, manual tracking of actin filaments .......................................................... 29

Figure 5.5 - AFM contact mode - Wikimedia Commons ............................................................ 30

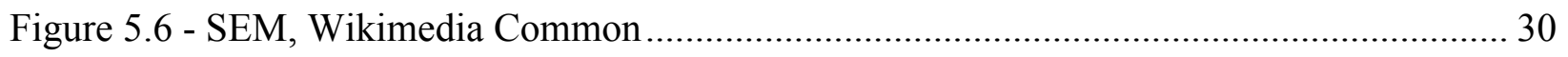

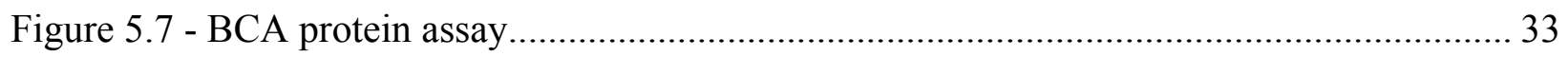

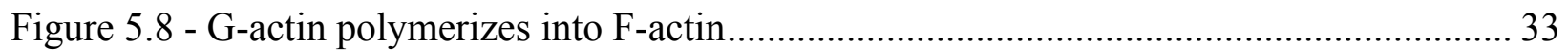

Figure 5.9 - F-actin-bead through primary and secondary antibodies ......................................... 35

Figure 5.10 - Carbon nanotube incubation with actin monomers.............................................. 36

Figure 5.11 - Polymerization of G-actin to F-actin on CNTs …………...................................... 37

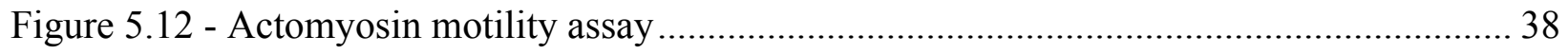

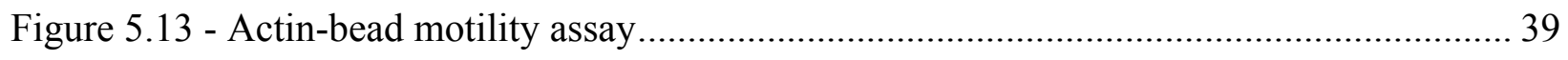

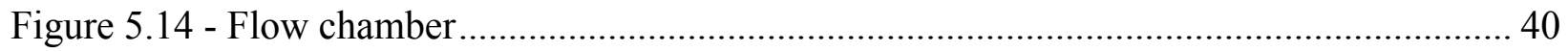

Figure 6.1 - Fluorescent actin filaments (F-actin) ………………………………………...... 41

Figure 6.2- Fluorescent actin filaments on PDDA-coated surface ………………………....... 42

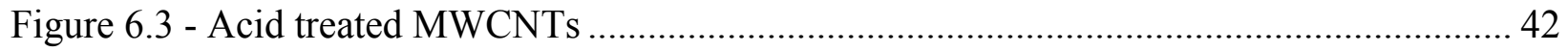

Figure 6.4 - MWCNTs in G-buffer on left and MWCNTs in water on right .............................. 43

Figure 6.5 - G-actin attached to MWCNTs on left and MWCNTs in G-buffer on right.............. 44

Figure 6.6 - A) MWCNT B) G-actin C) MWCNT/G-actin..................................................... 45

Figure 6.20 - MWCNT-F-actin hybrid assemblies on HMM ……………………...................... 58 


\section{Chapter 1 Introduction}

\subsection{What is Nanotechnolgy?}

Nanotechnology is defined as: "science, engineering, and technology conducted at the nanoscale, which is about 1 to 100 nanometers" [1]. One nanometer is a billionth of a meter $\left(10^{-9}\right.$ of a meter). Figure 1.1 shows various objects using a nanometer scale.

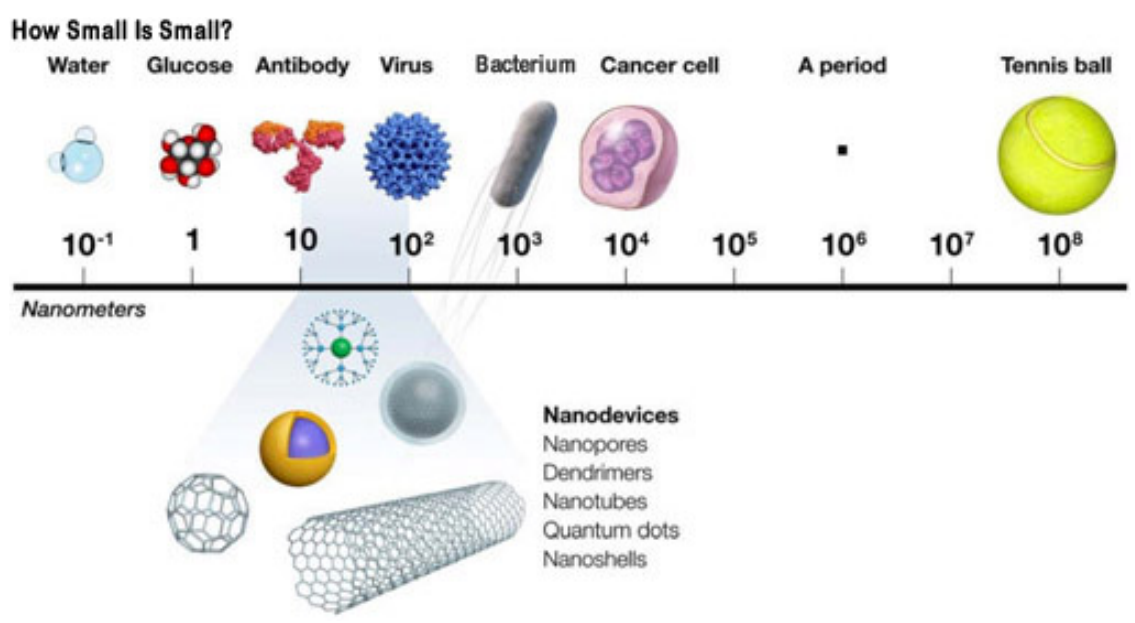

Figure 1.1 - Nanometer Scale, National Institutes of Health (NIH)

The concept of nanotechnology has been around for at least 50 years, with its basic principles and concepts being described by Richard Feynman in his seminal talk titled "There's Plenty of Room at the Bottom" at the California Institute of Technology in 1959. During this talk Feynman discussed the manipulation of materials at the atomic-level. Norio Taniguchi first introduced the term nanotechnology in 1974, in a paper titled "On the basic concept of nanotechnology" [2].

Today nanotechnology is being investigated in a variety of fields ranging from electronics [3] and energy [4] to medicine [5], food safety [6] and transportation [7]. For instance in medicine, nanotechnology may be utilized in the future for cancer therapy and diagnostic techniques as well as drug delivery and tissue engineering [8]. In electronics, nanoscale transistors have been made that are faster and more energy efficient when compared to their traditional counterparts [1]. 
One of the more interesting materials emerging in the field of nanotechnology is Carbon Nanotube (CNT). CNTs are hollow cylinders made of carbon atoms. Two main forms of CNTs are - Single-Walled Carbon Nanotubes (SWCNTs), which consist of a single graphene sheet and Multi-Walled Carbon Nanotubes (MWCNTs), which are made of multiple layers of graphene sheets $[9,10]$. A typical SWCNT is shown in Figure 1.2.

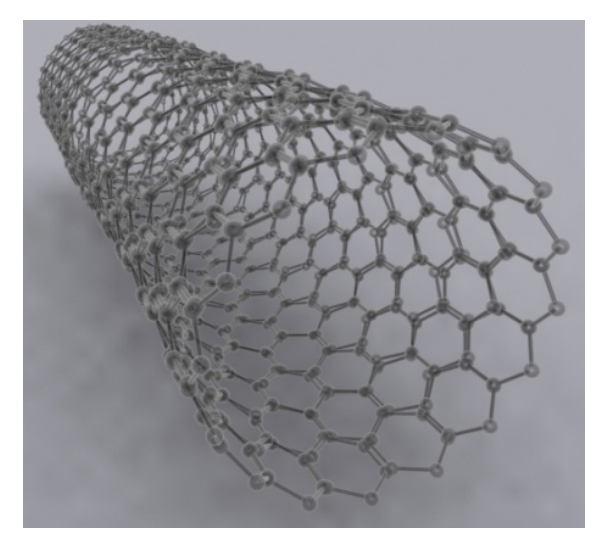

Figure 1.2 - Single-Walled Carbon Nanotube

As stand-alone materials CNTs have limited abilities in the field of biology and medicine unless combined with other biological agents. Combining nanomaterials, such as CNTs, with biomolecules (such as enzymes, antibodies/antigens/DNA) can lead to the creation of hybrid assemblies, which combines both the recognition abilities and function of the biomolecules along with the properties of the CNTs [11].

Another emerging area of research in the field of nanotechnology has been investigating transportation of biomolecules and nanoparticles in vitro through the use of molecular motors [12]. Motor proteins, such as kinesin and myosin and their associated filaments (microtubule and actin filaments), have been used in a variety of applications for the purpose of sorting [13], detection [14], and transportation [15,16]. Motor proteins and their filaments have been used along with Adenosine Triphosphate (ATP) as the energy source to create miniaturized and integrated devices; without the use of external pumps and energy sources in replacement of microfluidics for higher efficiency and sensitivity [17-19]. 


\subsection{Motivation and Proposed Work}

In this research actin was utilized in conjunction with CNTs to develop functional hybrid assemblies. Actin is present in almost all eukaryotic cells and serves as scaffold for molecular motor myosin.

One of the purposes of this research includes analyzing the behavior and functionality of actin monomers when immobilized onto CNTs when compared with free G-actin in solution. In the cell G-actin polymerizes to F-actin, a major component of the cellular cytoskeleton [20]. If the immobilized G-actin is still functional, then addition of extra free G-actin will lead to polymer-based structure onto MWCNTs scaffolds.

Another goal was to investigate the functionality of the CNT-F-actin. Recognition of actin filaments on the surface as well as motility of these proposed hybrids were tested using myosin and ATP in a gliding motility assay. Myosin is one of the motor proteins present in the cell that converts chemical energy to mechanical movement through hydrolysis of ATP. Actinmyosin assemblies participate in many cellular processes from contraction to cell motility and division [20]. Creating functional hybrid assemblies may facilitate possible solutions for transportation of biological and non-biological samples to specific locations in vitro. 


\subsection{Organization of this Thesis}

The thesis presented herein is organized as follows:

- Chapter 2: provides an overview of the background knowledge that is essential to understanding this work. In particular, an overview of CNTs, actin, myosin, streptavidin, and biotin is provided.

- Chapter 3: provides a closer look at the current state of the art in CNT and protein based system and their applications.

- Chapter 4: presents the experiments conducted in this research. This provides the foundation that was used to investigate the properties of CNT and actin-CNT hybrid assemblies.

- Chapter 5: provides an overview of the materials and methods that were required to conduct the experiments described in Chapter 4.

- Chapter 6: provides the results and conclusions obtained upon performing each of the experiments in Chapter 4.

- Chapter 7: provides the concluding remarks and presents potential areas of future work. 


\section{Chapter 2 Background}

\subsection{Carbon Nanotubes}

\subsubsection{Carbon Nanotube History and Properties}

Carbon Nanotubes (CNTs) are hollow cylinders made of carbon atoms. Sumio Iijima discovered MWCNTs in 1991. In 1993, Iijima and Ichihashi from Nippon Electric Company (NEC) as well as Bethune et al. from IBM independently published on the formation of singlewalled carbon nanotubes [21]. Figure 2.1 shows a typical single-walled carbon nanotube on the left and a multi-walled carbon nanotube on the right.

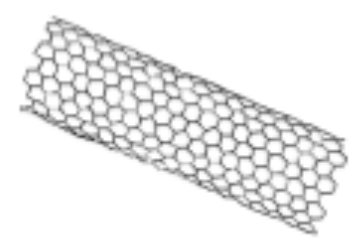

SWCNTS

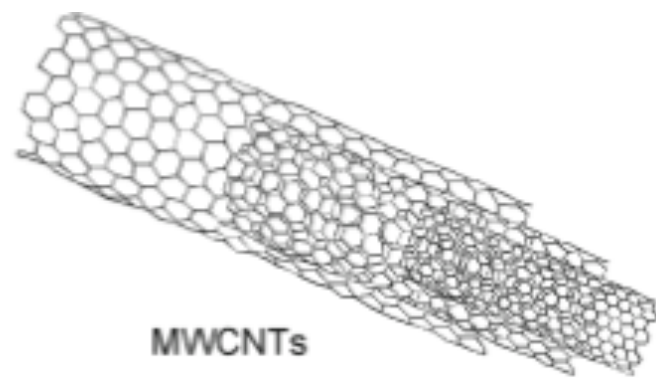

Figure 2.1 - Single-walled on the left and Multi-walled carbon nanotube on the right [22]

SWCNTs have diameters of 0.4-2 nm, while MWCNTS have multiple layers of graphene that results in a larger diameter ranging from 2 to $100 \mathrm{~nm}$ with lengths from nanometer to centimeters. The optical characteristics of SWCNTs provide better optical absorption and can be effective as biological imaging, while MWCNTs can be used to effectively transport larger biomolecules [9].

CNTs are nanomaterials with unique properties, for example large surface area, high electrical conductivity, chemical stability and mechanical strength that make them applicable in electronics [23-27], biosensors [28-30], drug delivery [31,32], tissue engineering [33], bioimaging [34,35], and more [36-38]. 


\subsubsection{Carbon Nanotube Functionalization}

Carbon nanotubes have highly hydrophobic surfaces, which limits their dispersion in aqueous solutions. Surface chemistry modification or functionalization is used to increase dispersity in biological and biomedical applications. Functionalization of carbon nanotubes can be done using covalent or non-covalent approaches based on the desired applications [36].

\subsubsection{Covalent functionalization of carbon nanotubes}

One of the most commonly used methods for covalent functionalization involves oxidation of CNTs using acid oxidizing agents such as nitric and sulfuric acids. This process enables formation of carboxyl groups onto the nanotube ends and at the defects site on their sidewalls. Oxidation increases carbon nanotubes solubility and also attachment of biomolecules such as proteins and DNAs via covalent binding for various applications [36]. However, such process can significantly influence the structure and properties of carbon nanotubes [39].

Another method for covalent functionalization that increases sidewall functionalization is cycloaddition reaction. Figure 2.2 and 2.3 illustrate covalent functionalization of carbon nanotubes using oxidation and cycloaddition of CNTs respectively [10].

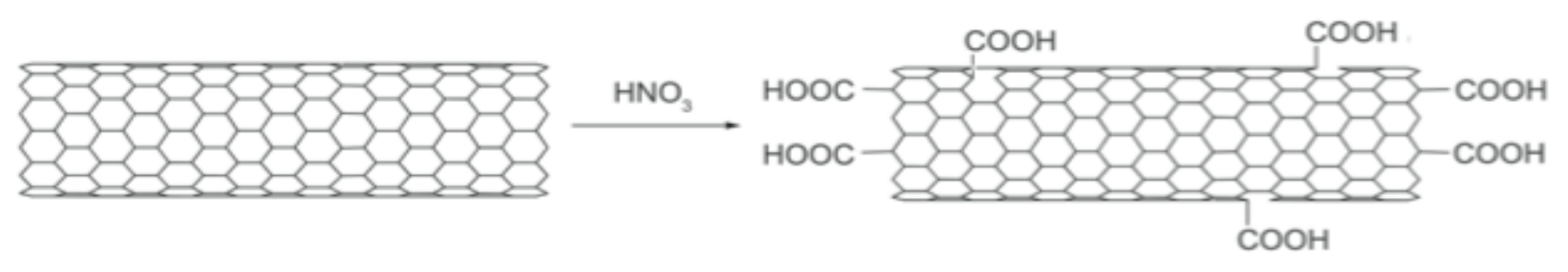

Figure 2.2 - Carbon nanotube oxidation [10]
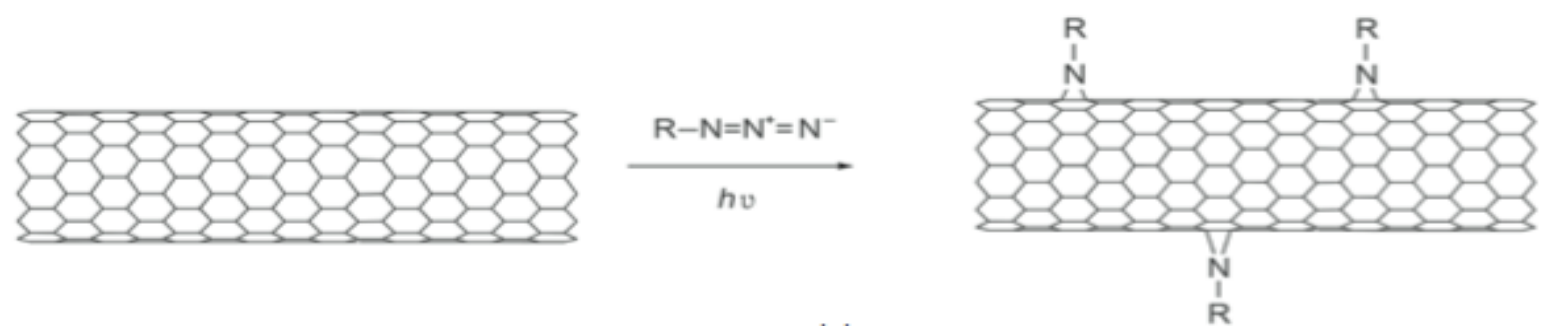

Figure $2.3-[2+1]$ cycloaddion of carbon nanotube [10]

\subsubsection{Non-covalent functionalization}

Different non-covalent functionalization approaches include: coating carbon nanotubes with surfactants, polymers and biomolecules through van der Waals forces, hydrophobic 
interactions and $\pi-\pi$ stacking [40]. As an example, polyethylene glycol (PEG) can be used for non-covalent coating and also prevention of non-specific protein binding [39].

Commercial availability and low cost of surfactants has made them interesting solutions for functionalization of carbon nanotubes. Generally, polymers have the advantage of robust surface adsorption over surfactants. Hydrophobic interactions of carbon nanotubes can dominate adsorption of polymers, and therefore affect the dispersion efficiency [36]. Figure 2.4 illustrates non-covalent attachment of single-stranded DNA on SWCNT through $\pi-\pi$ stacking.

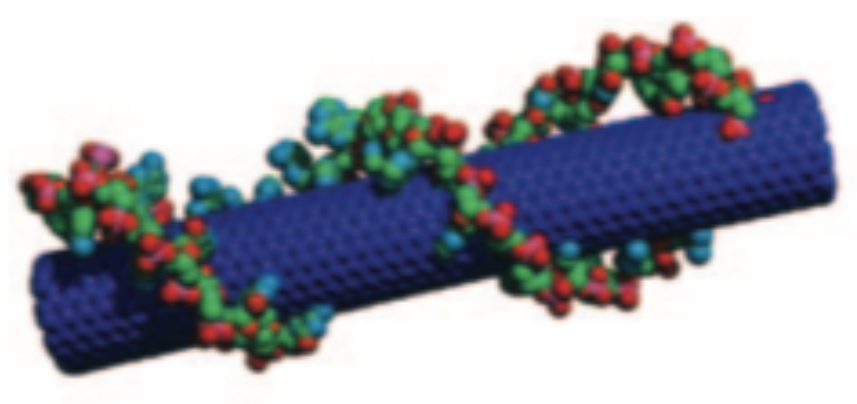

Figure 2.4 - Non-covalent coating of SWCNT with DNA [41]

Advantages of covalent functionalization include robustness when compared to noncovalent functionalization; however excessive oxidation can influence the structure and properties of the carbon nanotubes such as photoluminescence and Raman scattering [10].

Unlike in covalent functionalization, the physical properties and structure of CNTs are not affected by physical functionalization. However, based on the application, non-specific binding and denaturation of the attached target biomolecule may be some of the disadvantages [42]. 


\subsubsection{Carbon nanotube-based encapsulation}

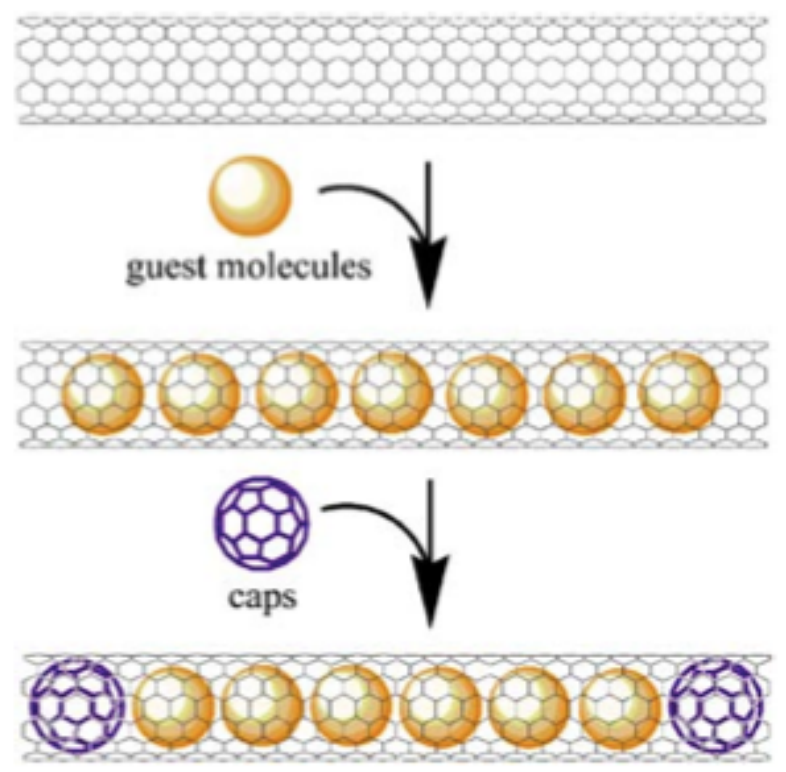

Figure 2.5 - Carbon nanotubes encapsulating drugs and fullerene [44]

Encapsulation of materials inside carbon nanotubes has been investigated for applications ranging from storage of liquids and materials, to drug delivery, or nanowires, etc [43]. Some of the materials investigated include liquids [45], biomolecules such as DNA [46] and protein [47], fullerene derivatives [48] and organics [49]. One of the advantages of encapsulating materials inside CNTs is protection and control delivery to specific and desired locations [50]. Figure 2.5 illustrates encapsulation of an anticancer drug and C60 fullerenes to seal the carbon nanotubes for protection of the drug [44]. 


\subsection{Structure and Function of Actin and Myosin}

The cytoskeleton consists of three cytoskeletal filaments: actin filaments, microtubules and intermediate filaments. These protein filaments are involved with many activities including the shape and movement of the cell, muscle contraction, and intracellular transport of organelles. Motor proteins are molecular motors that move along cytoskeletal filaments by converting chemical energy to mechanical movement through hydrolysis of ATP. For example myosin and kinesin motor proteins bind to and interact with actin filaments and microtubules respectively [20].

\subsubsection{Actin Filaments}

Actin is highly conserved protein present in almost all eukaryotic cells and serves as scaffold for myosin molecular motors. Actin filaments consist of double stranded helical arrangement of actin molecules (Globular actin or G-actin) with diameters from 7 to $9 \mathrm{~nm}$. They are polar structures with a plus and a minus end. The minus end also called "pointed end" is the slow growing side and the plus end or "barbed end" is the faster growing side. This means the barbed end polymerizes faster to form the F-actin than the pointed end [20]. Figure 2.6 on the left illustrates the arrangement of actin molecules (G-actin) in an actin filament (F-actin) with the structure repeating every 37 nanometers. The figure on the right is a three-dimensional model of an actin molecule using X-ray diffraction.
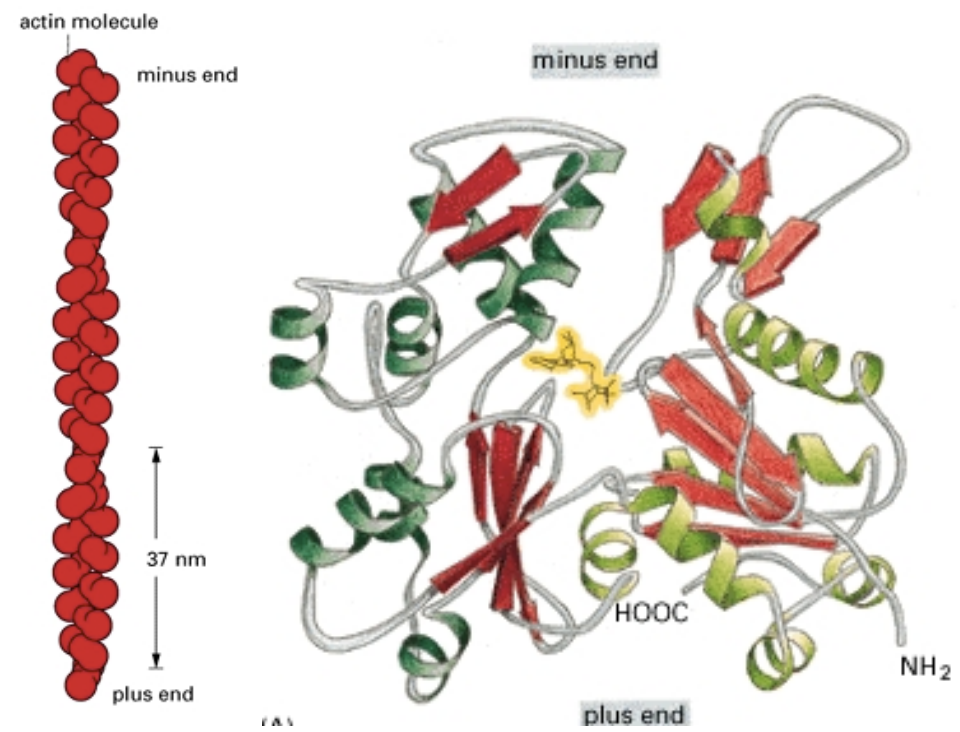

Figure 2.6 - Left: Actin filament, Right: Actin molecule, yellow represents a single molecule of ATP [20] 
Polymerization of actin molecules to actin filaments in vitro occurs by addition of $\mathrm{K}^{+}$and $\mathrm{Mg}^{2+}$ in the presence of ATP. The polymerization rate at the barbed end is up to 10 times faster than the pointed end. The critical concentration $(\mathrm{Cc})$ is an important factor in the polymerization process. At the $\mathrm{Cc}$ value, concentration of actin monomers is in equilibrium with actin filaments. This value is around $0.1 \mu \mathrm{M}$ for in vitro conditions and enables polymerization when G-actin concentration is above this value. Depolymerization of F-actin occurs below the critical concentration. After polymerization ATP is hydrolyzed to Adenosine Diphosphate (ADP) and trapped inside the actin filament until depolymerization occurs [20, 51]. Figure 2.7 illustrates the ATP hydrolysis procedure at the actin site.

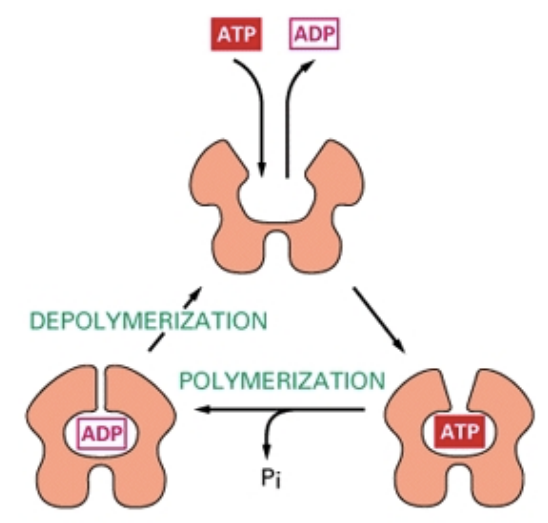

Figure 2.7 - ATP hydrolysis at the actin site [20]

The dynamic behavior of actin filaments in cells has been investigated using drugs that stabilize or destabilize F-actin. Cytochalasins are fungal products that attach to the barbed end and prevent polymerization while phalloidin toxins from Amanita mushroom bind along actin filaments to prevent depolymerization. Fluorescent derivatives of phalloidin can be used to observe actin filaments using fluorescent microscopy [20].

\subsubsection{Myosin Motor Proteins}

Myosin motor proteins are a class of molecular motors that recognizes and bind to the actin filaments. Myosin proteins convert chemical energy from ATP hydrolysis to mechanical work and produce the required energy for movement of actin filaments. Almost all myosin motors move along actin filaments from the minus end towards the plus end. Myosin-I and Myosin-II are the most studied myosin proteins as they are present in almost all eukaryotic cells [51]. 
Muscle myosin is one of the subfamilies of myosin (Myosin-II). Myosin-II is responsible for muscle contraction and cytokinesis and consists of two heavy chains and four light chains. Each of the two heavy chains has a head domain with an ATPase and actin binding site, a neck domain that light chains bind to, and a tail domain. The amino side is called the $\mathrm{N}$ terminus, which is the motor domain, and the carboxyl side is named the $\mathrm{C}$ terminus [20]. Figure 2.8 depicts myosin-II.

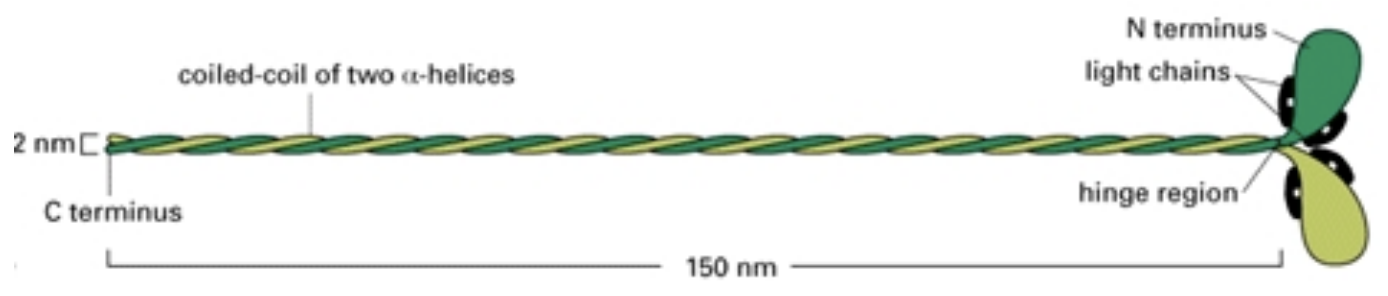

Figure 2.8 - Myosin-II [20]

Non-muscle cells contain smaller myosin motors including Myosin-I. Myosin-I is involved in cytoskeleton-membrane interactions including transportation of membrane vesicles. Depending on the tail of myosin motors, they can move vesicles or actin filaments [20]. Figure 2.9 shows the different roles of Myosin-I and Myosin-II.

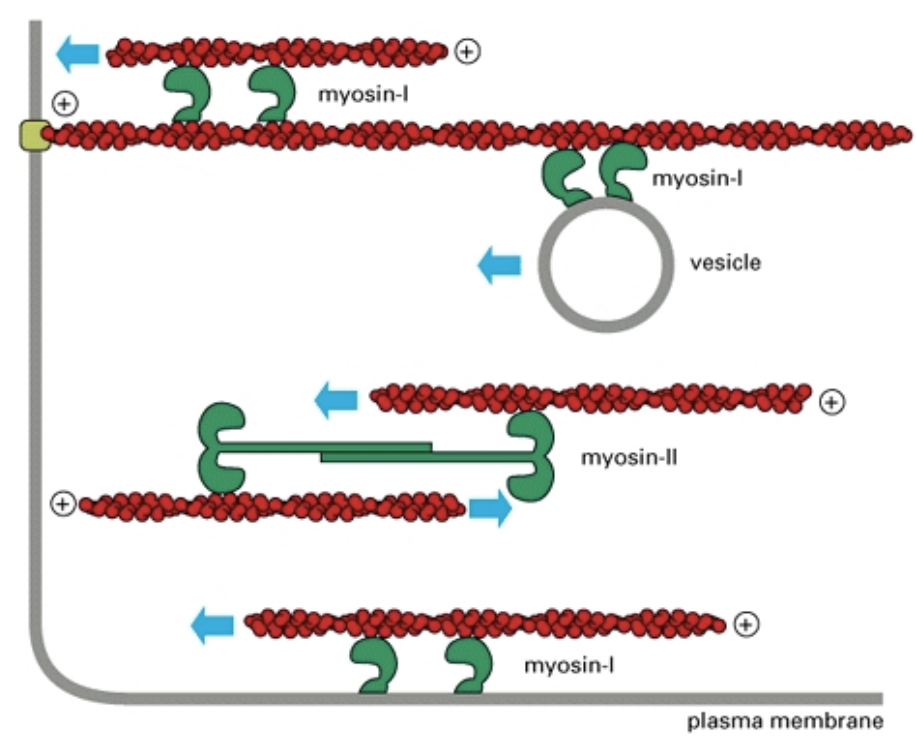

Figure 2.9 - Myosin motors roles in a eukaryotic cell [20] 


\section{Heavy MeroMyosin (HMM)}

Myosin-II can be cleaved into Heavy Meromyosin (HMM) and Light Meromyosin (LMM) using $\alpha$-chymotrypsin. HMM consists of head domains, light chains and part of the coiled-coil tail [52]. Figure 2.10 shows a diagram of myosin-II:

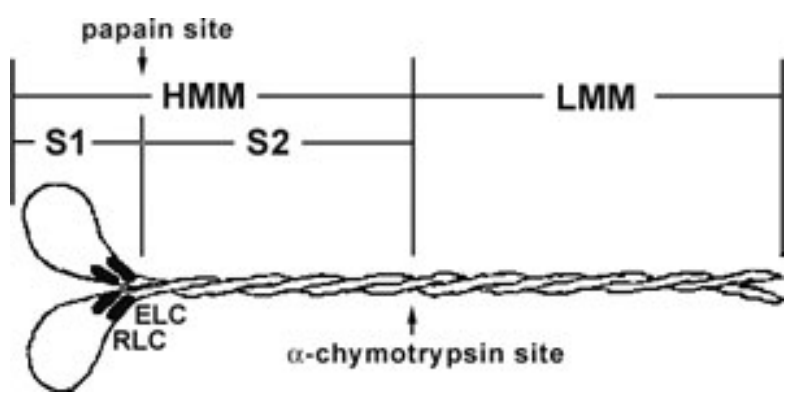

Figure 2.10 - Myosin diagram [52]

In work by Guo and Guilford [53] motility of mysoin-II was compared to HMM and subfragment- 1 for in vitro applications. The authors mention that results of motility assays have indicated a higher velocity for HMM-coated surface and lower velocity on subfragment-1 when compared to myosin. Unknown interactions between myosin and actin filaments may cause the observed slower movement of the filaments. Also, interaction of mysoin with nitrocellulosecoated surfaces for in vitro motility assays may cause denaturation of the tail and results in nonnative interactions between actin filaments and myosin. The authors further investigated effects of low ionic strength of solutions for in vitro motility assays on actin interaction with the tail domain (LMM). The results indicate that increasing the ionic strength to achieve ionic strengths close to physiological conditions, decreased the difference between velocities of HMM and HMM/LMM mixture [53].

\subsubsection{Actin-myosin interaction}

Actin-myosin assemblies participate in many cellular processes from contraction to cell motility and division. In the first step of actin movement, a myosin head binds tightly to an actin filament. This state ends rapidly by attachment of an ATP molecule. The binding of ATP reduces the affinity of the myosin head and allows movement along the filament [20]. Figure 2.11 illustrates these first two steps: 


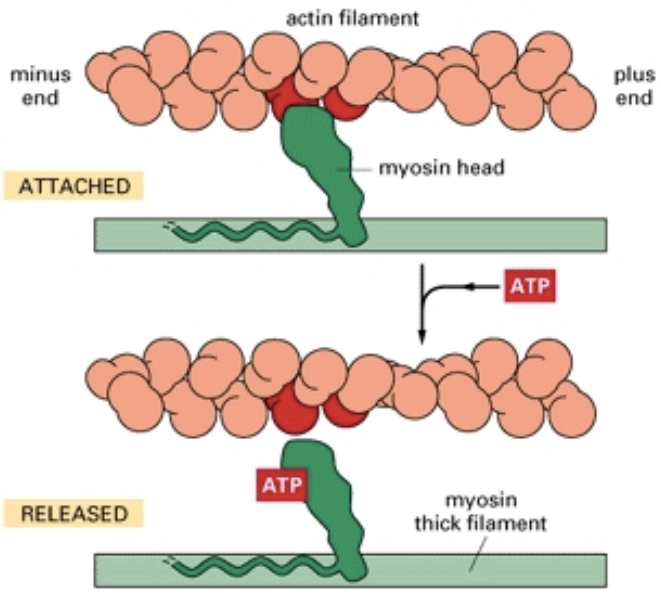

Figure 2.11 - Attachment of myosin and movement along actin [20]

Next, through ATP hydrolysis ADP and Pi are produced but remain attached to the myosin head. The myosin head is displaced along the filament, this new weak binding causes Pi to get released and also causes a power stroke. The power stroke releases ADP resulting in the myosin head binding tightly to the actin filament and returning to the start of a new cycle [20]. Figure 2.12 depicts these steps:

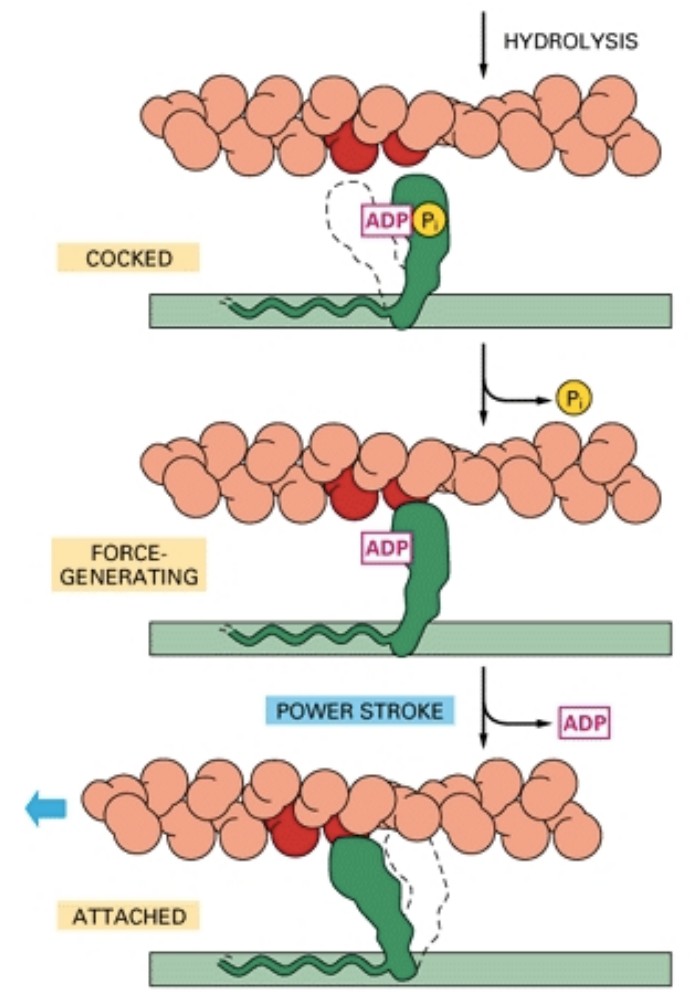

Figure 2.12 - Displacement of myosin along actin [20] 


\subsection{Structure and Function of Primary and Secondary Antibodies}

Antibodies $(\mathrm{Ab})$ are proteins produced by the immune system to detect and neutralize foreign and harmful targets. These large Y-shaped proteins recognize antigens (a unique part of the targets) through the antigen binding sites [54]. Figure 2.13 shows the interaction between an antibody and antigens.

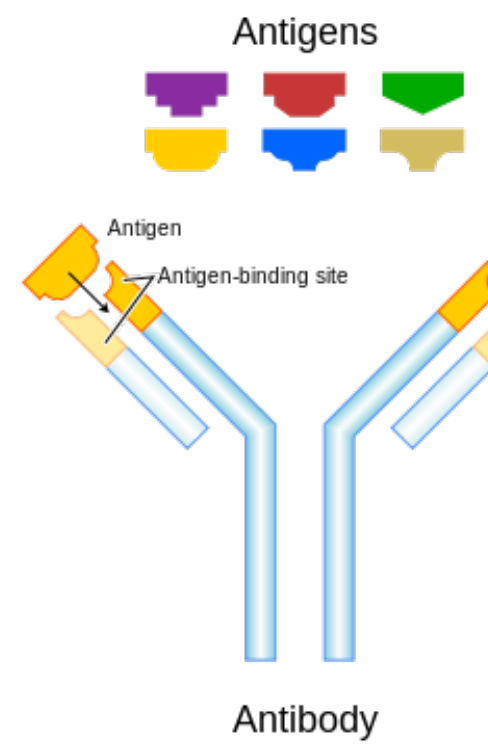

Figure 2.13 - Antibody and antigens, Wikimedia Common

Antibodies contain two identical heavy chains and two identical light chains that are connected through disulfide bonds. The class of an antibody is based on the type of heavy chains present in that antibody [54]. Figure 2.14 illustrates the structure of an antibody:

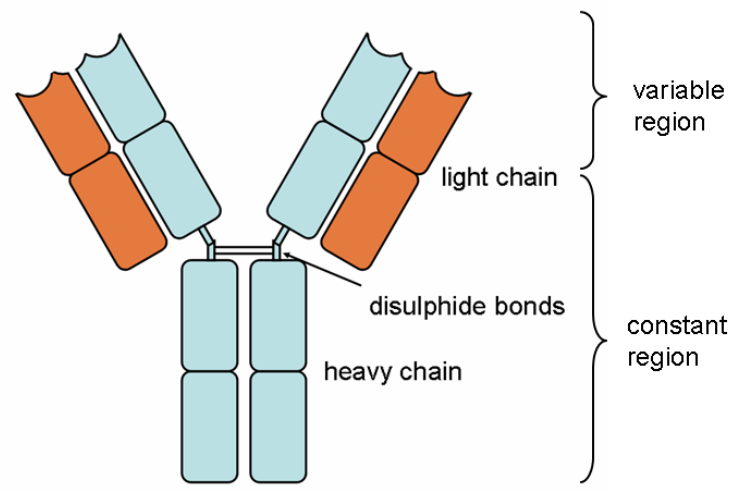

Figure 2.14 - Structure of an antibody, Wikimedia Commons 
Antibodies can be used in different bionanotechnology applications to detect a specific antigen. The two methods of detection include direct and indirect detections. Direct detection involves using a primary antibody that binds to a specific antigen. However, primary antibodies are usually unlabelled. Secondary antibodies labeled with probes can bind to primary antibodies or primary antibody fragments for indirect detection.

Secondary antibodies used for indirect detection offer advantages compared to labeled primary antibodies. Binding of several secondary antibodies to a primary antibody increases sensitivity through signal amplification; also secondary antibodies can bind to primary antibodies of the same isotype whereas primary antibodies bind to specific antigens with the same conserved domains [55]. Figure 2.15 illustrates primary and secondary antibodies detecting antigens:

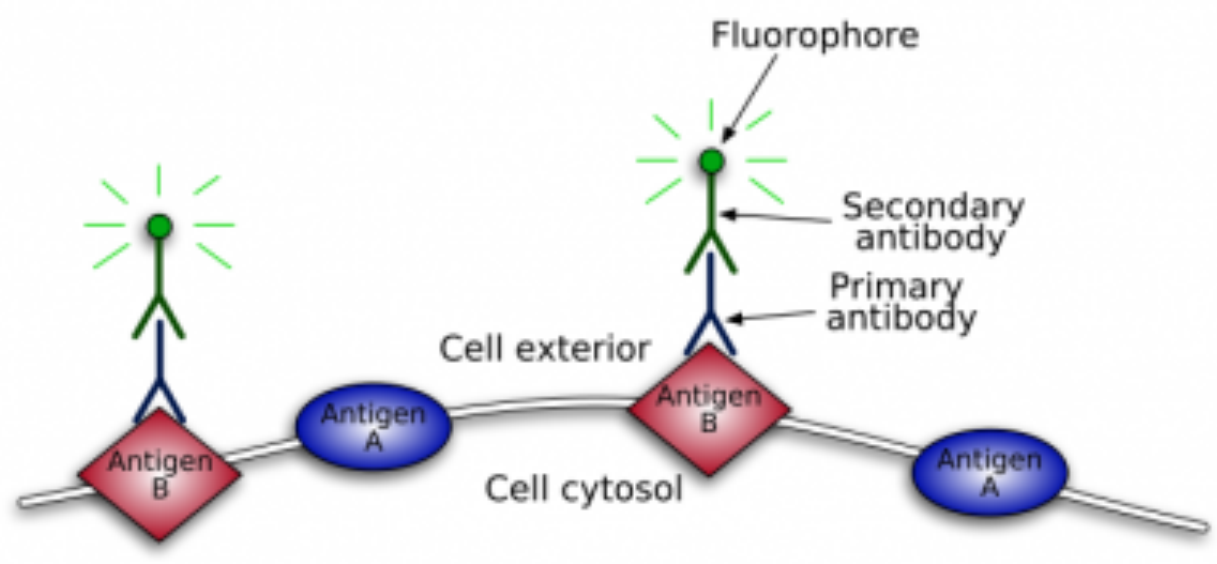

Figure 2.15 - Primary and secondary antibodies, Wikimedia Commons 


\subsection{Structure and Function of Streptavidin and Biotin}

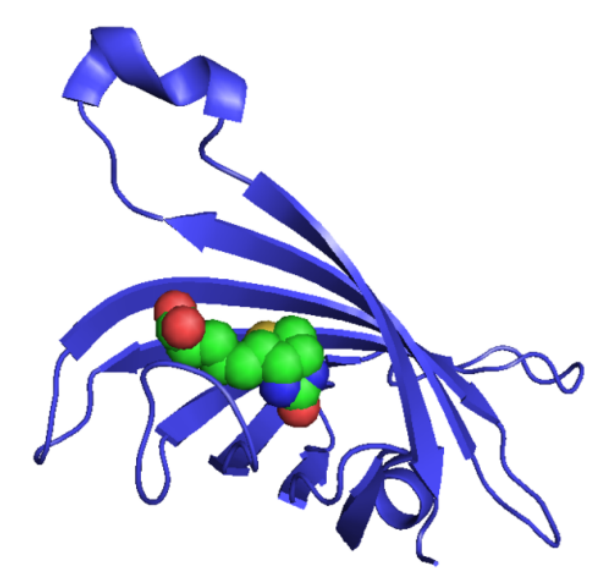

Figure 2.16 - Streptavidin (ribbon) bound to biotin (sphere), Wikimedia Common

Streptavidin, a protein isolated from bacterium Streptomyces avidinii, is a tetrameric protein that has four binding sites with a high binding affinity (dissociation constant $K_{d}=10^{-15}$ $\mathrm{mol} / \mathrm{L}$ ) for biotin (a water soluble B-vitamin present in every living cell, vitamin $\mathrm{B}_{7}$ ). The binding of streptavidin and biotin is one of the strongest non-covalent interactions and is heavily used in biotechnology and diagnostic applications [56]. Figure 2.16 illustrates the streptavidinbiotin interaction. Streptavidin-biotin interactions enable specific detection of the target of interest by functionalization of the target with biotin, which does not usually affect the biological activity of the target. Further, the bond is stable against $\mathrm{pH}$ and temperature changes, organic solvents and detergents [57]. 


\section{Chapter 3 Related Work}

In this section the current state of the art in CNT and protein based systems is described in detail.

\subsection{Carbon Nanotube- Microtubule Hybrid Assemblies}

Prior research in creating protein/CNT hybrid assemblies has focused on the use of microtubules [58]. In [58] combination of CNTs with tubulin created microtubule morphologies that would not be possible without the presence of the MWCNTs. AFM analysis of the tubulinMWCNT conjugates shows the creation of different patterns based on varying concentration of tubulin. Tubulin was also polymerized on the surface along the axis of MWCNTs and the nanotubes were encapsulated by the resulting microtubules. Figures 3.1 shows the Transmission Electron Microscopy (TEM) images of microtubule-MWCNT hybrids (a) and MWCNTs controls (b) .
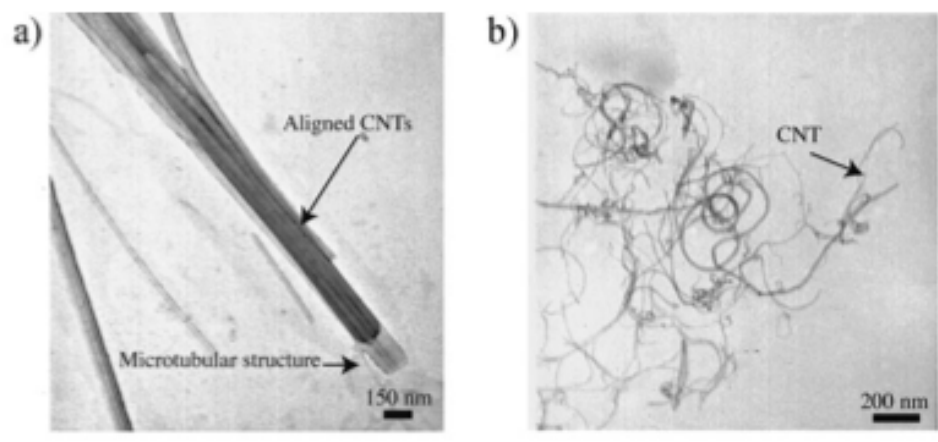

Figure 3.1 - TEM images of a) Microtubule-MWCNTs b) MWCNTS without tubulin [58]

The motility of microtubule-MWCNT biohybrids was examined on kinesin motor proteins-coated surfaces using the gliding motility assay. Briefly, in the gliding assay, the motors are fixed on the surface and in the presence of ATP the filaments glide on the kinesin-coated surface. The biohybrids showed sideway motions through fluctuation and translocation on kinesin motors. The irregular motions of microtubule-MWCNTs could have resulted from different polarity of biohybrids when compared to individual microtubules. Figure 3.2 compares movement of microtubules with the movement of the formed biohybrids. 


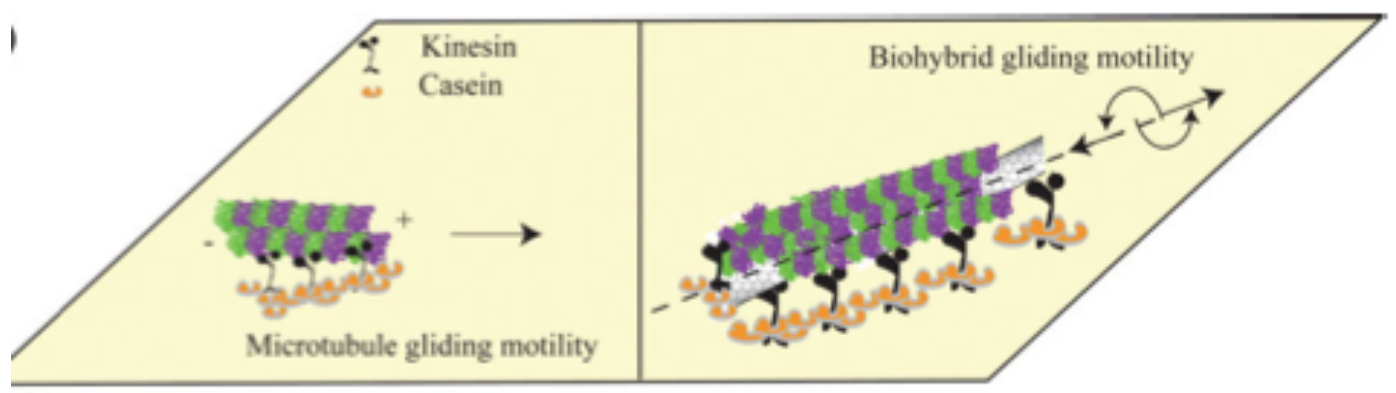

Figure 3.2 - Schematic of microtubule vs. microtubule-MWCNT biohybrid motility [58]

In [59], the authors investigated hybrid formation using biotinylated microtubules and streptavidin-MWCNT conjugates through strong and specific interaction between streptavidin and biotin. AFM analysis of MWCNT coated with streptavidin indicated uniform coverage of streptavidin on the surface of the nanotubes. Hybrid assemblies were then formed by incubation of streptavidin-MWCNT conjugates with biotinylated microtubules. The streptavidin-MWCNT and biotinylated microtubules hybrids were analyzed using TEM. The analyses revealed that the nanotubes were either in parallel and linear orientation, or bent and attached through their bent regions with the microtubules to form the biohybrids. The investigation of the motility assay using kinesin-coated surface resulted in gliding of the hybrid assemblies, therefore indicating the attachment of microtubles to MWCNTs did not interfere with kinesin affinity for microtubules. Figure 3.3 indicates a schematic of the hybrids as well as the motility assay using kinesin motor proteins.

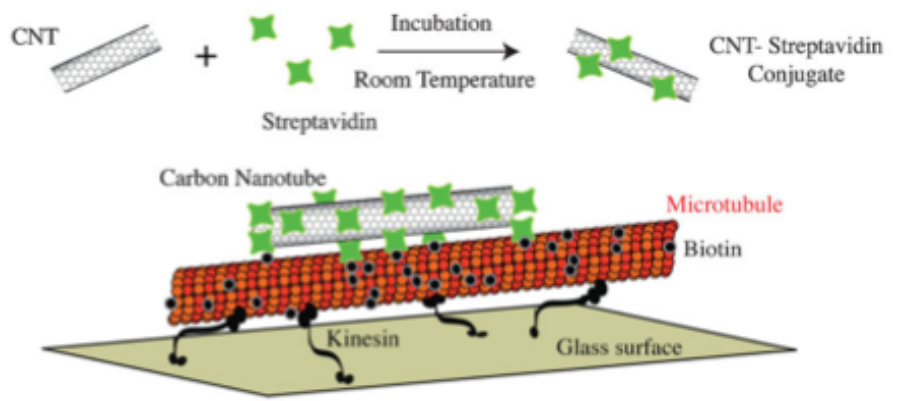

Figure 3.3 - Streptavidin-coated MWCNT and biotinylated microtubule hybrid [59] 


\subsection{In Vitro Sliding of Actin Labeled Quantum dots}

Actomyosin motility assays for transportation of cargo in nanotechnological applications is another open area of research for hybrid motility. The ability to transport quantum dots was investigated using streptavidin-coated CdSe quantum dots (Qdots) and biotinylated actin filaments. The results showed that there was no significant difference between velocity of actinquantum dots and individual actin filaments. Labeling filaments with Qdots enables location tracking of cargo in nanotechnological applications due to high stability of Qdots against photobleaching [60].

\subsection{Transportation of Cargo using Actin Bundles}

One approach in using actin filaments for transport of cargo on motor patterned surfaces in synthetic environment is creating actin bundles [61]. The researchers investigated transportation of cargo such as liposomes and single cells (Escherichia coli) using actin bundles and myosin motor proteins [62]. Liposomes were chosen due to their ability to encapsulate and transport molecules for nanotechnology applications, and E. coli was used based on its ability to produce proteins. Neutravidin was also used to link and attach the biotinylated liposome and $E$. coli to labeled actin bundles. Figure 3.4 shows the attachment of cargoes to actin bundles.
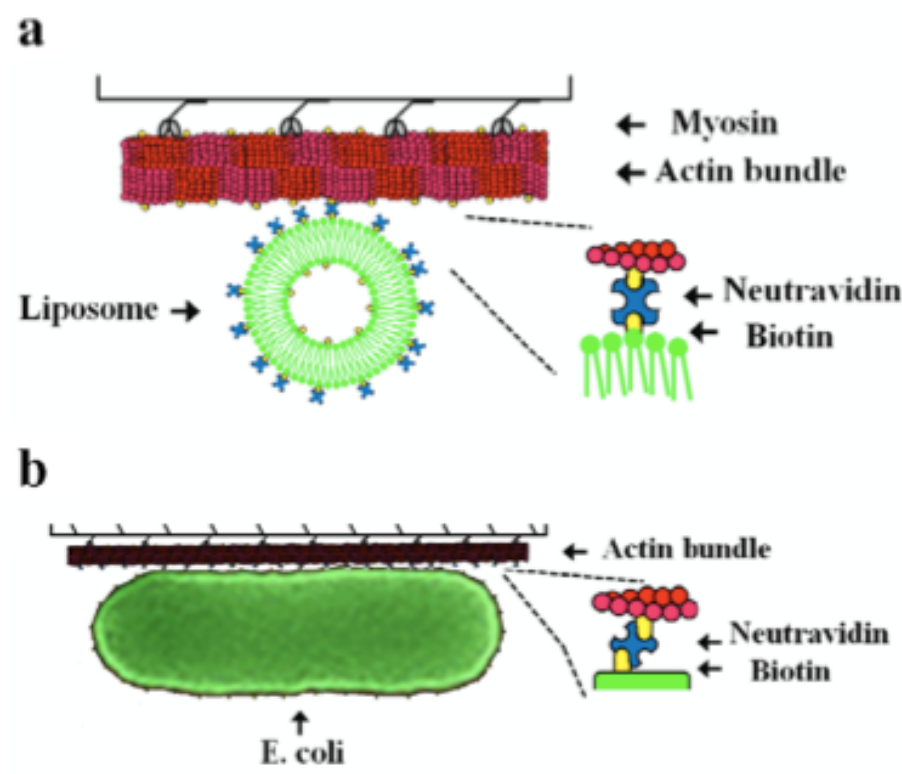

Figure 3.4 - a) biotinylated liposome attached to actin bundle b) E. Coli attached to actin bundle via neutravidin linker [62] 
Figure 3.5 confirms attachment of a liposome to actin bundles using TEM.
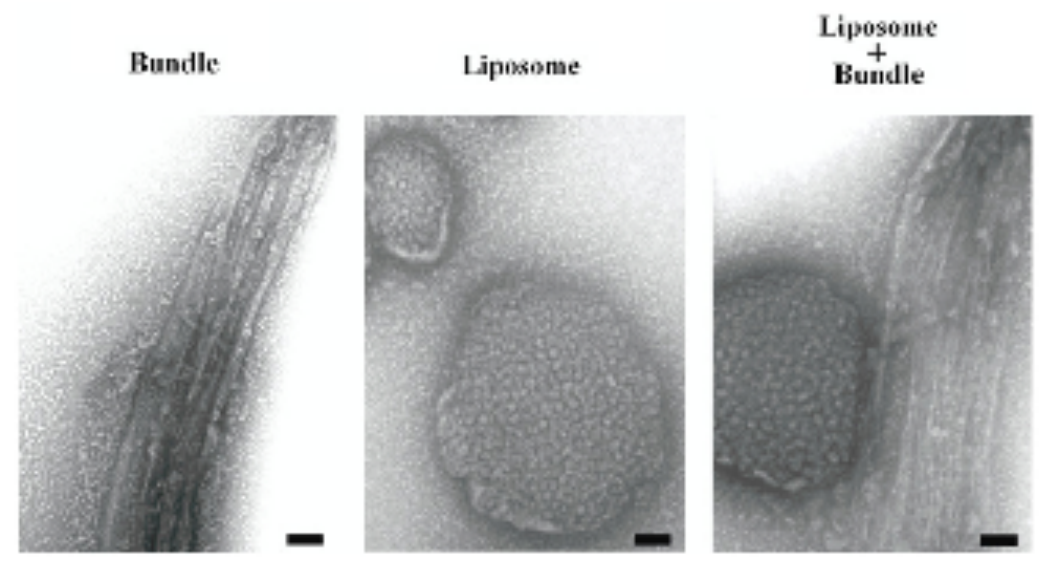

Figure 3.5 - Transmission electron microscopy of liposome attached to actin bundle [62]

The transportation of liposomes and E. coli cells were investigated using in vitro motility assays with F-actin and actin bundles. The results indicated that transportation of both samples were successful using actin bundles, however F-actin was able to transport liposomes but not $E$. coli cells. Also, F-actin/liposome complexes moved in random directions while actin bundle/liposomes indicated longer linear movement. These results indicated that actin bundles had a higher cargo transport capability and longer linear and stable movement when compared to F-actin [62].

\subsection{Transportation of Actin-coated liposomes}

Another method investigated the usage of actin and myosin to transport cargo through a decorating sample approach. In particular, actin filaments were attached to positively charged liposomes and the motility of these complexes was investigated [63]. Figure 3.6 shows a liposome (1-3 $\mu \mathrm{m})$ prepared by DOPC (neutral lipid) and DOTAP (cationic lipid) coated with actin filaments on HMM coated surface. 


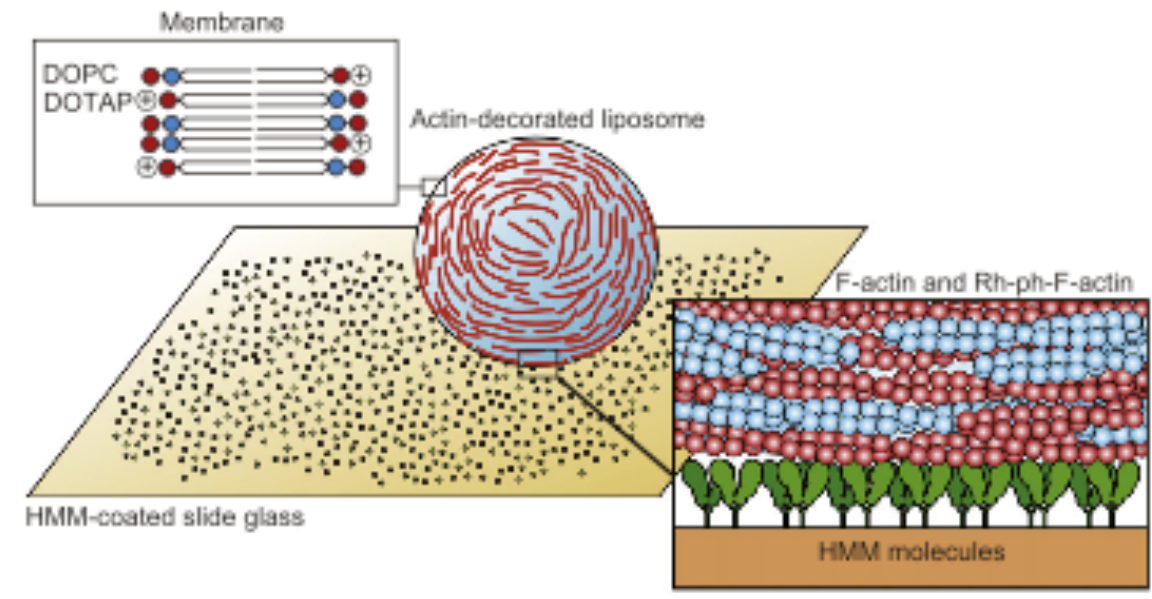

Figure 3.6 - Liposome coated actin filaments on HMM motor proteins [63]

The actin-coated liposomes showed straight movement on HMM covered surface; however the velocity of liposomes was considerably reduced when compared to the velocity of control actin filaments. This effect may be caused by limited interaction of actin filaments with myosin since non-specific attachment of liposomes to the surfaces might occur. The distance traveled was also dependent upon the percentage of DOTAP used for preparation of the liposomes. When 100\% DOTAP was used, the liposomes traveled a shorter distance than when $30 \%$ DOTAP was used. This effect might be due to the excessive positive charge of liposomes that could have possibly resulted in different arrangement and orientation of actin filaments on the surface [63]. Figure 3.7 illustrates movement of actin-coated liposomes (50\% DOTAP) on HMM-coated surface.

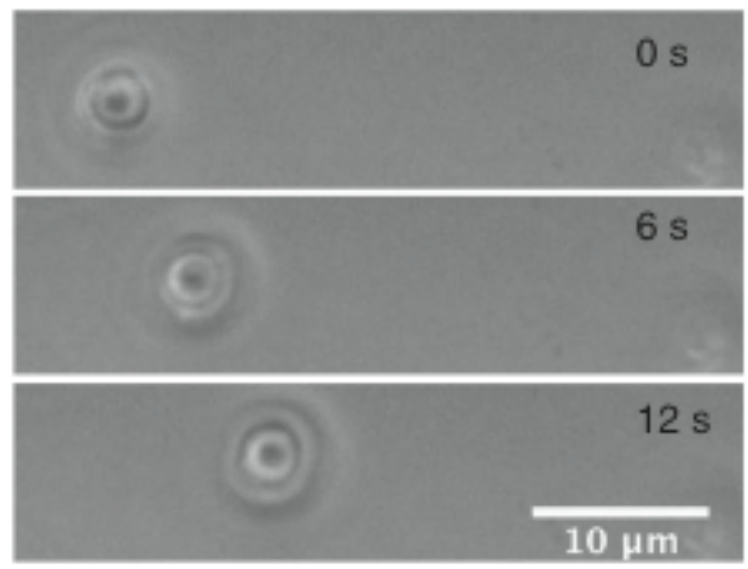

Figure 3.7 - Actin-coated liposomes at 6-second intervals on HMM-coated surface using phase-contrast [63] 


\section{Chapter 4 Experimental Process}

In this chapter an overview of the experimental process is provided. The details of the methods and materials used for each experiment are given further, in Chapter 5.

\subsection{MWCNTs and G-actin}

\subsubsection{Experiment: Investigate the effect of DI water and G-buffer on MWCNTs.}

The experiment determines the dispersion of MWCNTs in different solvents. In particular, upon performing a visual inspection, a more rigorous analysis was conducted by performing a solubility test to quantify the differences in dispersity of the MWCNTs in DI water and G-actin buffer (G-buffer) respectively. Dispersity was calculated based on the amount suspended in both solvents and the initial starting amount.

\subsubsection{Experiment: Investigate the attachment of actin monomers onto MWCNTs.}

The hypothesis tested was whether or not actin monomers attach to the hydrophobic CNTs. The amount of proteins added to the solution of MWCNTs was calculated based on the available surface area of the MWCNTs and surface area of actin monomers. After adding the proteins to MWCNTs solution, the amount of proteins attached and immobilized on the MWCNTs were calculated based on the difference between the initial amount and the amount that of free protein (unbound) washed out. The protein concentration was measured using Optical Density (OD) value of G-actin as well as the BCA protein assay kit.

MWCNTs/G-actin and MWCNTs (control) in G-buffer were visually compared to observe dispersion of MWCNTs in both conditions. To further confirm the attachment of actin monomers onto the MWCNTs, the MWCNT/G-actins conjugates were analyzed using AFM.

\subsubsection{Experiment: Investigate the functionality of MWCNT-G-actin conjugates.}

The functionality of immobilized G-actin (i.e. G-actin immobilized onto MWCNTs) was compared with the functionality of free G-actin in solution. In the cell G-actin polymerizes to Factin, a major component of the cellular cytoskeleton [20]. If the immobilized G-actin is still functional onto the MWCNTs support, it is expected that with the addition of free G-actin, the immobilized G-actin will polymerized onto MWCNTs scaffolds to lead to hybrid assemblies. 
Briefly, the functionality of the immobilized G-actin was tested by adding free G-actin to the MWCNT-G-actin conjugates. The resulting hybrids were labeled with rhodamine-phalloidin and investigated using optical microscopy.

\subsection{MWCNTs and F-actin}

Another set of experiments were conducted to determine the functionality of actin filaments on the surface of MWCNTs.

\subsubsection{Experiment: Investigate the functionality of the MWCNT-F-actin assemblies using antibody recognition.}

The functionality of the actin filaments was tested using antibodies. Anti-actin antibodies recognize and bind to actin filaments in solution. The presence of fluorescent beads attached to antibodies enables observation and detection of these interactions using fluorescent microscopy [55]. If the actin filaments are still functional, then incubation of antibody-coated beads with the structures of MWCNT-F-actin could result in the attachment of the beads to the actin filaments formed onto the MWCNTs scaffolds.

\subsubsection{Experiment: Investigate the functionality of the MWCNT-F-actin assemblies using gliding motility assay}

The functionality and movement of the MWCNT-F-actin hybrid assemblies were tested using gliding motility assays. In the gliding assay, the motors are fixed on the surface and in the presence of ATP the filaments glide on the myosin-coated surface [64]. The motility of MWCNT-F-actin assemblies was tested in the presence of ATP as the energy source, with the HMM-coated surface as the motor proteins to enable the movement. The actin filament and actin-bead motility assays were used as controls. 


\section{Chapter 5 Materials and Methods}

\subsection{Materials and Chemicals}

In this chapter the materials and methods used for the experiments described in Chapter 4 are mentioned.

\subsubsection{Chemicals}

Table 5.1 - Chemicals, manufacturer and part number

\section{Chemical}

Adenosine Triphosphate (ATP)

Anti-mouse IgG fluorescent particles

Anti-pan actin monoclonal antibody

BCA protein assay kit

Biotin-XX phalloidin

Bovine Serum Albumin (BSA)

Calcium chloride $\left(\mathrm{CaCl}_{2}\right)$

Catalase

Collodion

DL-Dithiothreitol (DTT)

Fluorescent bead

Glucose (D-(+)- Glucose)

Glucose oxidase (GO)

Imidazole

Magnesium chloride $\left(\mathrm{MgCl}_{2}\right)$

Potassium chloride $(\mathrm{KCl})$

Rabbit muscle powder

Rhodamine-Phalloidin

Sodium bicarbonate $\left(\mathrm{NaHCO}_{3}\right)$

Tris(hydroxymethyl)aminomethane (Tris-HCl)

\section{Manufacturer}

Sigma-Aldrich

Spherotech Inc.

Fisher Scientific

Pierce

Invitrogen

Sigma-Aldrich

Fisher Scientific

Sigma-Aldrich

Ernest F. Fullam, Inc.

Sigma-Aldrich

Spherotech Inc.

Sigma-Aldrich

BioChemika

Sigma-Aldrich

Sigma-Aldrich

Fisher Scientific

Pel-Freez Biologicals

Invitrogen

Fisher Scientific

Sigma-Aldrich

\section{Product Number}

A2383

MFP-0552-5

MA1-37018

23227

B7474

A7906

C77

C9322

D0632

SVFP-0552-5

G7528

49182

I 2399

M1028

P217

41995

R415

BP328

T5941 


\subsubsection{Instrumentation}

Table 5.2 - Device, manufacturer and model

Device

Centrifuge

Ultra-centrifuge

Spectrophotometer

Fluorescent Inverted microscope

Fluorescent Inverted microscope Camera

Atomic Force Microscope

Scanning Electron Microscope

\section{Manufacturer}

Fisher Scientific

Fisher Scientific

Fisher Scientific

Nikon

Hamamatsu Photonics

Asylum Research

JEOL

\section{Model}

Sorvall legend

Beckmann 70Ti rotor

BioMate 3

Eclipse TE200

C4742-80-12AG

MFP-3d-Bio

JSM 7600F

\subsubsection{Fluorescent Inverted microscope}

A Nikon inverted fluorescent microscope (Nikon Eclipse TE200) was used to conduct the fluorescent microscopy experiments. Fluorescent microscopy is performed by shining light at a sample with a wavelength that matches the excitation wavelength of the sample. The two excitation filters used were:

Table 5.3 - Fluorescent microscope filters

$\begin{array}{llll}\text { Filter Model } & \begin{array}{l}\text { Excitation Wavelength } \\ (\mathrm{nm})\end{array} & \begin{array}{l}\text { Dichromatic Mirror } \\ \text { Cut-on Wavelength }(\mathrm{nm})\end{array} & \begin{array}{l}\text { Emission Wavelength } \\ (\mathrm{nm})\end{array} \\ \text { B-2E/C } & 465-495 & 505 & 515-555 \\ \text { G-2E/C } & 528-553 & 565 & 590-650\end{array}$

The observation of F-actin was done using a 100xoil objective and the G-2E/C fluorescent filter. Figure 5.1 illustrates principles of a fluorescent microscope: 


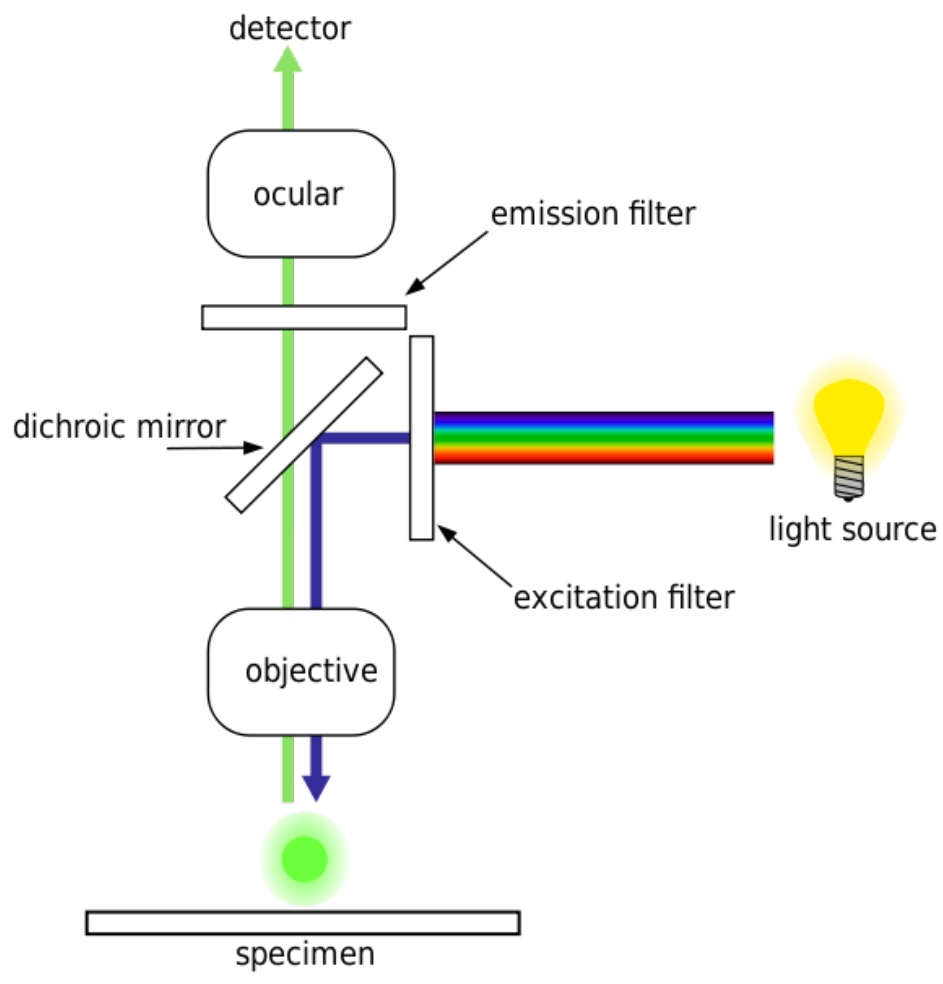

Figure 5.1 - Fluorescent Microscope, Wikimedia Commons

The fluorescent microscope images were captured using a Hamamatsu Photonics digital camera model C4742-80-12AG which acquires images at a rate of 8.9 frames per seconds at a 1344 x1024 pixel format.

The microscope, computer interface, camera and power supplies are shown in Figure 5.2: 


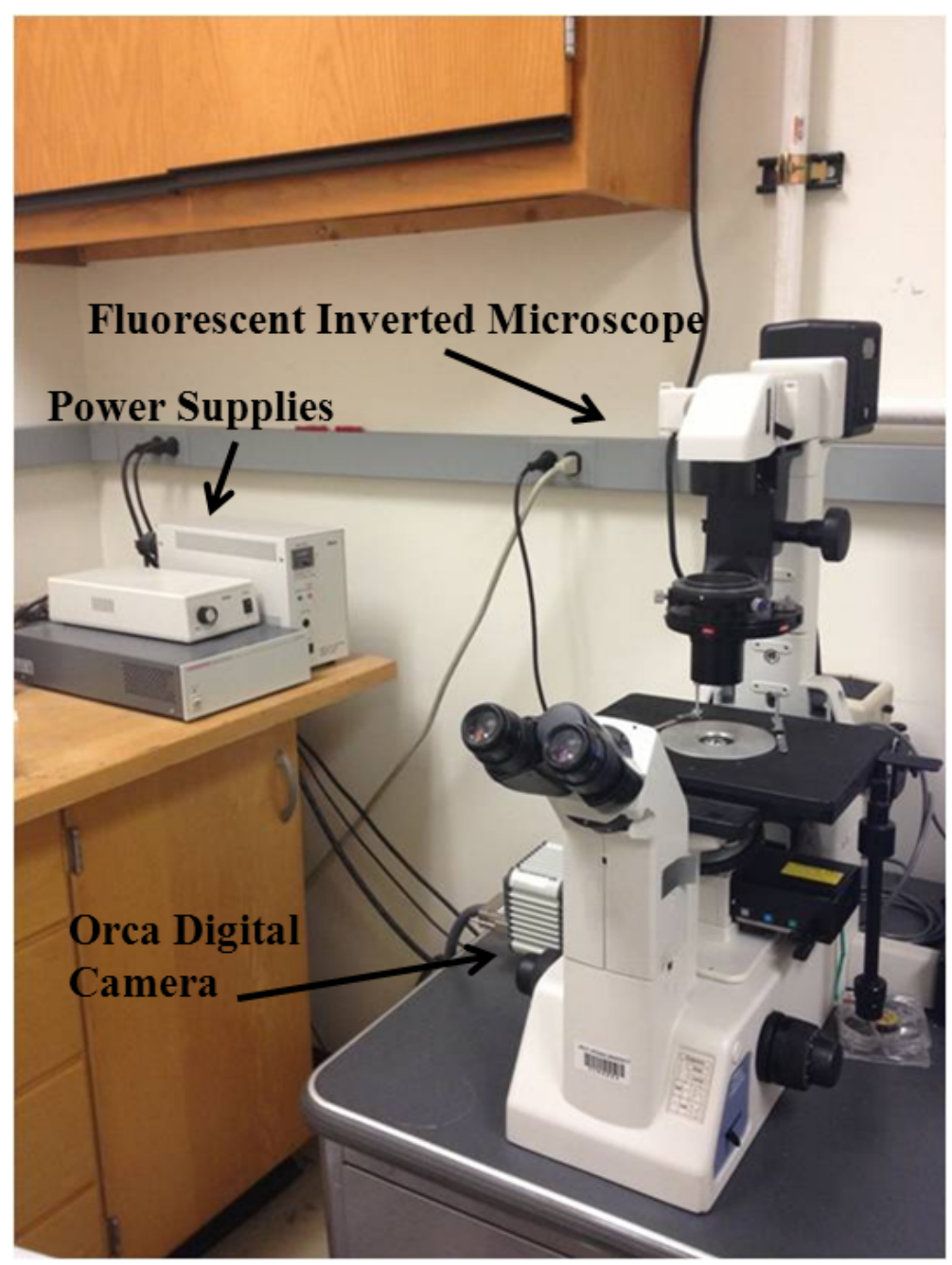

Figure 5.2 - Microscope and power supplies

\subsubsection{Image Recording}

\subsection{Wasabi}

The images and videos were acquired using the Wasabi software (Version 1.5). The software allows the user to control the CCD exposure time, frame rate and screen size through a user interface. Other functions include processing images and videos, e.g. control of image contrast, tint and blending images with different fluorescent filters, converting image sequences to videos, etc. Figure 5.3 shows the Wasabi software user interface for tint and blend of images. 


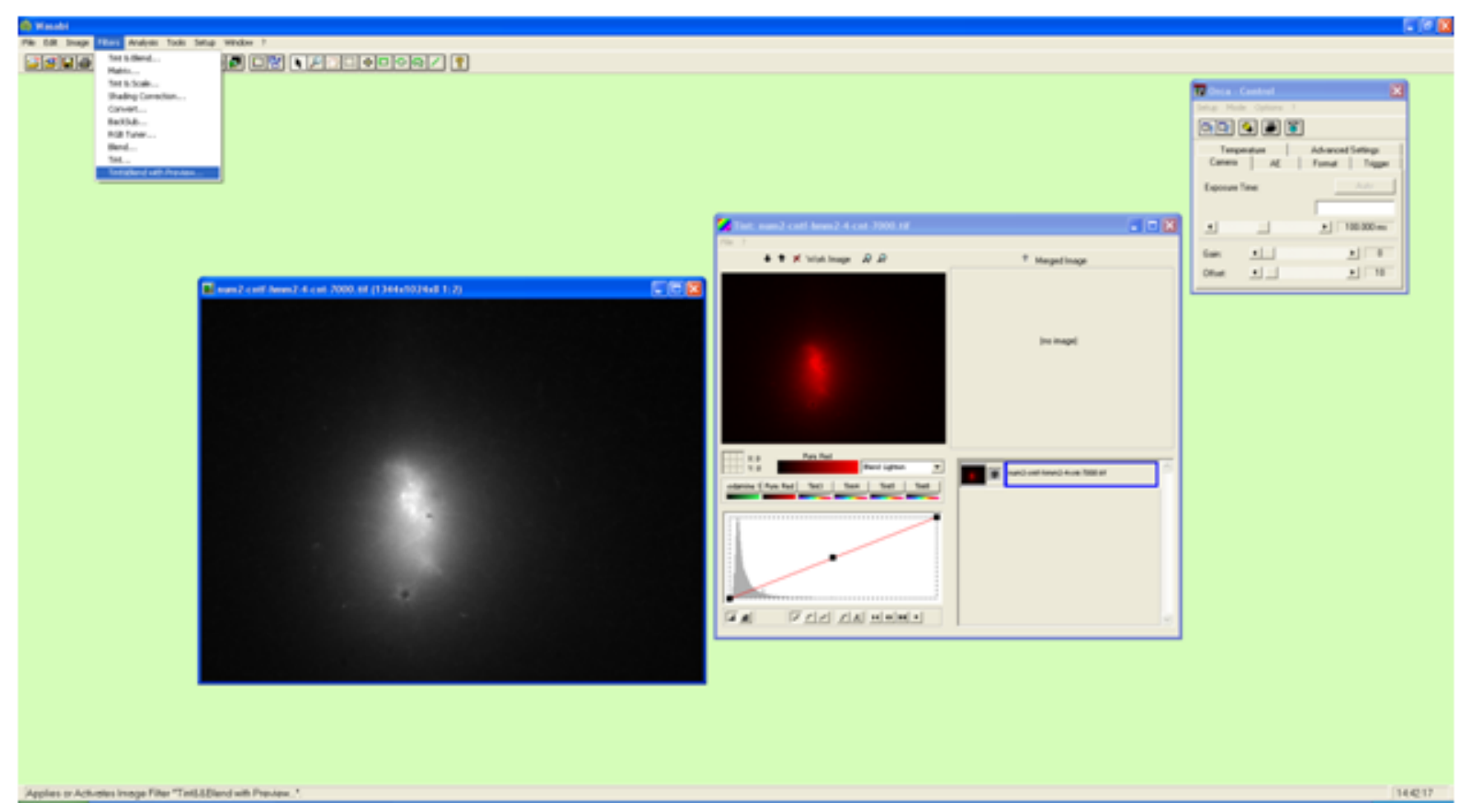

Figure 5.3 - Wasabi, tint and blend of images

\subsection{Image $\mathbf{J}$}

Analyses of images obtained from fluorescent microscopy were performed using Image $\mathrm{J}$ 1.45q. The software allows the user to conduct operations such as counting of elements, scaling images from pixels to units of length, tracking velocity of samples, etc. Figure 5.4 shows the Image $\mathrm{J}$ software user interface for manual tracking of particles. 


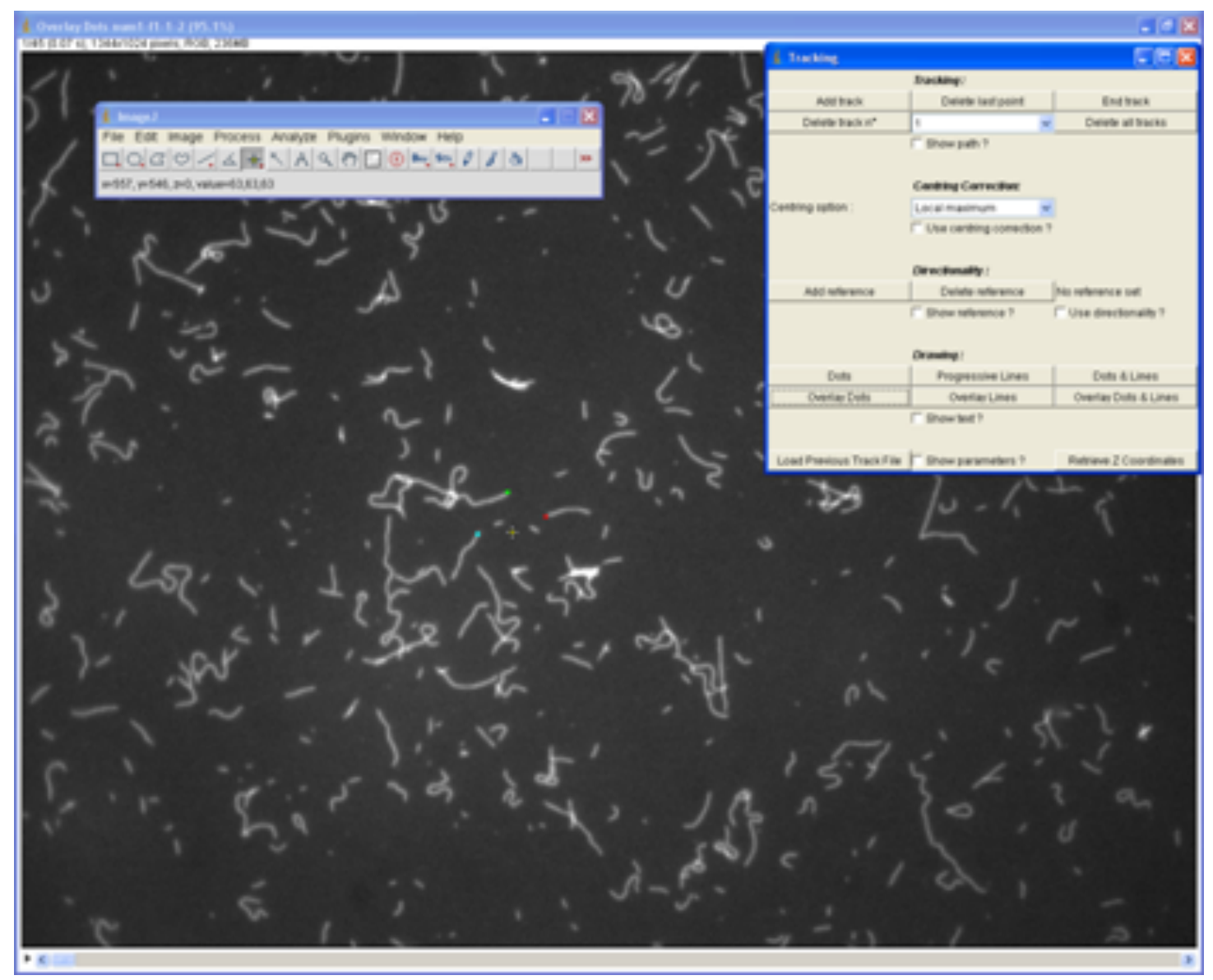

Figure 5.4 - Image J, manual tracking of actin filaments

\subsection{VirtualDub}

Processing and editing of videos were done using VirtualDub 1.9.11. The software allows the user to perform tasks such as cutting videos, changing frame rate of desired videos and also converting videos to image sequences.

\subsection{Atomic Force Microscopy (AFM)}

AFM was performed using an Asylum Research Instruments MFP-3D-Bio with AC240TS tip microscope. For AFM, the samples were deposited on mica $(0.1 \mathrm{mg} / \mathrm{ml}$ concentration) and vacuum dried for 24 hrs. Figure 5.5 shows the schematic of an AFM contact mode: 


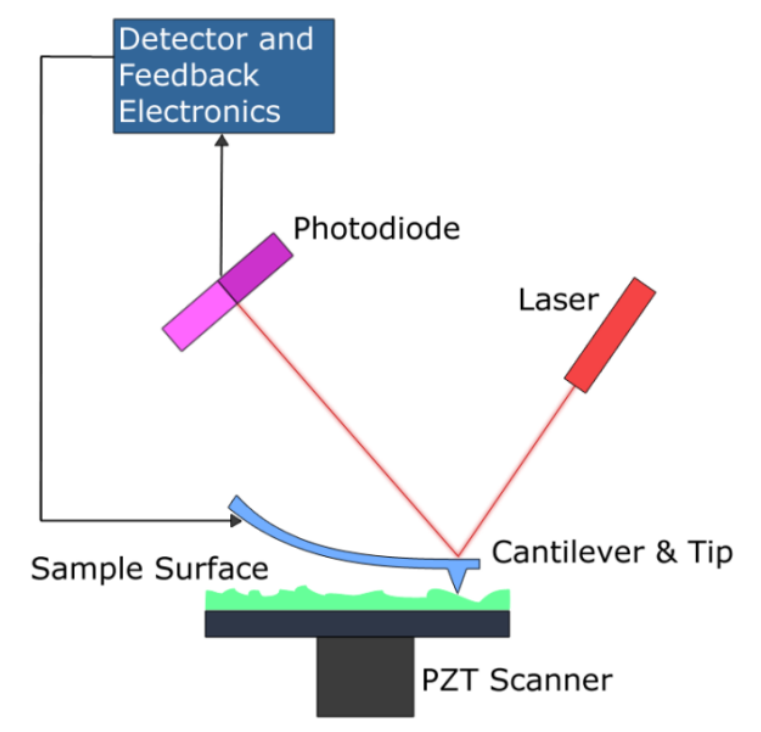

Figure 5.5 - AFM contact mode - Wikimedia Commons

\subsection{Scanning Electron Microscopy (SEM)}

Scanning electron microscopy was performed using a JEOL 7600F microscope. The samples $(1 \mathrm{mg} / \mathrm{ml}$ concentration) were deposited on silica wafer and vacuum dried for $24 \mathrm{hrs}$. Figure 5.6 shows the schematic of an SEM:

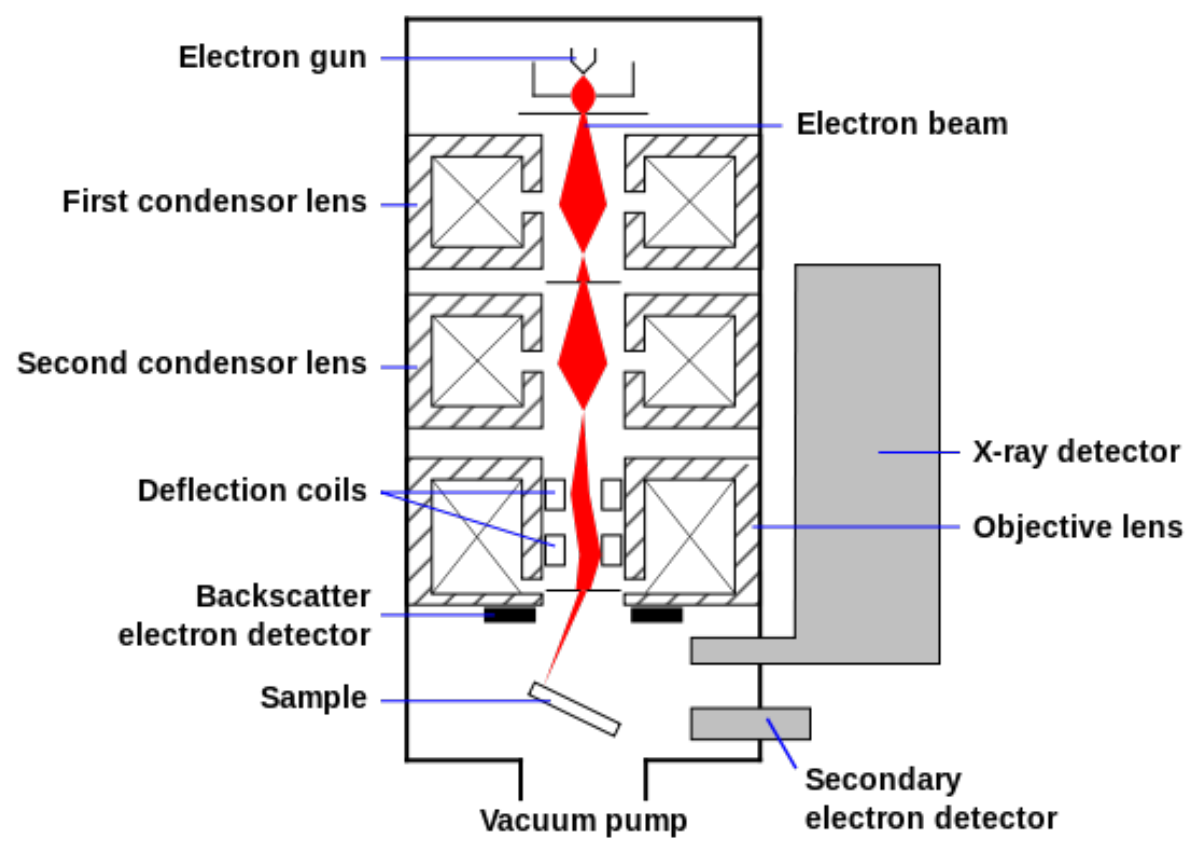

Figure 5.6 - SEM, Wikimedia Common 


\subsection{Methods}

\subsubsection{Buffers}

- G-actin Buffer (G-buffer): $2 \mathrm{mM}$ Tris- $\mathrm{HCl}, 0.2 \mathrm{mM} \mathrm{ATP,} 0.2 \mathrm{mM} \mathrm{CaCl}_{2}, 0.5 \mathrm{mM}$ DTT $\mathrm{pH} 8.0$

- Motility Buffer (M-buffer): $25 \mathrm{mM} \mathrm{KCl}, 2 \mathrm{mM} \mathrm{MgCl}_{2}, 0.2 \mathrm{mM} \mathrm{CaCl}_{2}, 25 \mathrm{mM}$ Imidazole $\mathrm{pH} 7.0$

\subsubsection{Protein Purification}

\subsubsection{F-actin Purification [65]:}

1. Grind rabbit muscle acetone powder for $10 \mathrm{mins}$

2. Pour grinded powder into a microtube and mix with $5 \mathrm{~mL}$ of $1 \mathrm{M} \mathrm{NaHCO}_{3}$ for $10 \mathrm{mins}$ on ice to separate G-actin from powder

3. Centrifuge the mixture at $4000 \mathrm{rpm}$ for $10 \mathrm{mins}$ at $4^{\circ} \mathrm{C}$

4. Decant the supernatant into an empty microtube and store on ice

5. Add $5 \mathrm{~mL} \mathrm{NaHCO}_{3}$ into the microtube of step 2 and stir for $10 \mathrm{mins}$ on ice

6. Centrifuge the mixture at $4000 \mathrm{rpm}$ for $10 \mathrm{mins}$ at $4^{\circ} \mathrm{C}$

7. Decant the supernatant into the microtube of step 4

8. Centrifuge the mixture of supernatants at $4000 \mathrm{rpm}$ for $10 \mathrm{mins}$ at $4^{\circ} \mathrm{C}$

9. Decant the supernatant into an ultra-centrifuge container and centrifuge at $40000 \mathrm{rpm}$ for 1 hour at $4^{\circ} \mathrm{C}$

10. Decant the supernatant into an empty microtube and add $3 \mathrm{M} \mathrm{KCl}$ with 100:1 (v/v) ratio (supernatant: $\mathrm{KCl}$ ) to induce actin polymerization

11. After 12 hours incubation at $4^{\circ} \mathrm{C}, \mathrm{G}$-actin will polymerize into $\mathrm{F}$-actin

12. Centrifuge the solution at $40000 \mathrm{rpm}$ for $1: 30$ hours at $4^{\circ} \mathrm{C}$

13. Discard the supernatant, the pellet at the bottom is F-actin

14. Add M-buffer to the pallet and mix well, store at $4^{\circ} \mathrm{C}$ 


\subsubsection{G-actin Purification}

\subsection{Similar method described for F-actin}

1. Grind rabbit muscle acetone powder for $10 \mathrm{mins}$

2. Pour grinded powder into a microtube and mix with $5 \mathrm{~mL}$ of $1 \mathrm{M} \mathrm{NaHCO}$ for 10 mins on ice to separate G-actin from powder

3. Centrifuge the mixture at $4000 \mathrm{rpm}$ for $10 \mathrm{mins}$ at $4^{\circ} \mathrm{C}$

4. Decant the supernatant into an empty microtube and store on ice

5. Add $5 \mathrm{~mL} \mathrm{NaHCO}_{3}$ into the microtube of step 2 and stir for $10 \mathrm{mins}$ on ice

6. Centrifuge the mixture at $4000 \mathrm{rpm}$ for $10 \mathrm{mins}$ at $4^{\circ} \mathrm{C}$

7. Decant the supernatant into the microtube of step 4

8. Centrifuge the mixture of supernatants at $4000 \mathrm{rpm}$ for $10 \mathrm{mins}$ at $4^{\circ} \mathrm{C}$

9. Decant the supernatant into an ultra-centrifuge container and centrifuge at 40000 rpm for 1 hour at $4^{\circ} \mathrm{C}$

10. Add G-buffer to the supernatant and mix well, store at $4^{\circ} \mathrm{C}$

\subsection{Using the dialysis kit}

1. Inject the F-actin solution into a dialysis cassette

2. Attach a float buoy and dialyze against G-buffer for 2 hours at $4^{\circ} \mathrm{C}$

3. Change the buffer and dialyze for another 2 hours at $4^{\circ} \mathrm{C}$

4. Change the buffer and dialyze over night at $4^{\circ} \mathrm{C}$

5. Withdraw the dialyzed solution, now G-actin, and store at $4^{\circ} \mathrm{C}$

\subsubsection{Measuring Protein Concentration}

\subsubsection{Optical Density Value}

1. Prepare different concentrations of protein: $5,10,20,40,80$ times dilution

2. Measure Optical Density (OD) values at $290 \mathrm{~nm}$ wavelength using a spectrophotometer

3. Compare the values with $0.633(\mathrm{OD}$ value of $1 \mathrm{mg} / \mathrm{ml}$ of F-actin and G-actin at $290 \mathrm{~nm}$ ) to determine protein concentration

\subsubsection{BCA Protein Assay Kit}

1. Prepare different concentrations of protein: $5,10,20,40,80$ times dilution 
2. Prepare the working reagent (WR) by adding 50 parts of Reagent $A$ to 1 part of Reagent B (both reagents are included in the assay kit)

3. Add $50 \mu \mathrm{l}$ of protein solutions to $1 \mathrm{~mL}$ of $\mathrm{WR}$ and incubate the mixture in a water bath at $60^{\circ} \mathrm{C}$ for $30 \mathrm{mins}$

4. Measure the absorbance of mixtures at $562 \mathrm{~nm}$ using a spectrophotometer

5. Create a standard curve using different concentrations and determine protein concentration

Figure 5.7 illustrates different colors based on the concentration of protein, which can be measured using a spectrophotometer. The higher concentration will result in a darker purple colored solution.

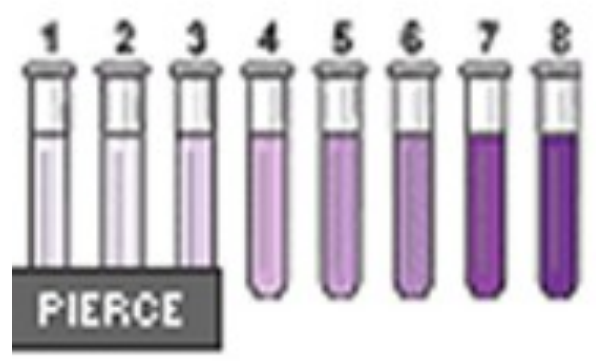

Figure 5.7 - BCA protein assay

\subsubsection{G-actin to F-actin polymerization}

G-actin was polymerized into F-actin by addition of M-buffer to G-actin solution. Increasing the ionic strength by addition of $\mathrm{KCl}$ will also induce polymerization. Adding $\mathrm{M}$ buffer enables an increase in the ionic strength and storage in M-buffer. Figure 5.8 shows the polymerization process.

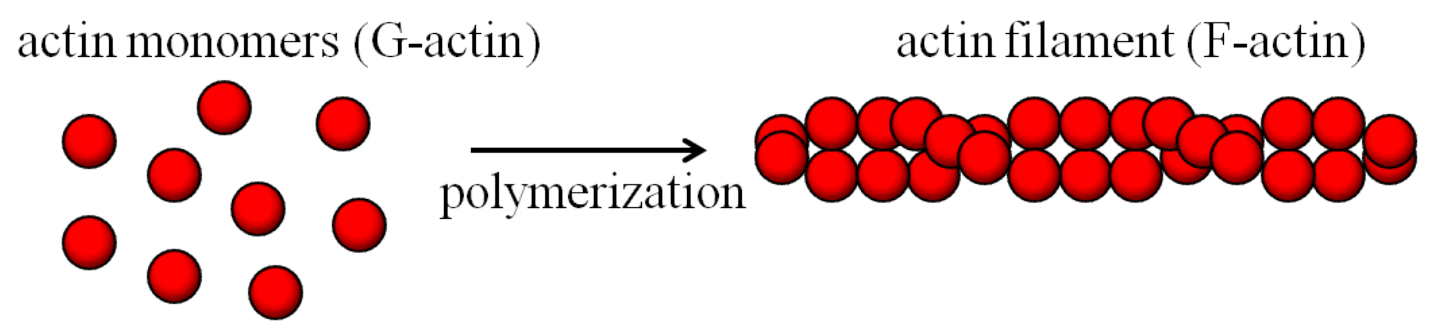

Figure 5.8 - G-actin polymerizes into F-actin 


\subsubsection{F-actin Labeling and observation}

As mentioned before, phalloidin toxins from Amanita mushroom bind along actin filaments and prevent depolymerization. Fluorescent derivatives of phalloidin can be used to observe actin filaments using fluorescent microscopy [20]. Labeling of F- actin was performed using rhodamine-phalloidin or biotin-XX phalloidin with 1:1 ratio for fluorescence observation. Interaction of Biotin with streptavidin allows for attachment of biotin labeled F-actin (biotinylated F-actin) to streptavidin-coated beads and samples. The mixture was stored over night at $4^{\circ} \mathrm{C}$ to allow uniform and complete binding before observation.

F-actin was observed using anti-photo bleaching reagents and the fluorescent microscope. The solution contains: $1 \mu 1250 \mu \mathrm{g} / \mathrm{ml}$ labeled F-actin, $1 \mu 1$ 1000mM DTT, $1 \mu 121.6 \mathrm{mg} / \mathrm{ml}$ Glucose Oxidase, $1 \mu 13.6 \mathrm{mg} / \mathrm{ml}$ Catalase, $1 \mu 1450 \mathrm{mg} / \mathrm{ml}$ Glucose and $95 \mu 1 \mathrm{M}$-buffer.

\subsubsection{Antibody and bead attachment onto F-actins}

Anti-actin antibodies (primary antibody) were incubated with actin filaments followed by addition of antibody-coated fluorescent beads (secondary antibody). $10 \mu 1200 \mu \mathrm{g} / \mathrm{ml}$ of anti-actin antibody was incubated with $10 \mu \mathrm{l} 250 \mu \mathrm{g} / \mathrm{ml}$ labeled F-actin for $1 \mathrm{hr}$. After an hour antibody coated fluorescent beads $(0.1 \% \mathrm{w} / \mathrm{v}, 0.4-0.6 \mu \mathrm{m})$ were added to the mix solution and incubated for another hour. Anti-photo bleaching reagents $(1 \mu 1$ 150mM ATP, $1 \mu 1$ 1000mM DTT, $1 \mu 1$ $21.6 \mathrm{mg} / \mathrm{ml}$ Glucose Oxidase, $1 \mu 13.6 \mathrm{mg} / \mathrm{ml}$ Catalase, $1 \mu 1450 \mathrm{mg} / \mathrm{ml}$ Glucose) were added to the solution. Figure 5.9 illustrates attachment of fluorescent beads to actin filaments through primary and secondary antibodies. 


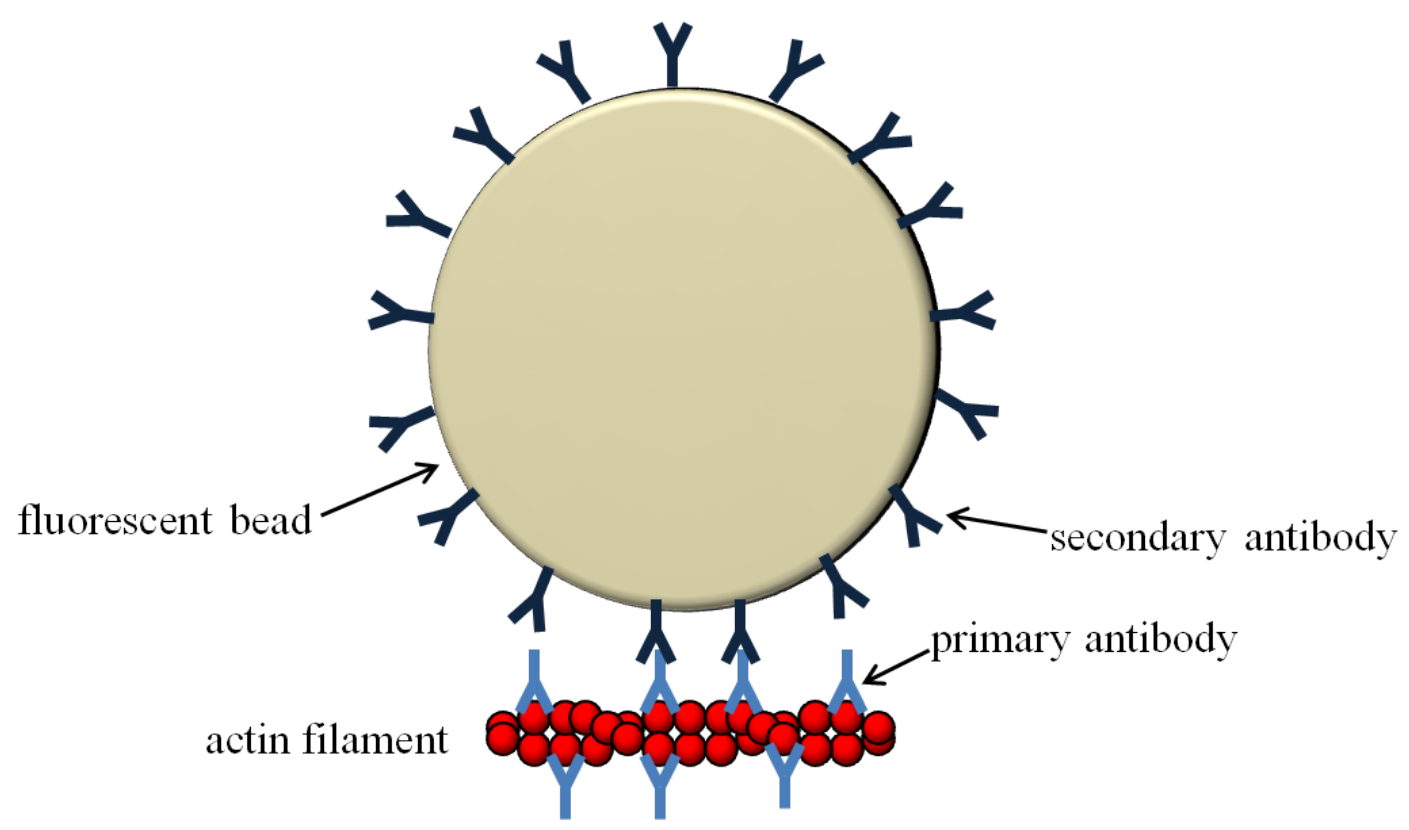

Figure 5.9 - F-actin-bead through primary and secondary antibodies

\subsubsection{Oxidation of CNTs}

Oxidized multi walled carbon nanotubes (MWCNTs) were prepared by adding $45 \mathrm{ml}$ sulfuric acid $\left(\mathrm{H}_{2} \mathrm{SO}_{4}\right)$ and $15 \mathrm{ml}$ nitric acid $\left(\mathrm{HNO}_{3}\right)$ to MWCNTs $(100 \mathrm{mg}$, diameter $(15 \pm 5) \mathrm{nm}$, length 5-20 $\mu \mathrm{m}$, NanoLab, Newton, MA). The suspension was sonicated for $3 \mathrm{hrs}$ at room temperature. The acid mixture was diluted in water $(200 \mathrm{ml})$ and the solution was filtered through a $0.2 \mu \mathrm{m}$ filter membrane (Millipore, USA). This procedure was repeated six times to remove all the catalyst residues.

\subsubsection{Dispersion Test}

The MWCNTs (acid treated for 3 hrs) were dispersed in DI water (pH 6.25) and G-actin Buffer ( $\mathrm{pH} 8$ ) respectively. First, MWCNTs were diluted in the different solvents in individual vials to generate $1 \mathrm{mg} / \mathrm{ml}$ solution. Next, $1 \mathrm{ml}$ of the suspension was centrifuged at $3000 \mathrm{rpm}$ for 5 mins. Subsequently, part of the supernatant $(0.8 \mathrm{ml})$ was removed and filtered through a 0.2 $\mu \mathrm{m}$ GTTP membrane filter. After complete drying under vacuum, the amount of MWCNTs on the filter membrane was collected and measured. Dispersion was calculated based on the amount suspended and the initial starting amount.

\subsubsection{G-actin immobilization onto MWCNTs}

Actin monomers (G-actin) $(5 \mathrm{nM})$ were added to MWCNTs $(250 \mu \mathrm{g})$ in G-buffer. The amount was calculated using surface area of G-actin for interaction with CNTS. The mixture was 
shaken for $2 \mathrm{hrs}$ at $200 \mathrm{rpm}$ and $4^{\circ} \mathrm{C}$. Subsequently, the mixture was centrifuged for 5 mins at $10,000 \mathrm{rpm}$, and the supernatant was collected. Finally, the mixture was washed 6 times to remove unbound protein, and the washes were also collected to help investigate the amount immobilized onto the MWCNTs as described below. Figure 5.10 illustrates the general procedure used to immobilize actin monomers onto CNTs.

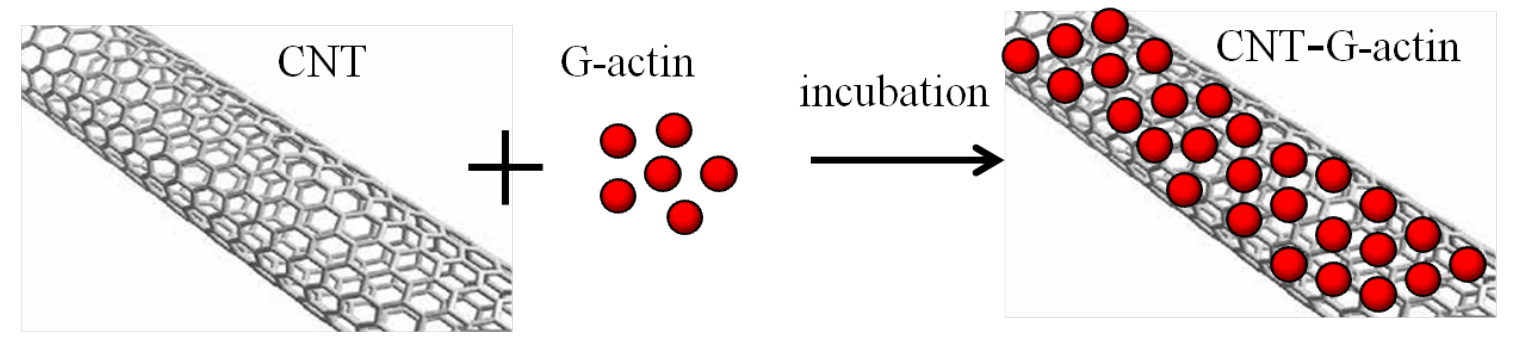

Figure 5.10 - Carbon nanotube incubation with actin monomers

\subsubsection{Calculation of G-actin loading onto MWCNTs}

The protein concentration of collected supernatant and washes was measured using the BCA protein assay kit. The working reagent was prepared by adding 50 parts of Reagent A to 1 part of Reagent B (both reagents are included in the assay kit). Either supernatant, washes or control $(50 \mu \mathrm{l})$ was added to the working reagent $(1 \mathrm{ml})$ and the mixture was incubated in a water bath at $60^{\circ} \mathrm{C}$ for 30 mins. The absorbance of the mixture was measured at $562 \mathrm{~nm}$ using the spectrophotometer. The standard curve was created using G-actin as the control. The loading of G-actin on MWCNTs was calculated based on the difference of initial amount of protein added and amount that was washed out or in the supernatant.

\subsubsection{Polymerization of G-actin on MWCNTs to F-actin}

For the polymerization process, MWCNT-G-actin conjugates were incubated with free G-actin $(250 \mu \mathrm{g} / \mathrm{ml})$ for an hour at room temperature. The resulting structures were labeled with rhodamine-phalloidin and analyzed using fluorescent microscopy. Figure 5.11 illustrates the process of polymerization on the carbon nanotubes with addition of G-actin. 


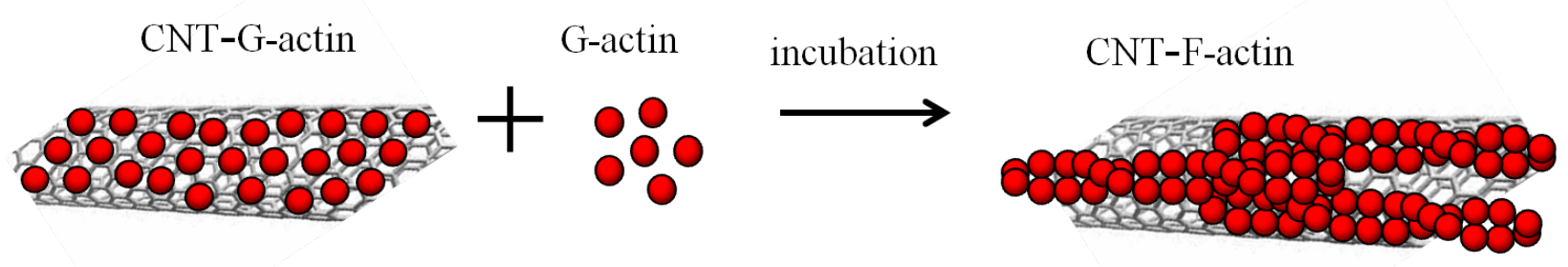

Figure 5.11 - Polymerization of G-actin to F-actin on CNTs

\subsubsection{Antibody and bead attachment onto CNT/F-actins}

Anti-actin antibodies (primary antibodies) were incubated with CNT/actin filaments; subsequently, antibody coated fluorescent beads (secondary antibodies) were added. 10 $\mu 1$ $200 \mu \mathrm{g} / \mathrm{ml}$ anti-actin antibody was incubated with $10 \mu \mathrm{CNT} / \mathrm{F}$-actin for $1 \mathrm{hr}$. After an hour, $10 \mu \mathrm{l}$ antibody coated fluorescent beads $(0.1 \% \mathrm{w} / \mathrm{v}, 0.4-0.6 \mu \mathrm{m})$ was added to the mix solution and incubated for another hour. Anti-photo bleaching reagents $(1 \mu 1$ 150mM ATP, $1 \mu 1$ 1000mM DTT, $1 \mu 121.6 \mathrm{mg} / \mathrm{ml}$ Glucose Oxidase, $1 \mu 13.6 \mathrm{mg} / \mathrm{ml}$ Catalase, $1 \mu 1450 \mathrm{mg} / \mathrm{ml}$ Glucose) were added to the solution.

\subsubsection{Motility Assays}

\subsubsection{F-actin motility assay}

The F-actin solution used for motility included F-actin and anti-photo bleaching reagents; ATP was added to the solution to induce actin motility. The solution contains: $1 \mu 1250 \mu \mathrm{g} / \mathrm{ml}$ labeled F-actin, $1 \mu 1$ 150mM ATP, $1 \mu 1$ 1000mM DTT, $1 \mu 121.6 \mathrm{mg} / \mathrm{ml}$ Glucose Oxidase, $1 \mu 1$ $3.6 \mathrm{mg} / \mathrm{ml}$ Catalase, $1 \mu 1450 \mathrm{mg} / \mathrm{ml}$ Glucose and $94 \mu 1 \mathrm{M}$-buffer.

1. Coat the surface of a cover slip with $0.2 \%$ collodion and bake in oven for 30 minutes at $75^{\circ} \mathrm{C}$.

2. Make a flow chamber using the collodion covered cover slip.

3. Add HMM $(200 \mu \mathrm{g} / \mathrm{ml})$ to the flow cell and wait 5 minutes for the HMM to attach to the surface.

4. Add BSA ( $1 \mathrm{mg} / \mathrm{ml})$ and wait for 5 minutes to prevent non-specific binding of $\mathrm{F}$ actin.

5. Wash with M-buffer to remove unattached HMM and BSA. 
6. Add F-actin solution and record the movement and motility.

Figure 5.12 shows the behavior and movement of actin filaments in the presence of ATP and HMM in the gliding motility assay.

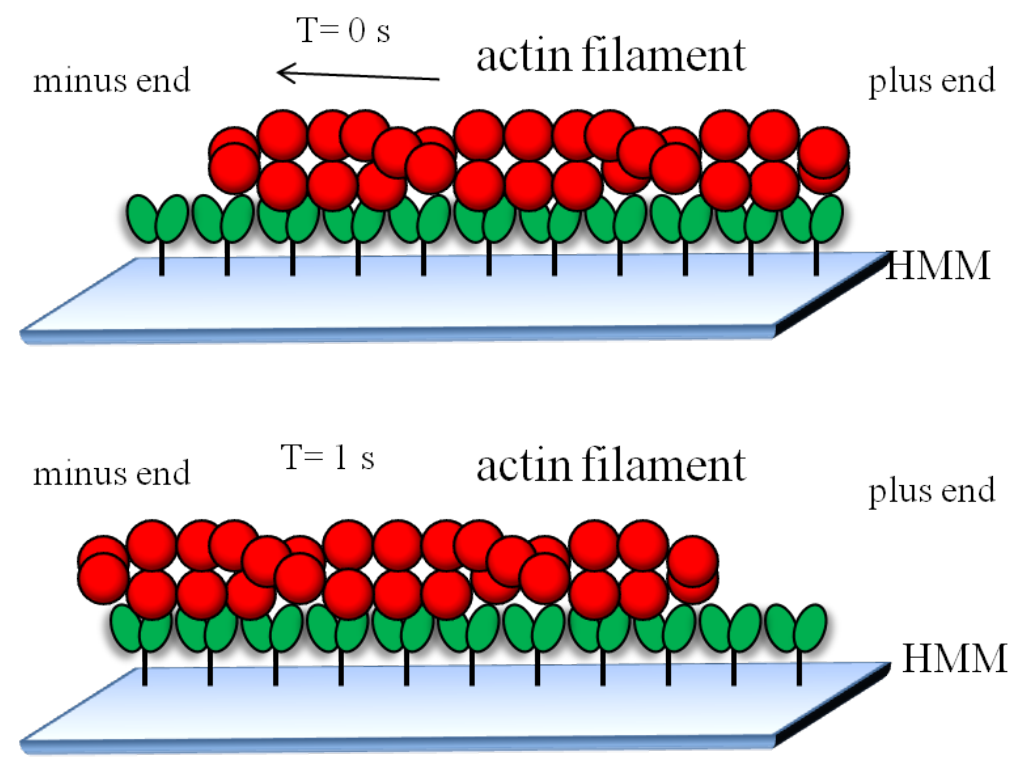

Figure 5.12 - Actomyosin motility assay

\subsubsection{Bead motility assay}

Actin filaments are attached to beads using streptavidin coated beads (fluorescent bead) and biotinylated F-actin. $1 \mu 1$ fluorescent bead $(0.1 \% \mathrm{w} / \mathrm{v}, 0.4-0.6 \mu \mathrm{m})$ was added to $93 \mu 1 \mathrm{M}$ buffer and sonicated for $1 \mathrm{~min}$ to spread beads evenly in M-buffer. This increased the dispersion of beads and attachment to biotinylated F-actin. F-actin and anti-photo bleaching reagents were added to the solution. The final solution contains: $1 \mu 1$ fluorescent bead, $1 \mu 1250 \mu \mathrm{g} / \mathrm{ml}$ labeled Factin, $1 \mu 1$ 150mM ATP, $1 \mu 1$ 1000mM DTT, $1 \mu 121.6 \mathrm{mg} / \mathrm{ml}$ Glucose Oxidase, $1 \mu 13.6 \mathrm{mg} / \mathrm{ml}$ Catalase, $1 \mu 1450 \mathrm{mg} / \mathrm{ml}$ Glucose and $93 \mu 1$ M-buffer.

After 30 minutes the motility procedure was conducted. The motility procedure was similar to the F-actin motility assay with the difference of adding the F-actin/bead mix in the last step (step 6). Figure 5.13 shows the attachment of beads to actin filaments through streptavidin and biotin interactions as well as the motility assay. 


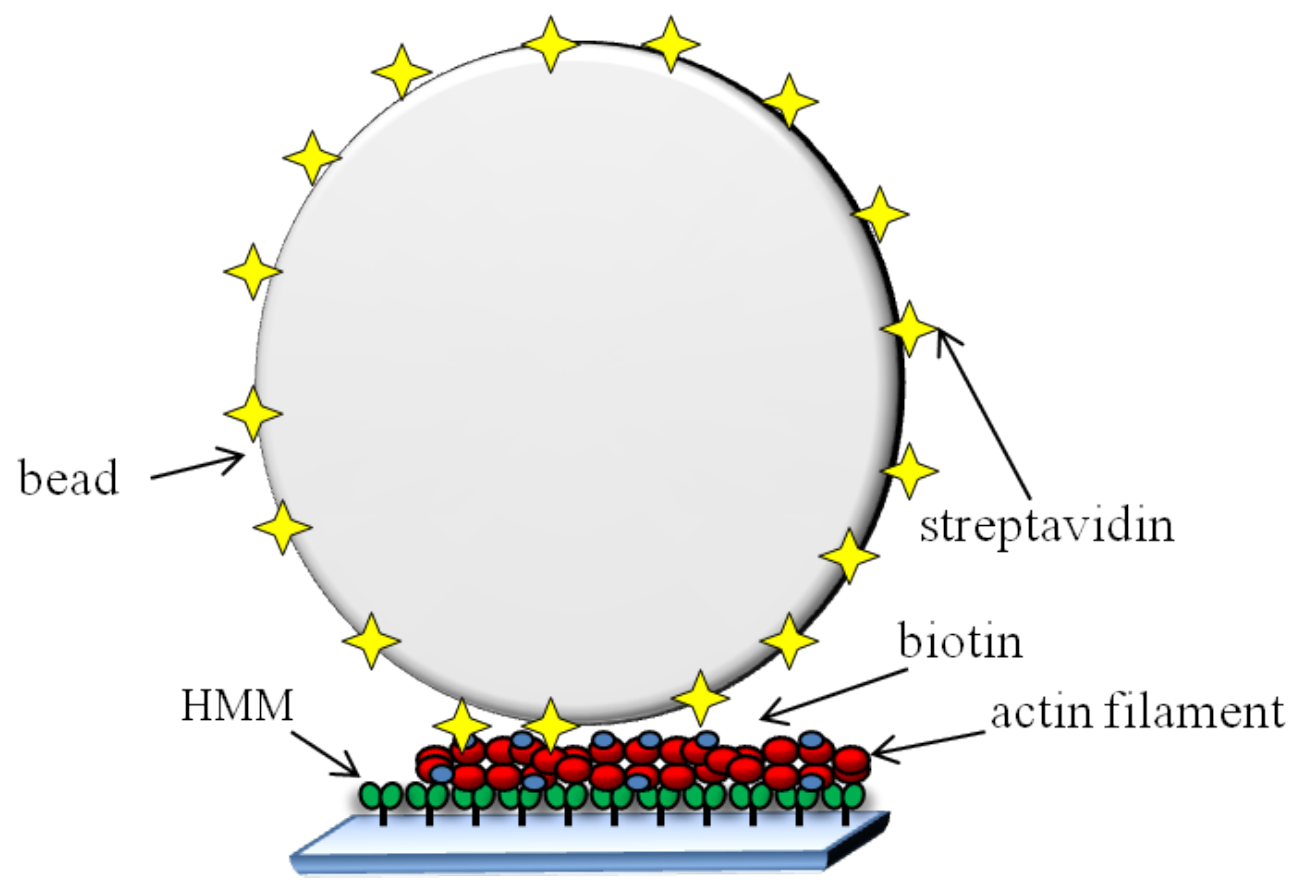

Figure 5.13 - Actin-bead motility assay

\subsubsection{CNT/F-actin motility assay}

The procedure was similar to F-actin motility assay with the only difference being the addition of CNT/F-actin hybrids in the last step (step 6).

\subsubsection{Cleaning Cover slips}

The cover slips were cleaned before experiments to ensure removal of dirt and unwanted particles.

1. Put cover slips in a Petri dish and fill with detergent and DI water 1:20, sonicate for 5 minutes

2. Put cover slips in another Petri dish filled with DI water and sonicate for 5 minutes

3. Rinse with acetone under sonication

4. Rinse with 2-propanol under sonication

5. Rinse with DI water under sonication

6. Dry the cover slips for 5 minutes in oven at $75^{\circ} \mathrm{C}$

\subsubsection{Flow Chamber}

The optical microscopy experiments were performed in a $100 \mu \mathrm{m}$ thick flow chamber. The flow chamber was assembled using a microscope slide (Corning micro slides) and a glass 
cover slip (Corning cover glass, $18 \times 18 \mathrm{~mm}^{2}$ ) that was separated using double-sided tape. The samples were perfused in the space created and observed under the microscope.

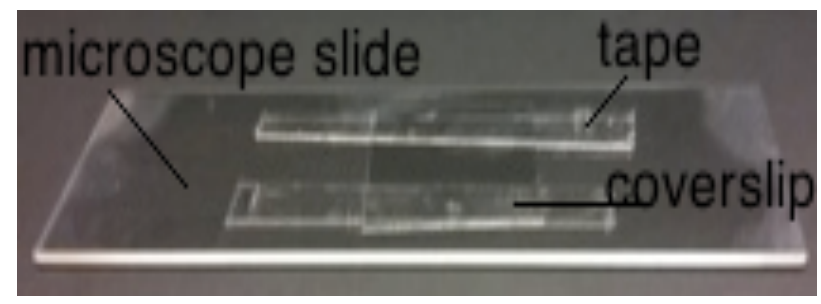

Figure 5.14 - Flow chamber 


\section{Chapter 6 Results and Discussions}

\subsection{F-actin observation}

Actin filaments were observed using fluorescence microscopy. Figure 6.1 shows the actin filaments at a concentration of $2.5 \mu \mathrm{g} / \mathrm{ml}$ in M-buffer:

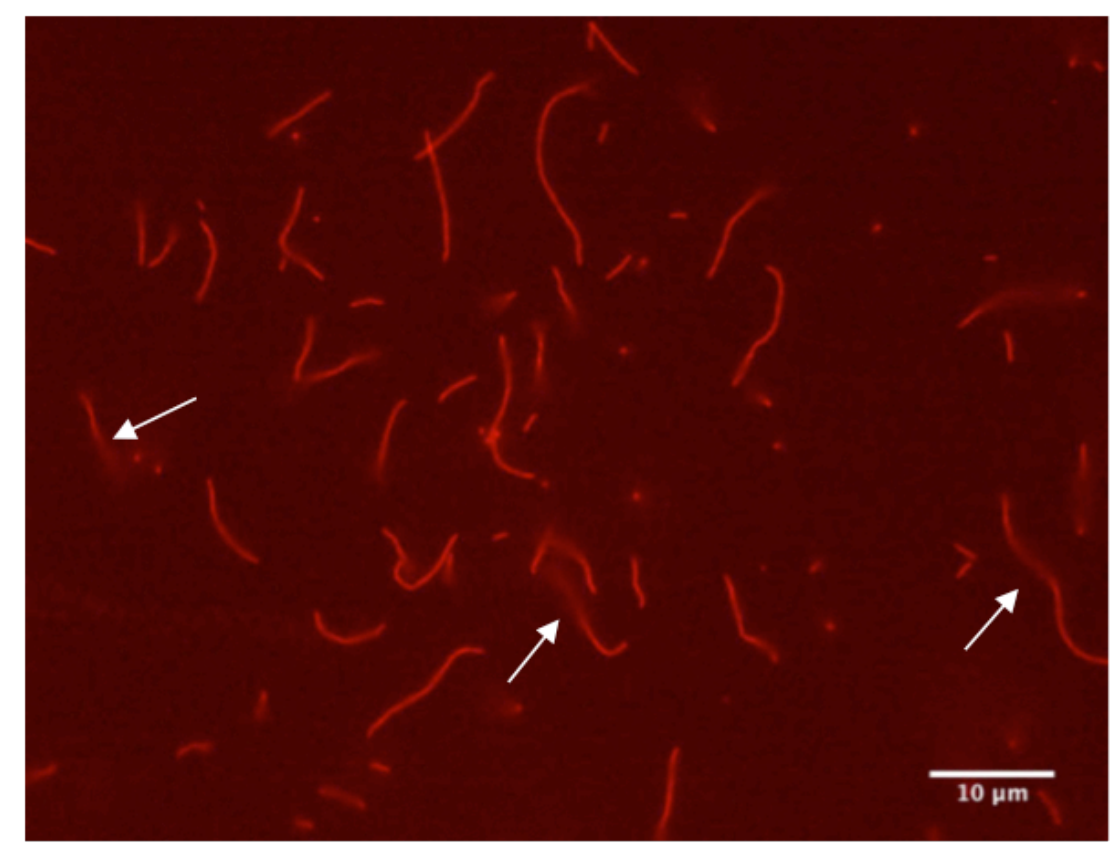

Figure 6.1 - Fluorescent actin filaments (F-actin)

The surface shows non-specific attachment of filaments on the cover slip. However, some of the actin filaments, which are not fully attached on the surface, exhibit a "diffuse" end and Brownian motion. A number of these filament ends are shown in Figure 6.1. Better observation and full attachment of the actin filaments on the surface were achieved using Poly (Diallyl Dimethyl Ammonium Chloride) (PDDA). PDDA creates a sticky surface due to long amino chains [66], and enables non-specific attachment of actin filaments. The cover slips were placed in $1 \%(\mathrm{v} / \mathrm{v})$ of PDDA and DI water for a time duration ranging from $30 \mathrm{mins}$ to $1 \mathrm{hr}$, followed by rinsing and drying for removal of excess PDDA.

Figure 6.2 shows F-actin attached on the surface covered with PDDA. The results indicate that the average length of F-actin was between $15 \pm 5 \mu \mathrm{m}$, which is consistent with prior results [67]. 


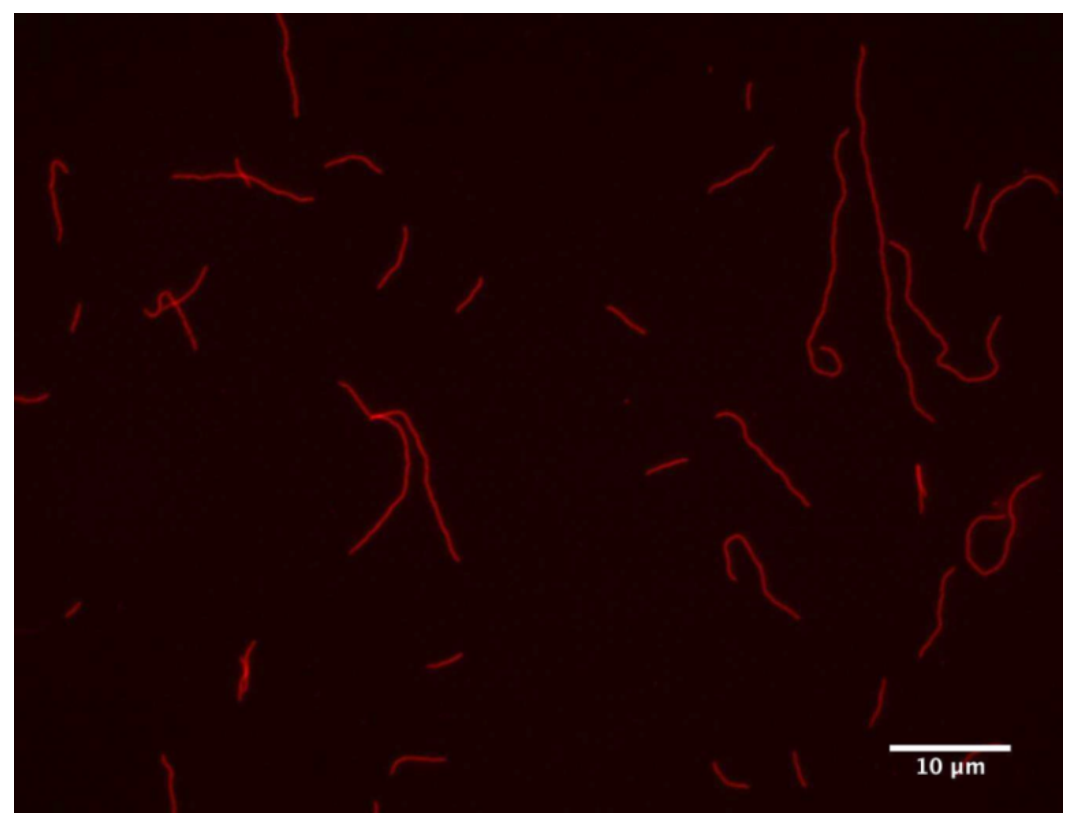

Figure 6.2- Fluorescent actin filaments on PDDA-coated surface

\subsubsection{Acid treated MWCNTs}

The Scanning Electron Microscopy (SEM) images below shows the acid treated MWCNTs that were used for the experiments. The image on the left is magnified 20,000 times, while the one on the right is magnified 50,000 times.

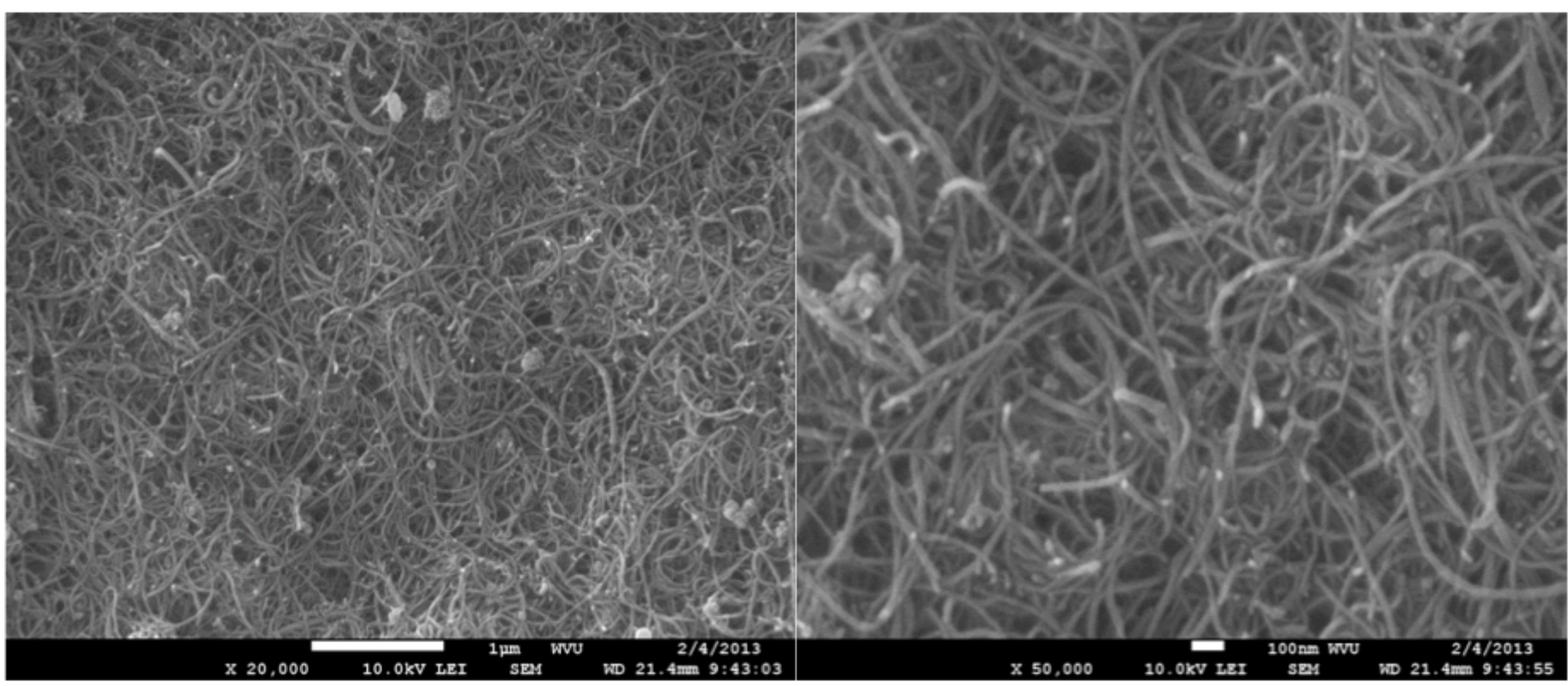

Figure 6.3 - Acid treated MWCNTs 


\subsection{MWCNTs and G-actin}

\subsubsection{MWCNTs in G-actin Buffer (G-buffer)}

The dispersion of MWCNTs in G-buffer was investigated and compared with MWCNTs in water (control). The visual inspection of the two samples did not reveal any major differences in the dispersion. Figure 6.4 shows both samples. The sample on the left is MWCNTs in Gbuffer and the sample on the right shows dispersion of MWCNTs in water.

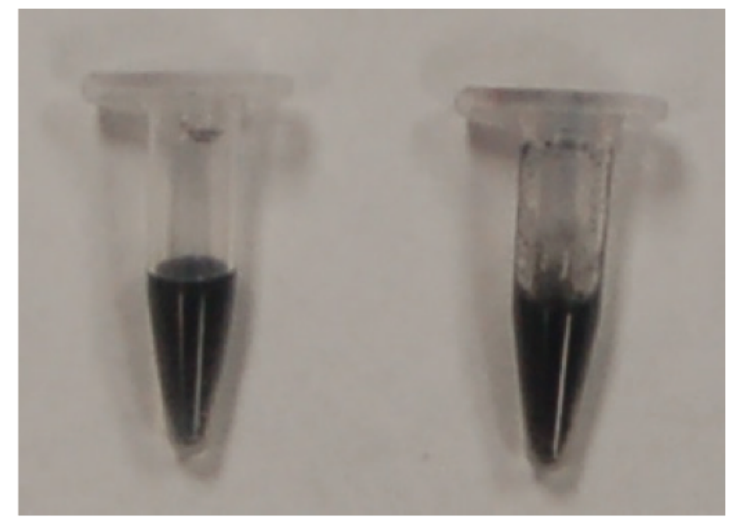

Figure 6.4 - MWCNTs in G-buffer on left and MWCNTs in water on right

The dispersion test showed however that there was a higher dispersion ratio of the MWCNTs in G-buffer- by a factor of 1.25- when compared with dispersion of the MWCNTs in water. This was due to the different $\mathrm{pH}$ condition that the two dispersants have, i.e. DI water ( $\mathrm{pH}$ 6.25) and G-buffer ( $\mathrm{pH} 8$ ). Similar results were observed in [68] for solutions with different $\mathrm{pH}$ condition. The formation of carboxyl groups on the surface of MWCNTs influences the solubility in different solvents. Addition of acid treated MWCNTs to solvents leads to deprotonation of the carboxylic acid groups. Higher $\mathrm{pH}$ values of dispersants result in higher degree of deprotonation. This produces more carboxylate anions that repel each other [69], which increases solubility of the MWCNTs.

\subsubsection{Attachment of G-actin to MWCNTs}

Next, the attachment of G-actin onto MWCNTs dispersed in G-buffer was investigated. The resulting MWCNT-G-actin conjugates and MWCNTs in G-buffer are shown in Figure 6.5. The sample on the left illustrates the MWCNT-G-actin conjugates, while the sample on the right shows the MWCNTs dispersed in G-buffer. 


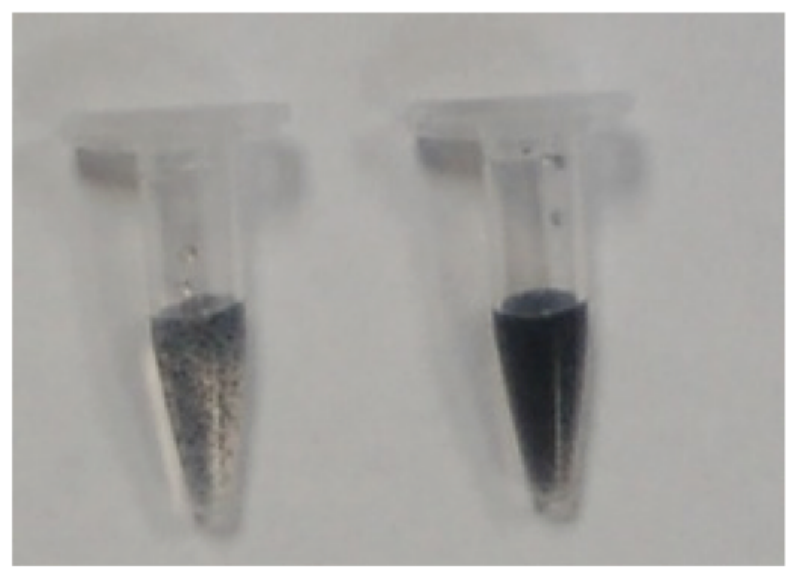

Figure 6.5 - G-actin attached to MWCNTs on left and MWCNTs in G-buffer on right

Visual inspection of the samples shows that the conjugates solution tends to form conglomerates when compared with the control (MWCNTs dispersed in G-buffer). Conglomerates formation is a result of the hydrophobic- hydrophobic interactions of the individual MWCNT-G-actin conjugates, with strong hydrophobic interactions being formed between G-actin (pI 5.23) and the hydrophobic MWCNTs dispersed in G-buffer during the incubation time.

\subsubsection{Observing MWCNTS using DIC and fluorescent microscopy}

A fluorescent microscope was used to observe G-actin covered samples. As mentioned earlier, chapter 5, rhodamine-phalloidin has F-actin binding sites, which stabilizes polymerized actin monomers and prevents depolymerization. Labeling these conjugates resulted in observation of actin monomers aggregates and short filaments. In Figure 6.6 the top left image (A) illustrates bundles of CNTs using the Differential Interference Contrast (DIC) of the microscope. The top right image (B) illustrates G-actin aggregates on CNTs using a fluorescent microscope. Finally, the figure on the bottom left (C) shows the merged image of A and B. 


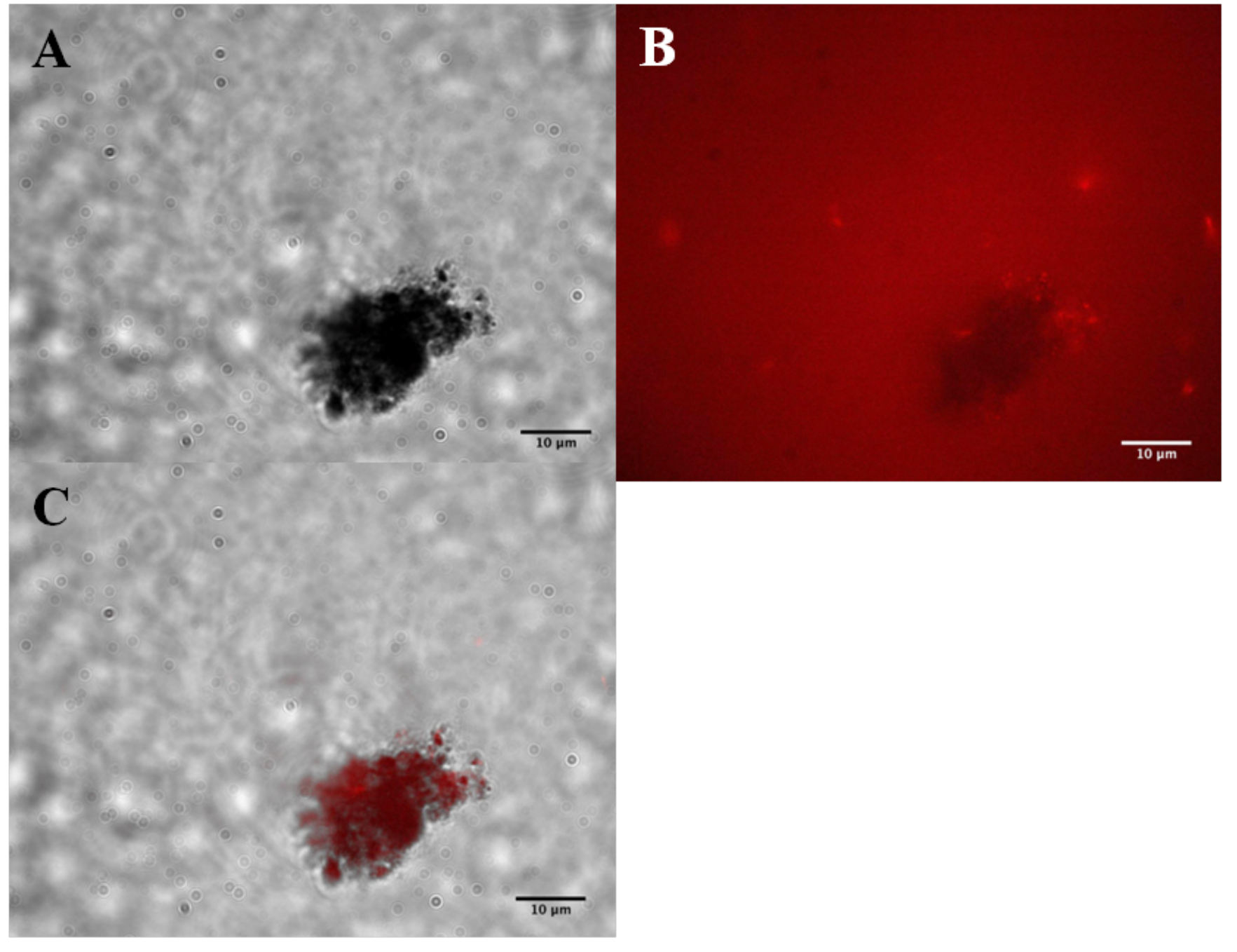

Figure 6.6 - A) MWCNT B) G-actin C) MWCNT/G-actin 


\subsubsection{Atomic Force Microscopy (AFM) for observation of G-actin}

AFM was used to confirm the attachment of G-actin to CNTs. There is close to full coverage of the MWCNTs by G-actin protein (diameter of 5nm [70]) as illustrated in Figure 6.7 when compared with control MWCNTs. The arrow indicates presence of proteins on CNTs. By comparing the diameters of carbon nanotubes in both images coverage of CNTs with protein was determined. The lower image in both figures is magnified to further illustrate the morphology of CNTs with and without proteins respectively.
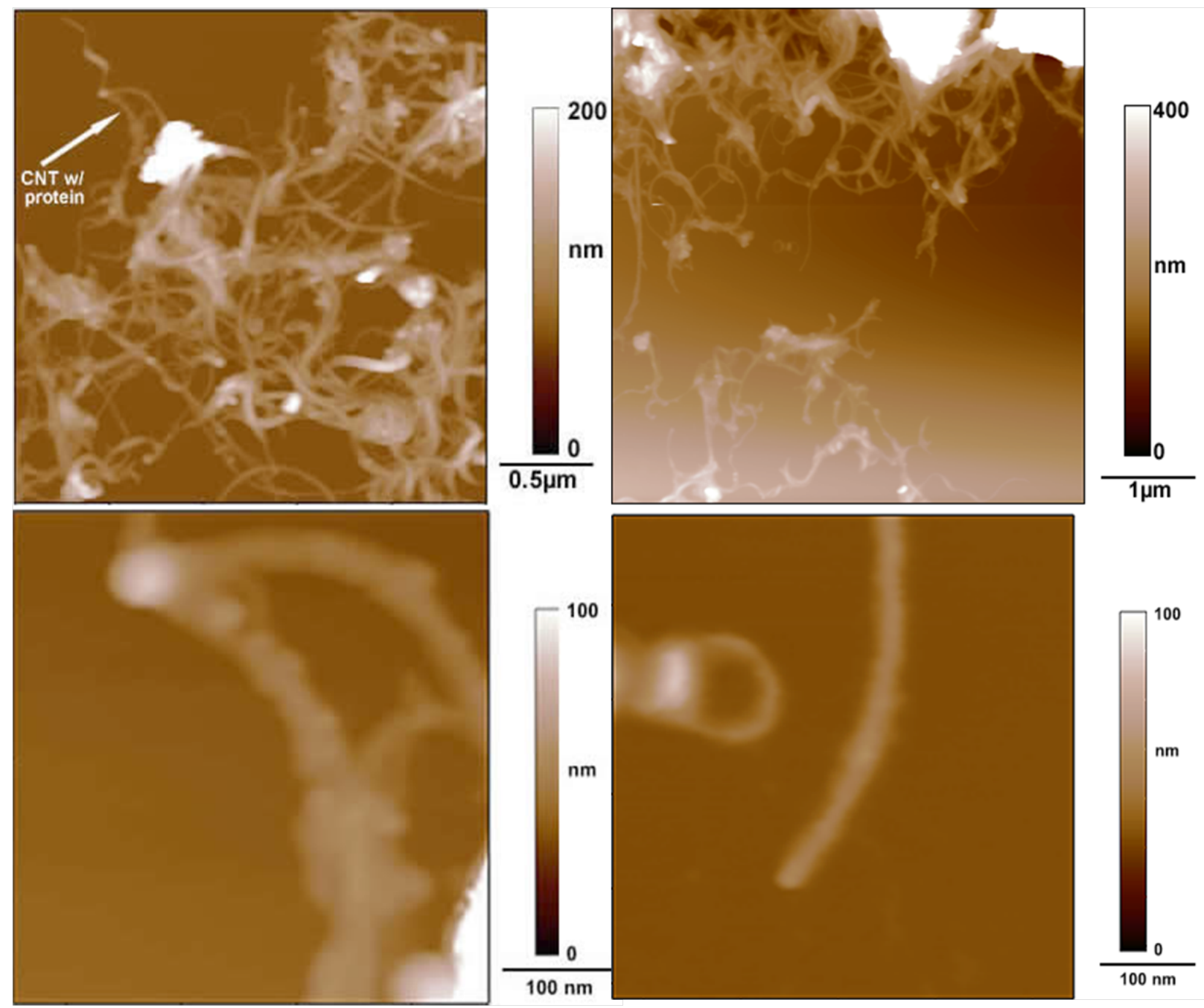

Figure 6.7 - AFM image of G-actin/CNTs (Left), AFM image of CNTs in G-buffer (Right) 


\subsection{MWCNTs and F-actin}

\subsubsection{Functionality of MWCNT-G-actin conjugates}

The functionality of immobilized G-actin was investigated to determine whether addition of free G-actin would lead to F-actin- based structures with MWCNTs as scaffolds.

The resulting structures were labeled with rhodamine-phalloidin and analyzed using fluorescent microscopy. Part A of the image shows the Differential Interference Contrast (DIC) image of MWCNT-G-actin conjugates polymerized with free G- actin, while part B shows fluorescent images of actin filaments on CNTs. Lastly, C illustrates a merged image of MWCNTs and F-actin indicating the co-localization of actin filaments with the MWCNTs. These preliminary results indicated F-actin filament formation onto MWCNT-scaffolds, thus creating the so-called "smart" hybrids.

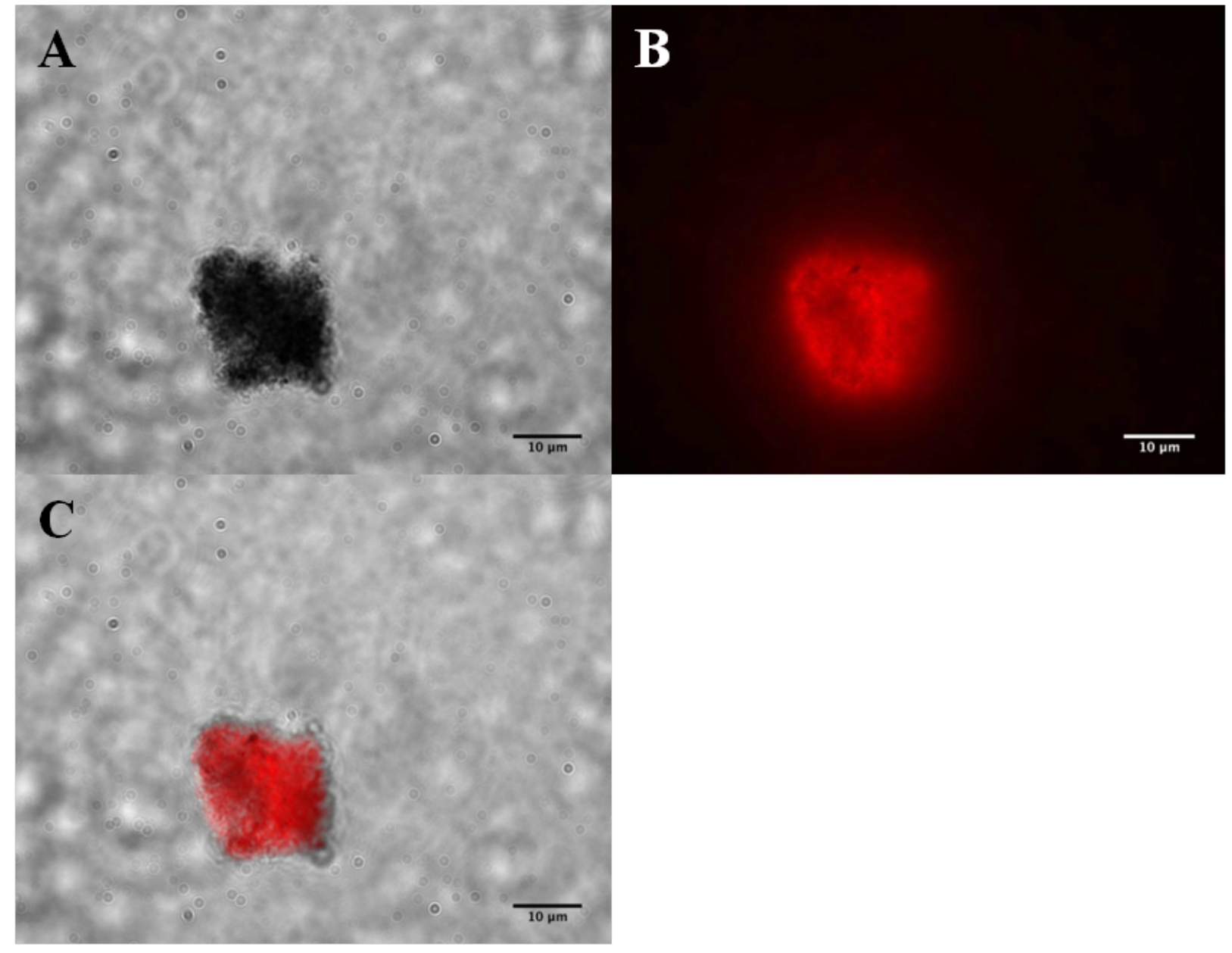

Figure 6.8 - A) MWCNT B) F-Actin C) MWCNT/F-actin 


\subsubsection{Functionality of MWCNT-F-actin hybrid assemblies}

\subsubsection{Recognition of MWCNT-F-actin assemblies using antibody}

The recognition capability of MWCNT-F-actin assemblies using antibodies was also investigated. To ensure proper control, attachment of antibodies to individual actin filaments was tested first. Briefly, anti-actin antibodies (primary antibodies) were incubated with actin filaments, followed by addition of antibody-coated fluorescent beads (secondary antibodies). The image below (Figure 6.9) on the left indicates attachment of fluorescent beads (secondary antibodies) to actin filaments in the presence of the primary antibody. The image on the right is the control without the presence of the primary antibody, thus indicating beads are not attached to the actin filaments.

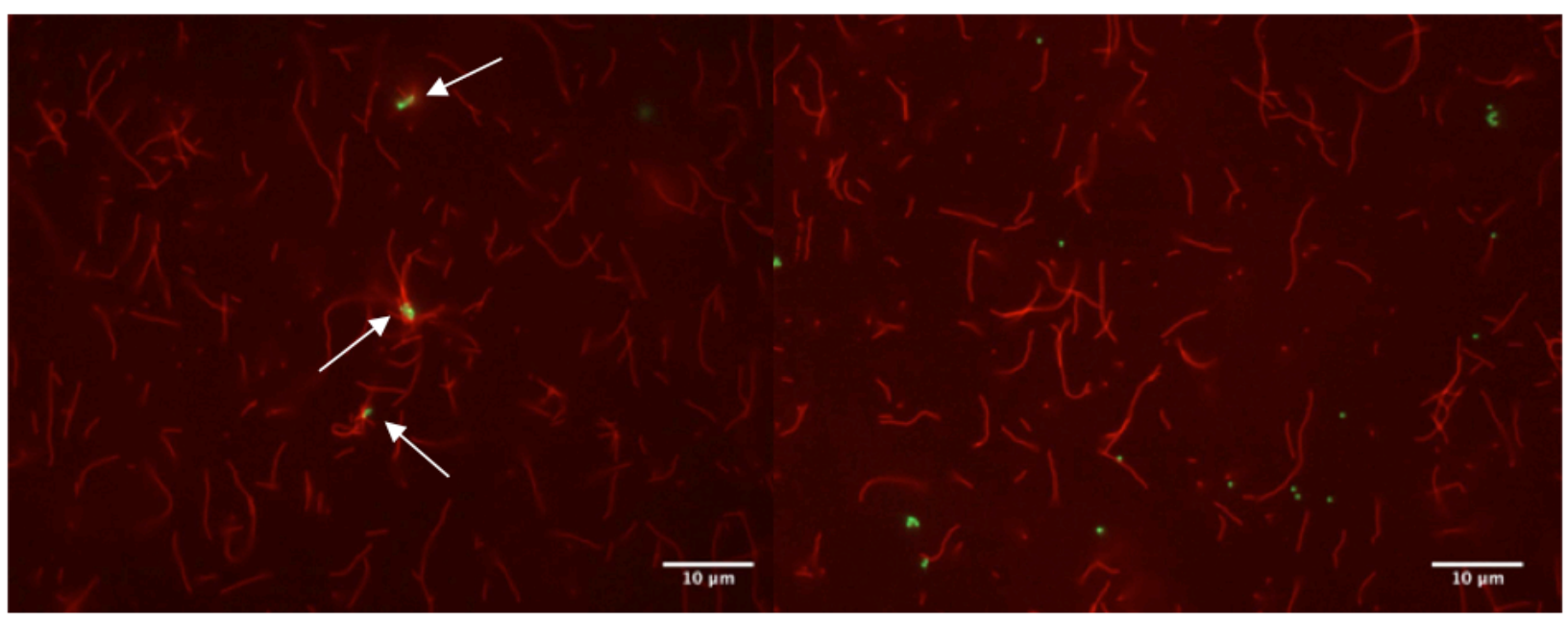

Figure 6.9 - Primary and secondary antibody (Left), secondary antibody (control) (Right)

After confirming attachment of fluorescent beads to actin filaments through the primary antibody, recognition of the antibodies to F-actin on the surface of CNTs was investigated and compared with fluorescent beads without the presence of the primary antibody (control). The number of beads indicates dependence upon the conglomerate and its size. The preliminary results indicate that the number of beads on the surface of the CNTs is on average 5 times greater when using the primary antibody $(\mathrm{N}=36)$. These 36 samples were collected from 10 flow cells and 5 separate experiments performed over 3 days. The number of beads was counted using the Image J "Analyze Particles" function. The results confirm recognition of the actin filaments on MWCNTs using anti-actin antibodies. 


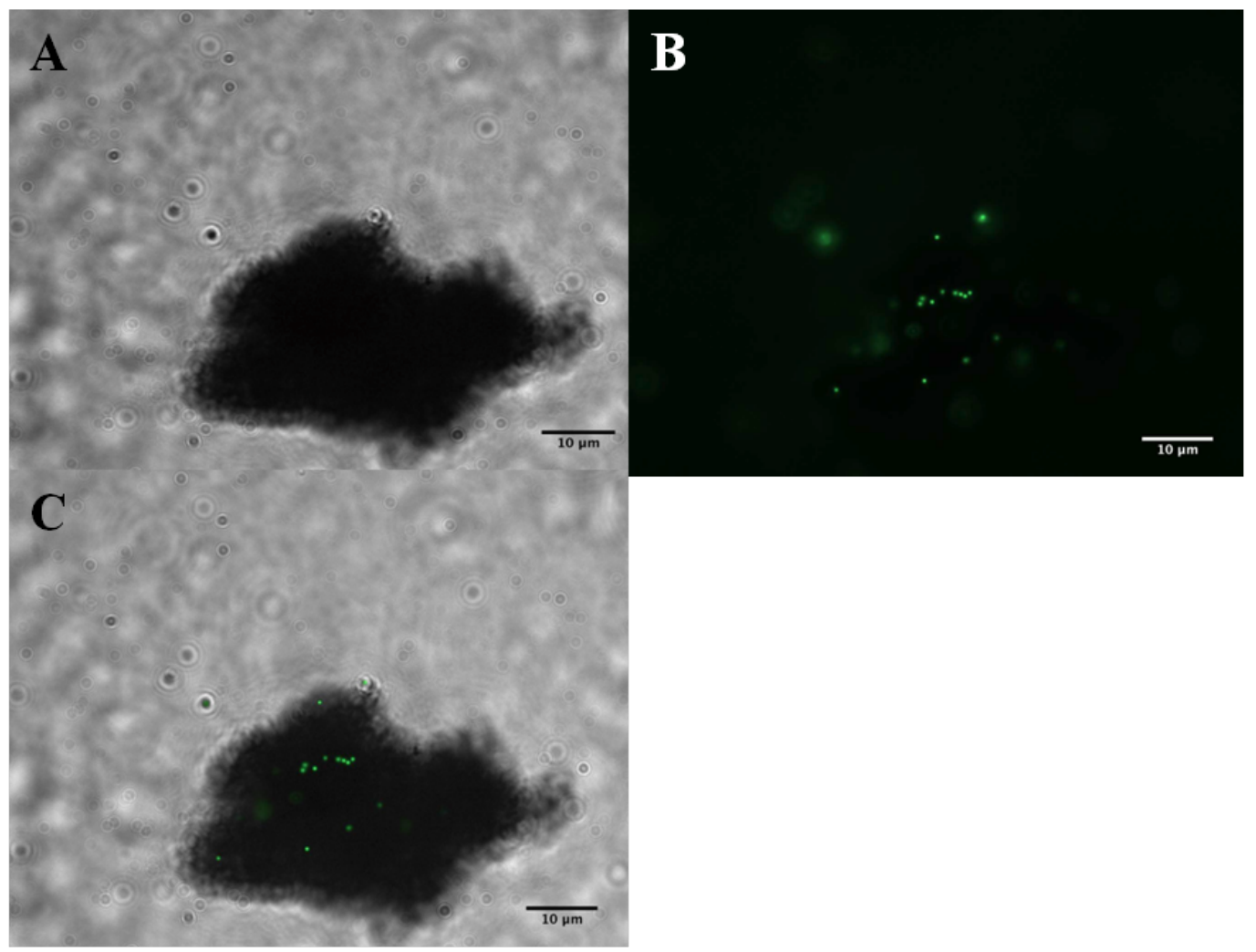

Figure 6.10 - A) MWCNTs B) Primary and secondary antibodies C) Merged image of A and B

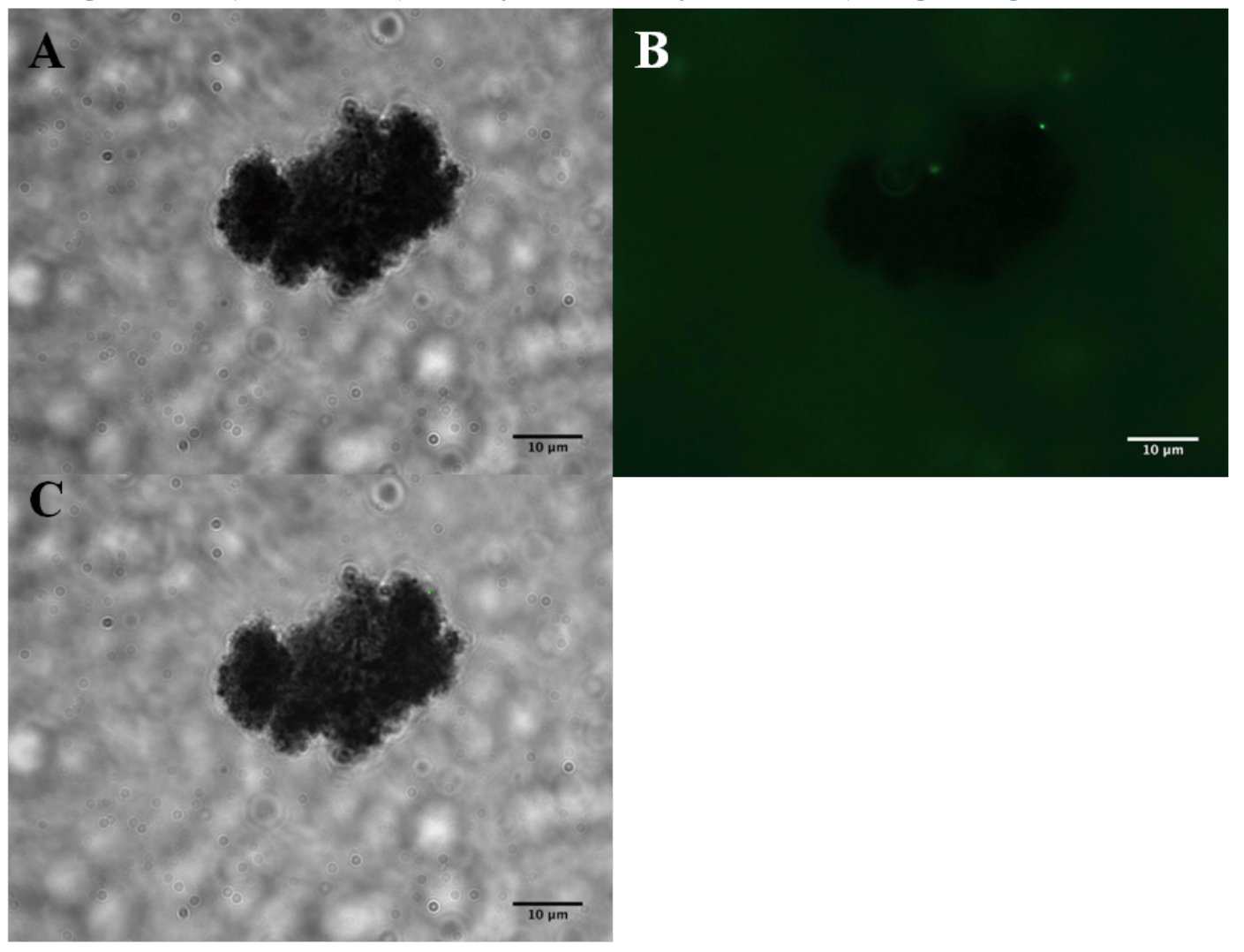

Figure 6.11 - A) MWCNTs B) Secondary antibodies C) Merged image of A and B 
The images below (Figure 6.12 and 6.13) confirm the same results. Unlike the prior experiment, a higher concentration of beads ( 5 times) was used to determine if the antibodies recognized the actin filaments. Once again based on the preliminary results, a higher number of beads attached to the surface (on average 10 times) when using the primary antibody ( $\mathrm{N}=24)$. These 24 samples were collected from 8 flow cells and 4 separate experiments performed over 2 days.

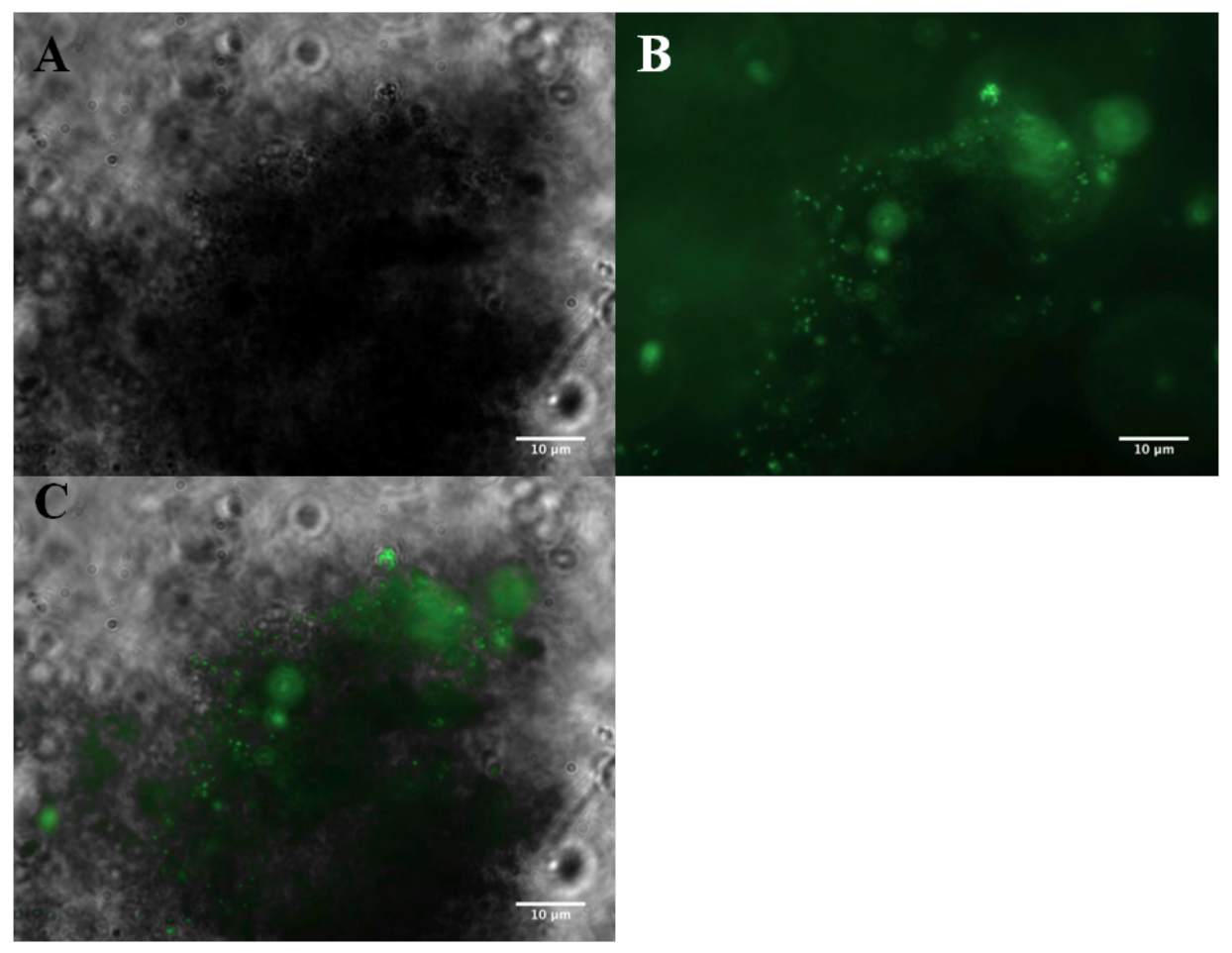

Figure 6.12 - A) MWCNTs B) Primary and secondary antibodies C) Merged image of A and B 


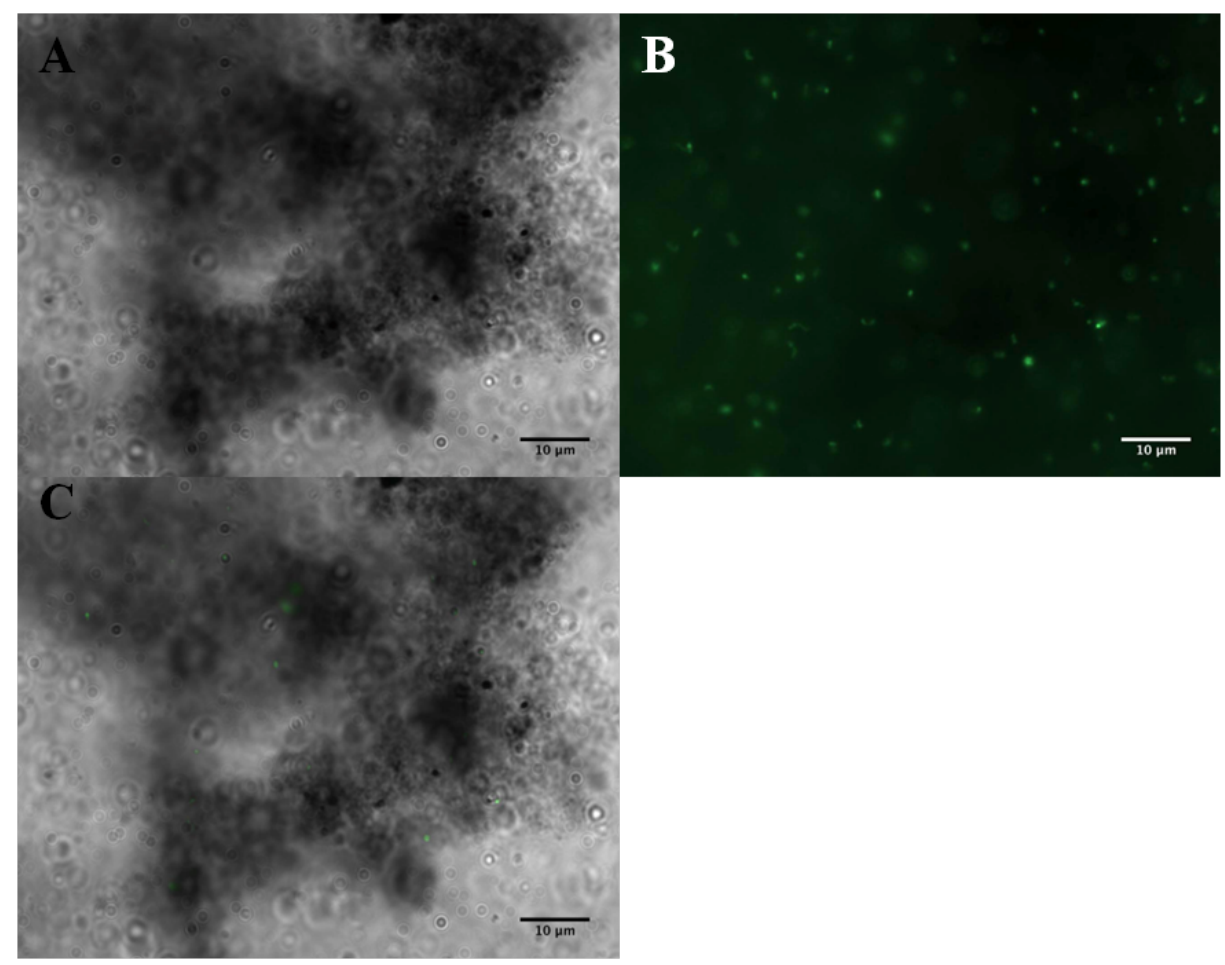

Figure 6.13 - A) MWCNTs B) Primary and secondary antibodies C) Merged image of A and B

\subsubsection{Motility of MWCNT-F-actin hybrid assemblies}

As mentioned in 6.3.2.1, the functionality of the assemblies was tested using antibodies to investigate whether they were able to recognize the actin filaments formed by polymerization of free actin onto the actin immobilized onto the carbon nanotube surfaces. However, attachment of limited number of beads was observed without the presence of the primary antibodies. The beads may have attached to non-functional actin filaments created on the surface of the MWCNTs non-specifically, which also resulted in non-specific attachment of the secondary antibodies. To further confirm functionality of the filaments, motility of these hybrid assemblies was also investigated.

\subsection{Actomyosin motility assay}

In the first step, motility of actin filaments and velocities were quantified. The averages of velocities indicate that the ambient temperature affects the velocity. This is caused by the dependence of ATPase rates to temperature [71]. Experiments were performed at different temperatures $\left(20^{\circ} \mathrm{C}\right.$ and $\left.25^{\circ} \mathrm{C}\right)$. The results are shown as mean $\pm \mathrm{SEM}$ (Standard Error of Mean). 
The average velocities at $20^{\circ} \mathrm{C}$ and $25^{\circ} \mathrm{C}$ are $0.83 \pm 0.03 \mu \mathrm{m} / \mathrm{s}(\mathrm{N}=30)$ and $1.27 \pm 0.07 \mu \mathrm{m} / \mathrm{s}(\mathrm{N}=50)$ respectively. The samples were collected from 15 flow cells and 5 separate experiments performed over 4 days. Based on the results the room temperature was kept between $25^{\circ} \mathrm{C}$ and $26^{\circ} \mathrm{C}$ for the remainder of the experiments. The measured values are presented in Figure 6.14.

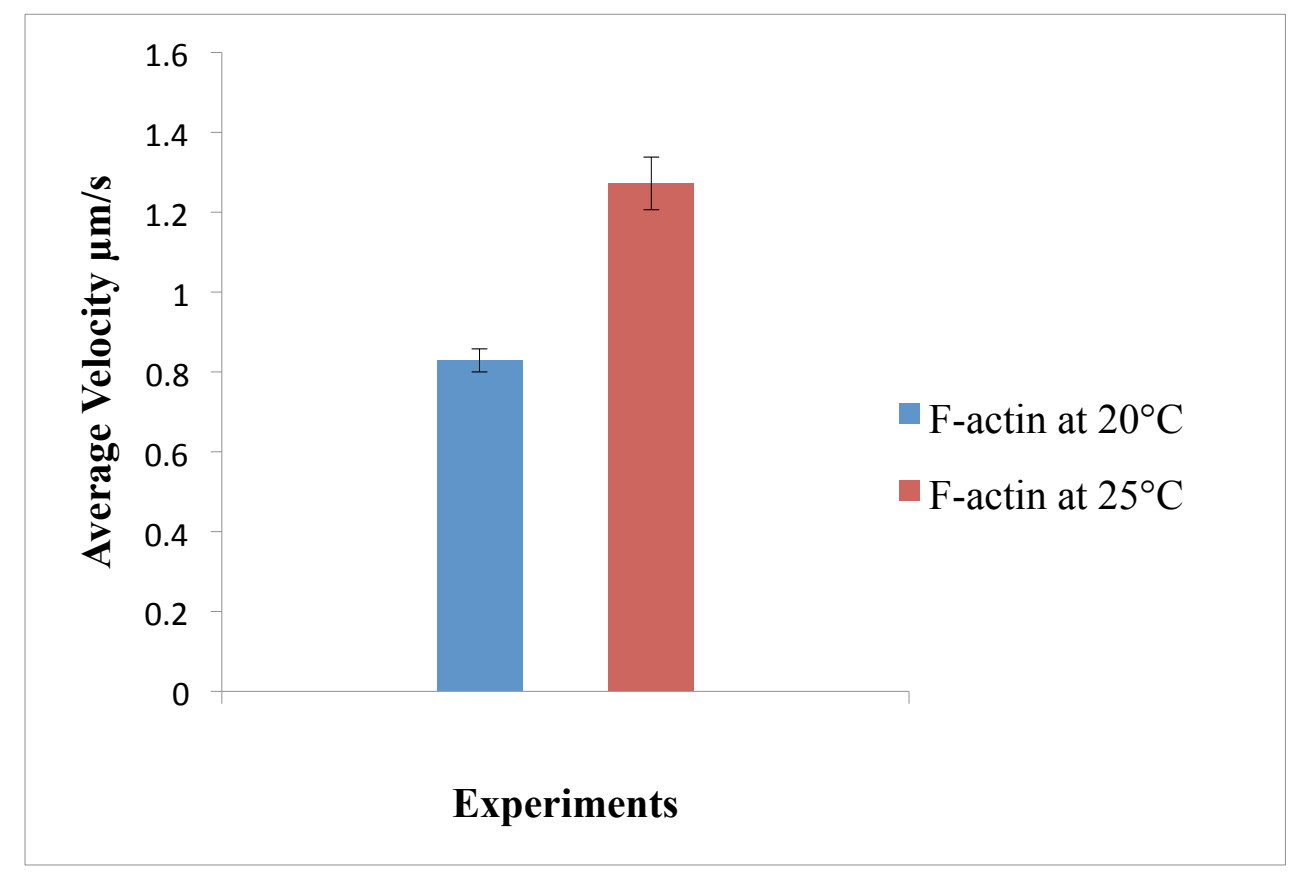

Figure 6.14 - Average velocity of actin filaments

The actin filaments indicated lower velocity at $20^{\circ} \mathrm{C}$ when compared to $\mathrm{F}$-actin at $25^{\circ} \mathrm{C}$. To determine if the difference in average velocity between the two values was statistically significant the Welch's t-test was used. The following hypotheses were also tested:

NULL: There is no difference in the average velocity for both samples

ALT: The average velocity for F-actin at $25^{\circ} \mathrm{C}$ is higher than F-actin at $20^{\circ} \mathrm{C}$

The NULL hypothesis is strongly rejected with $\mathrm{P} \leq 0.005$, indicating that the F-actin at $25^{\circ} \mathrm{C}$ exhibited significantly higher velocity.

\subsection{Actin-bead motility assay}

Movement and velocity of beads attached to actin filaments were investigated to demonstrate the ability of transporting carbon nanotubes using actomyosin motility assays. The successful attachment of streptavidin-coated beads onto biotinylated actin filaments is shown in Figure 6.15. However, bundles and aggregates of biotinylated filaments were also observed due 
to the high concentration of streptavidin on beads $\left(1.69 \times 10^{4}\right.$ streptavidin/particle $)$ and interaction with biotin on the filaments.

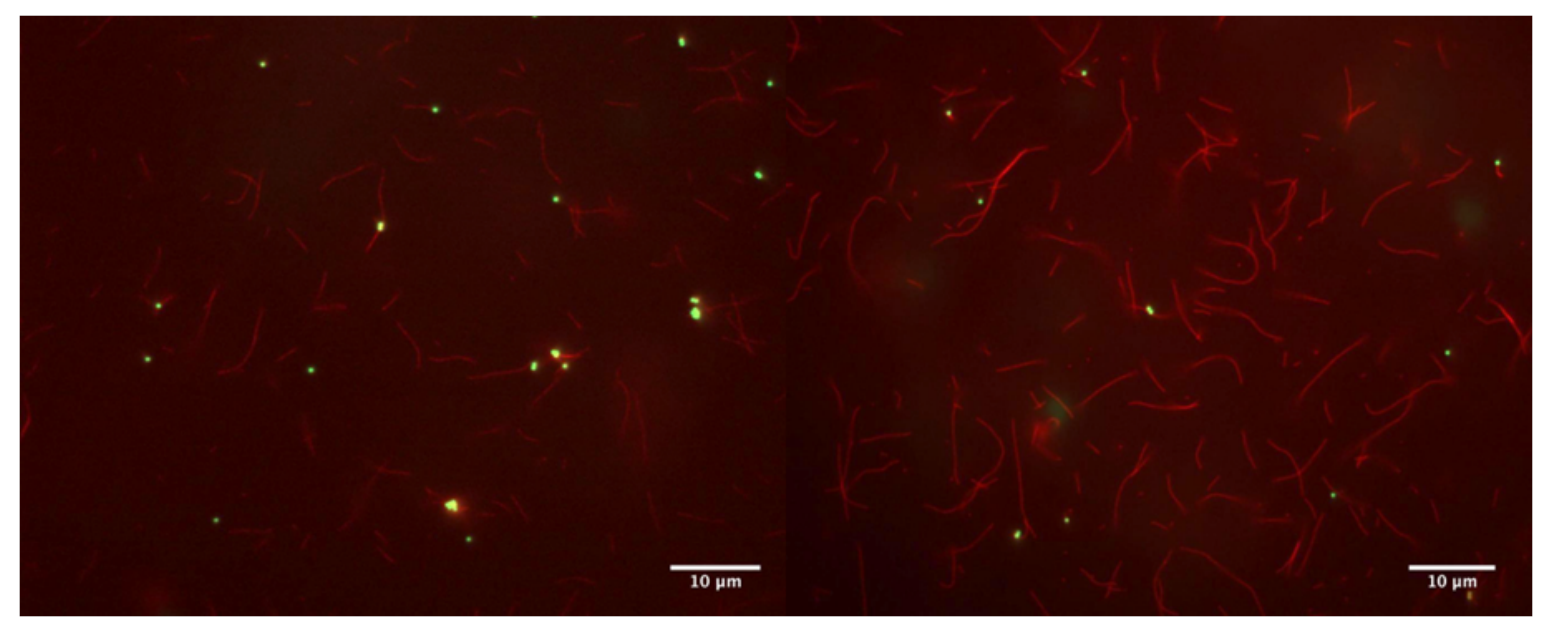

Figure 6.15 - Biotinylated actin filaments and beads (Left), actin filaments and beads (Right)

The motility of beads attached to actin filaments on HMM coated surface was investigated. The images below (Figure 6.16,Figure 6.17) show movement and gliding of the beads on HMM coated surfaces at 1second intervals. 


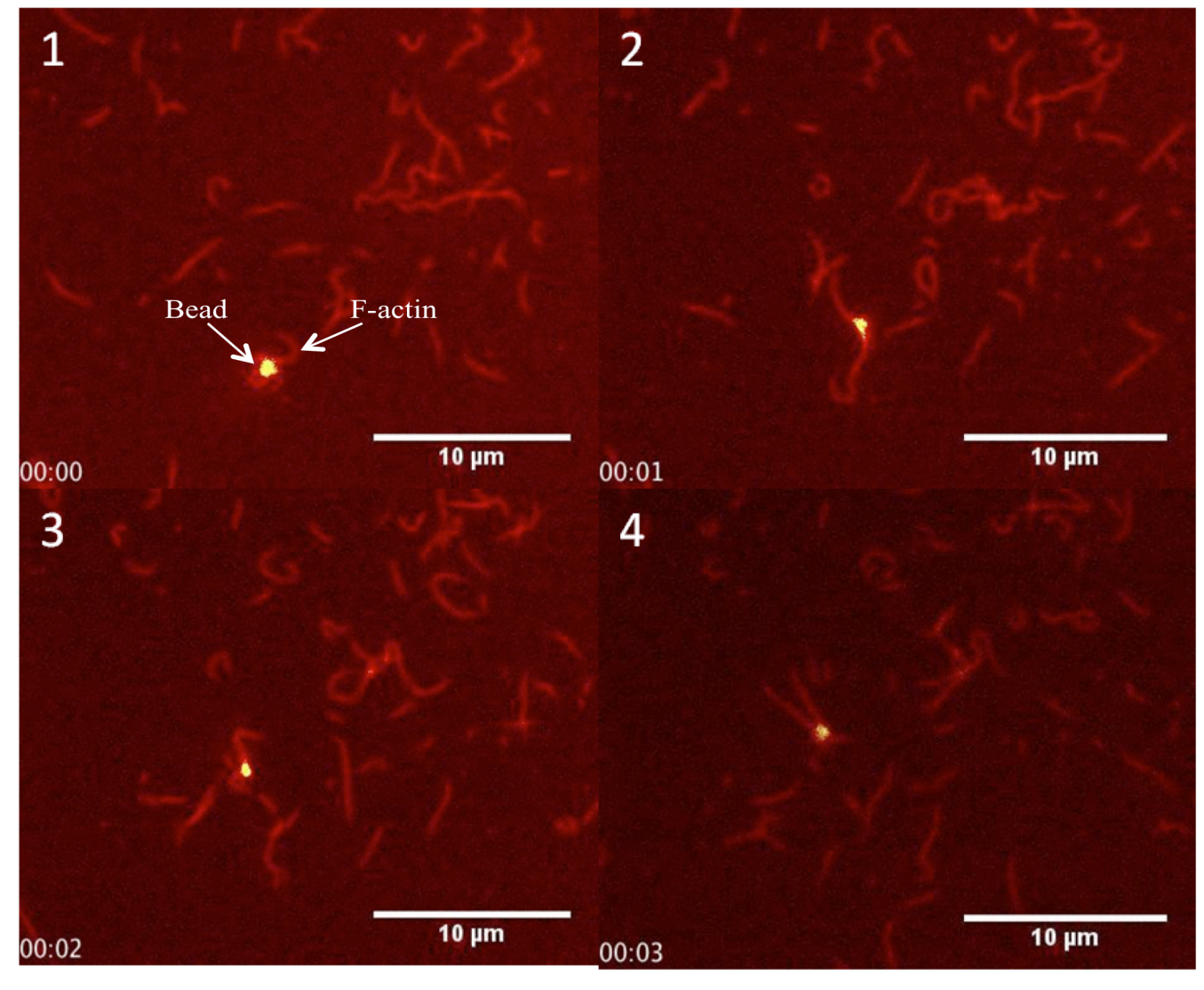

Figure 6.16 - Actin-bead motility assay 


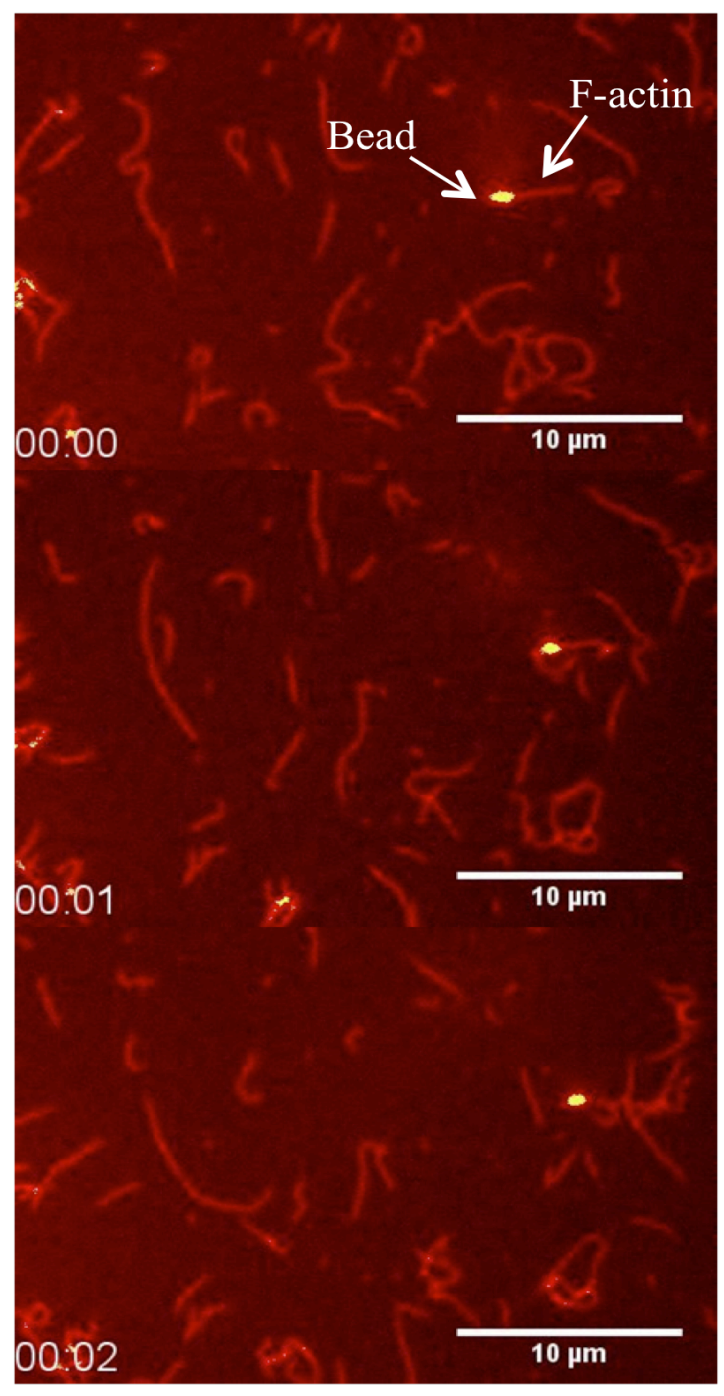

Figure 6.17 - Actin-bead motility assay

The velocities of beads were compared with unloaded actin filaments. The average velocities of actin filaments with beads and without beads at $25^{\circ} \mathrm{C}$ are $1.06 \pm 0.1 \mu \mathrm{m} / \mathrm{s}(\mathrm{N}=33)$ and $1.25 \pm 0.08 \mu \mathrm{m} / \mathrm{s}(\mathrm{N}=67)$ respectively. The samples were collected from 15 flow cells and 5 separate experiments performed over 4 days. 


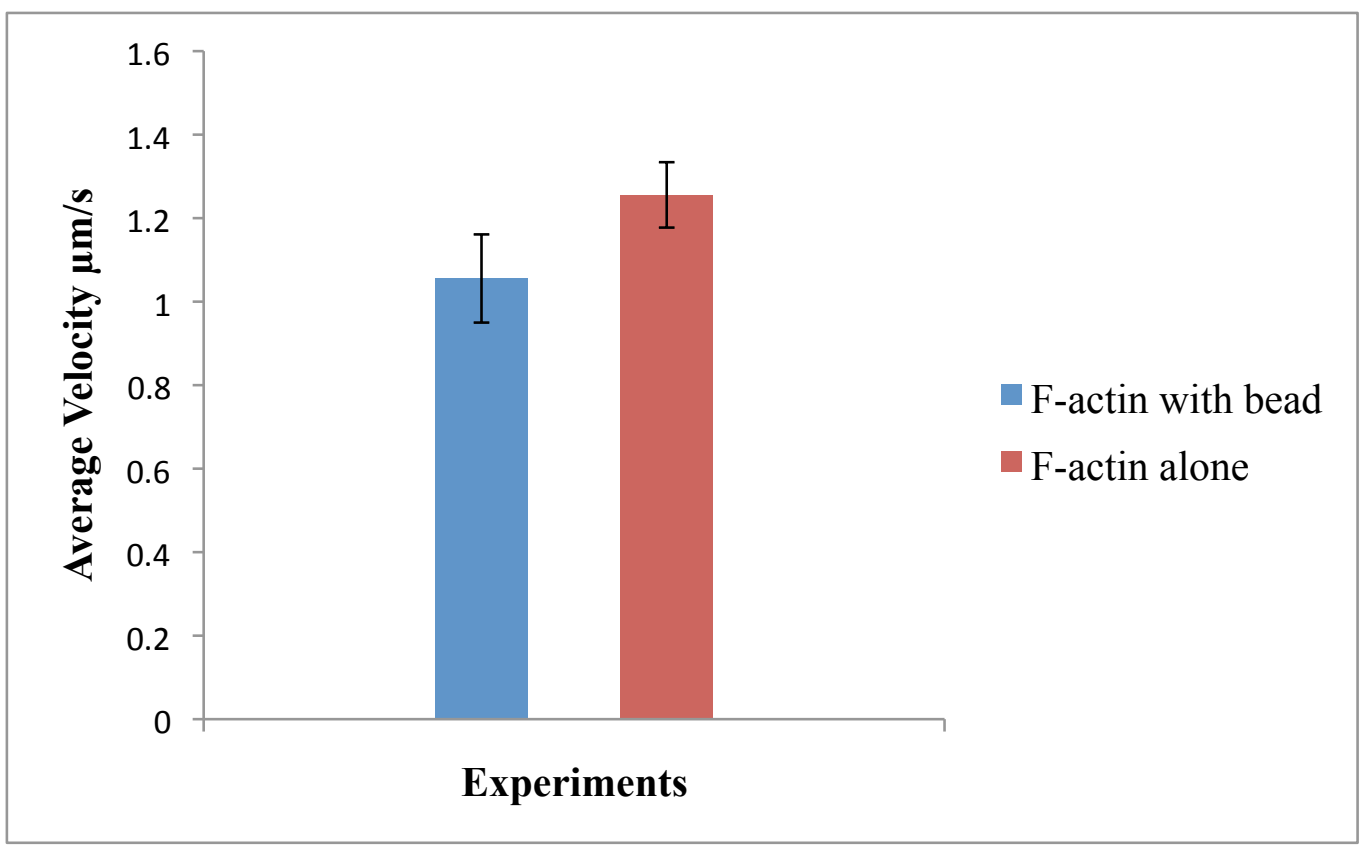

Figure 6.18 - Average velocity of loaded and unloaded actin

The F-actin- beads indicated lower velocity when compared to single actin filaments. To determine if the difference in average velocity between the F-actin with and without bead was statistically significant the Welch's t-test was used and the following hypotheses were tested:

NULL: There is no difference in the average velocity for F-actin with and without beads

ALT: The average velocity for F-actin without beads is higher

The NULL hypothesis is strongly rejected with $\mathrm{P} \leq 0.05$, indicating that the F-actin without beads exhibited significantly higher velocity.

Addition of higher number of beads (higher concentration) further disabled the actin motility. This may be due to the attachment of beads through biotin-streptavidin interaction onto actin filaments, and blocking interaction of filaments with myosin motors. Similar results were observed when increasing the number of quantum dots added onto actin filaments [72], causing significant blocking of actin and myosin interactions.

\subsection{CNT-F-actin hybrid assembly motility}

Movement and velocity of CNT-F-actin hybrids was investigated to demonstrate functionality of actin filaments attached on the surface of carbon nanotubes. The images below (Figure 6.19) indicate displacement and limited movement of CNT-F-actin assemblies after 5 seconds. The calculated average velocity was $0.74 \mu \mathrm{m} / \mathrm{s}$. 


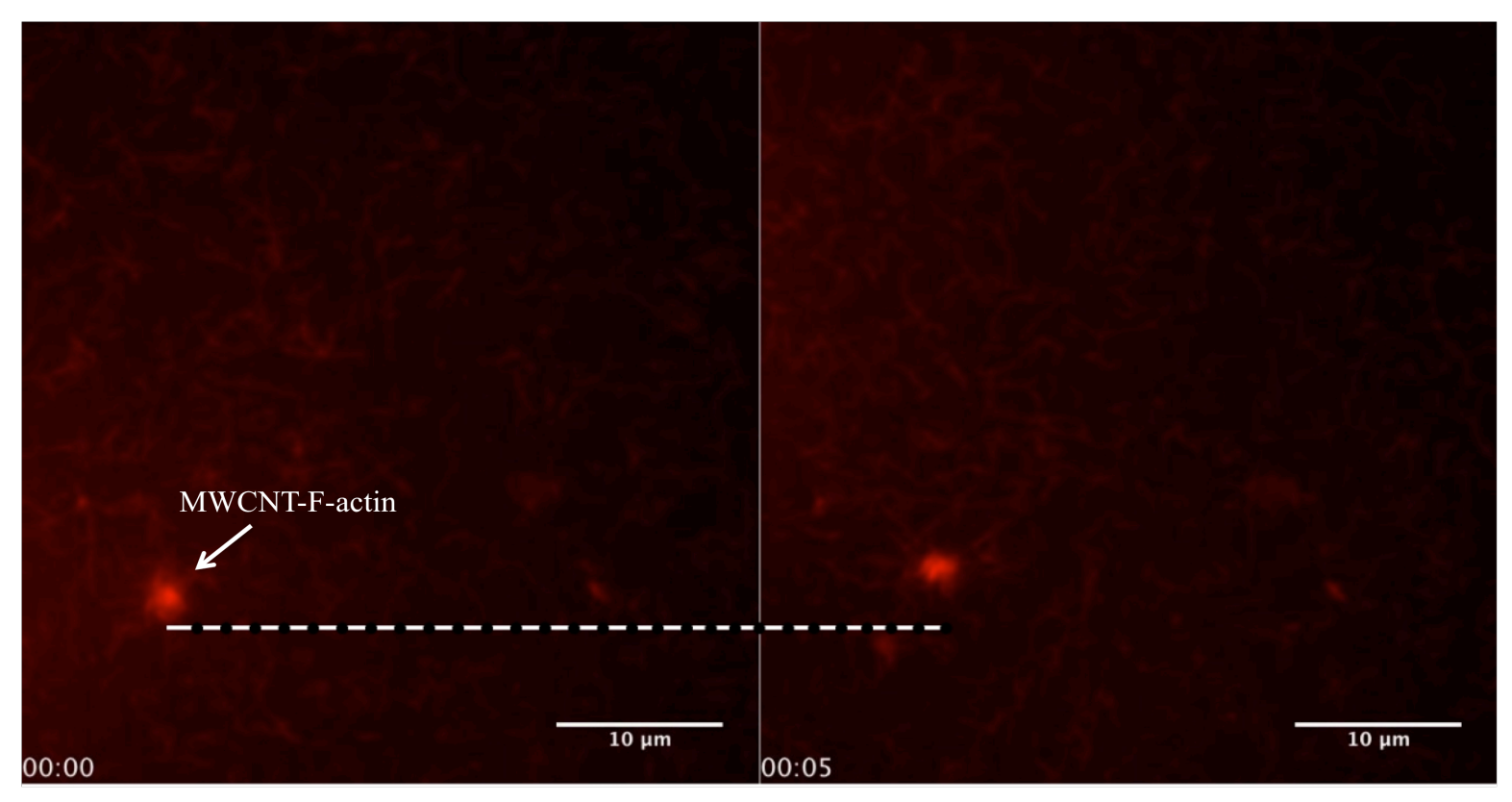

Figure 6.19 - MWCNT-F-actin hybrid assemblies on HMM

Figure 6.20 indicates another sample of CNT-F-actin assemblies after 10 seconds. The hybrid assemblies indicate irregular movement and fluctuation with velocity of $1.03 \mu \mathrm{m} / \mathrm{s}$. The results presented herein are preliminary, and should be further investigated in future experiments with a larger sample size. 


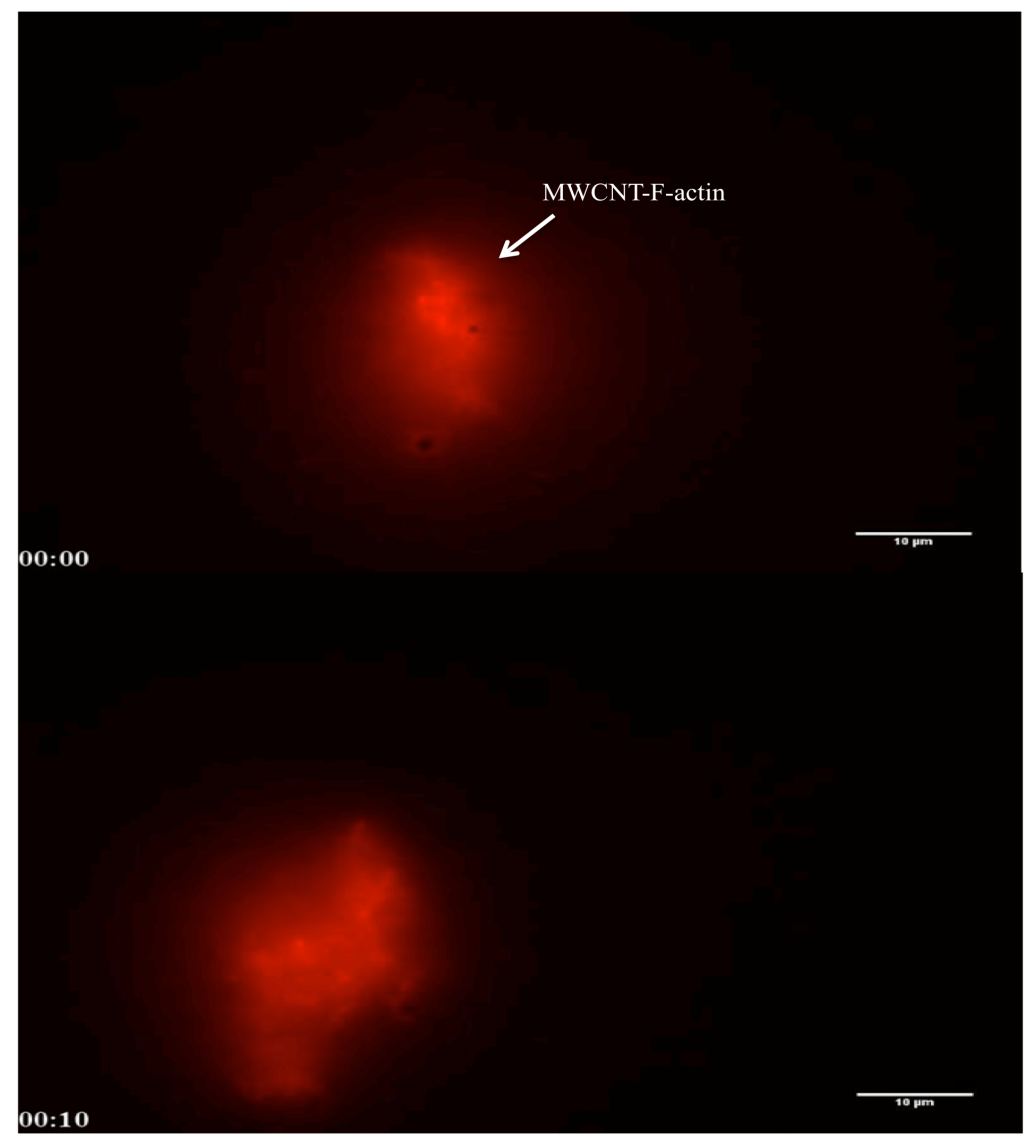

Figure 6.7 - MWCNT-F-actin hybrid assemblies on HMM

The correlation between the size and radius of the carbon nanotubes and drag force associated with these nanotubes was investigated. The drag force caused by spheres can be calculated based on the following equation, where $\eta$ is the viscosity of the medium, $\mathrm{R}$ and $\mathrm{V}$ are the radius and velocity of the sphere respectively:

$$
\mathrm{F}=(8 \pi / 3) \eta \mathrm{R} \mathrm{V}[64]
$$

The drag force of beads with diameter of 400-600 $\mathrm{nm}$ through a solution with viscosity of water $(\sim 1 \mathrm{mPa} . \mathrm{s})$ is $\sim 3.5-5 \mathrm{fN}$ and for CNT aggregates with diameter of $10-30 \mu \mathrm{m}$ is $\sim 85-250 \mathrm{fN}$. These values indicate that a single myosin head is able to produce higher force (3-4 $\mathrm{pN}$ [73]). Multiple motors interact with individual actin filaments and large particles should be transported. However, a high number of the agglomerates showed very limited displacement or movement. A few of the hybrid assemblies indicate fluctuation, however the displacement was observed for a very short period of time and no movement was detected after that time period. These results may be caused by the inability of the myosin motors to recognize polarity of actin filaments 
formed on the carbon nanotubes. Sideway movements of CNT and microtubule hybrid assemblies were also observed in previous studies [58].

Attachment of the filaments on the carbon nanotubes surfaces may also cause steric hindrance of myosin. This is due to the direct attachment of large surface of actin filaments onto the nanotubes, and therefore prevents the attached filaments from interacting with myosin motors [74]. The length of actin filaments polymerized on the surface could also introduce another limiting factor in particular by the inability of myosin motors to move and interact with short actin filaments present on the surface of the carbon nanotubes. The actin filaments moving on myosin motors require continuous interaction with myosin heads to stay associated with the surface and also for each head to release and attach to the moving filaments [75]. The observed results may also be due to different arrangement and orientation of actin filaments on the MWCNT agglomerates, and thus the disabling unidirectional movement of such agglomerates. Similar results were observed for movement of actin-coated liposomes [63]. 


\section{Chapter 7 Conclusions and Outlook}

The results of this research indicate that actin monomers (G-actin) attach to MWCNT. The AFM images showed close to full coverage of the MWCNTs by G-actin protein. The attached G-actins were also functional and polymerized into actin filaments on MWCNTs scaffolds. Specific antibodies were able to recognize the actin filaments on the surface of carbon nanotubes. These preliminary results are envisioned to be useful for future biosensor applications with the protein acting as an agent for specific detection [16].

The motility of CNT-F-actin hybrid assemblies was also investigated on HMM-coated surface. A large number of the assemblies showed limited or no movement. These results may be caused by several factors and reasons: inability of the myosin motors to recognize polarity of actin filaments, limited interaction of the actin filaments with myosin due to direct interaction with MWCNTs, polymerization of short actin filaments on the surface of the nanotubes and different arrangement and orientations of actin filaments.

Further investigation of the MWCNT-F-actin could be performed using Scanning Electron Microscopy (SEM) and Transmission Electron Microscopy (TEM) [76]. These methods may allow visualization of the morphology of the MWCNT-F-actin hybrid assemblies.

The same experiments could be done using SWCNTs due to their smaller diameter, and pristine (without acid treatment) MWCNTs to compare the results and further investigate interaction of actin with CNTs.

The motility of the biohybrids could also be tested using processive myosin (e.g. myosin V) instead of non-processive myosin (e.g. myosin II). Processive myosin remains attached to actin filaments [61] and may enable detectable movement of the hybrid assemblies.

The movement of carbon nanotubes using myosin motors can also be investigated using bio-linkers such as streptavidin and biotin to attach actin filaments onto carbon nanotubes. This method would be achieved in a manner similar to streptavidin-coated beads and biotinylated actin. Using a linker to attach and combine these nanomaterials may also enable longer travel distance and movement of the assemblies. Transportation of the biohybrids using ATP as the energy source and myosin motor proteins may facilitate possible solutions for transportation of biological and non-biological samples to specific locations. 


\section{Chapter 8 Bibliography}

[1] National Nanotechnology Initiative: http://www.nano.gov/nanotech-101/what/definition

[2] Allhoff, F., Lin, P., \& Moore, D. (2010). What is nanotechnology and why does it matter: from science to ethics. Wiley-Blackwell.

[3] Avouris, P., Appenzeller, J., Martel, R., \& Wind, S. J. (2003). Carbon nanotube electronics. Proceedings of the IEEE, 91(11), 1772-1784.

[4] Serrano, E., Rus, G., \& Garcia-Martinez, J. (2009). Nanotechnology for sustainable energy. Renewable and Sustainable Energy Reviews, 13(9), 2373-2384.

[5] Roco, M. C. (2003). Nanotechnology: convergence with modern biology and medicine. Current Opinion in Biotechnology, 14(3), 337-346.

[6] Siegrist, M., Stampfli, N., Kastenholz, H., \& Keller, C. (2008). Perceived risks and perceived benefits of different nanotechnology foods and nanotechnology food packaging. Appetite, 51(2), 283-290.

[7] Agarwal, A., \& Hess, H. (2010). Biomolecular motors at the intersection of nanotechnology and polymer science. Progress in Polymer Science, 35(1), 252-277.

[8] Shi, J., Votruba, A. R., Farokhzad, O. C., \& Langer, R. (2010). Nanotechnology in drug delivery and tissue engineering: from discovery to applications. Nano letters, 10(9), 3223-3230.

[9] Baughman, R. H., Zakhidov, A. A., \& de Heer, W. A. (2002). Carbon nanotubes--the route toward applications. Science, 297(5582), 787-792.

[10] Liu, Z., Tabakman, S., Welsher, K., \& Dai, H. (2009). Carbon nanotubes in biology and medicine: in vitro and in vivo detection, imaging and drug delivery. Nano research, 2(2), 85-120.

[11] Willner, I., \& Willner, B. (2010). Biomolecule-based nanomaterials and nanostructures. Nano letters, 10(10), 3805-3815.

[12] Korten, T., Månsson, A., \& Diez, S. (2010). Towards the application of cytoskeletal motor proteins in molecular detection and diagnostic devices. Current opinion in biotechnology, 21(4), 477-488.

[13] Ionov, L., Stamm, M., \& Diez, S. (2005). Size sorting of protein assemblies using polymeric gradient surfaces. Nano letters, 5(10), 1910-1914.

[14] Lin, C. T., Kao, M. T., Kurabayashi, K., \& Meyhofer, E. (2008). Self-contained, biomolecular motor-driven protein sorting and concentrating in an ultrasensitive microfluidic chip. Nano letters, 8(4), 1041-1046.

[15] Hiyama, S., Moritani, Y., Gojo, R., Takeuchi, S., \& Sutoh, K. (2010). Biomolecular-motor-based autonomous delivery of lipid vesicles as nano-or microscale reactors on a chip. Lab Chip, 10(20), 2741-2748.

[16] Hess, H., Clemmens, J., Qin, D., Howard, J., \& Vogel, V. (2001). Light-controlled molecular shuttles made from motor proteins carrying cargo on engineered surfaces. Nano Letters, 1(5), 235-239.

[17] Hess, H. (2011). Engineering applications of biomolecular motors. Annual review of biomedical engineering, 13, 429-450. 
[18] Nitta, T., Tanahashi, A., Obara, Y., Hirano, M., Razumova, M., Regnier, M., \& Hess, H. (2008). Comparing guiding track requirements for myosin-and kinesin-powered molecular shuttles. Nano letters, 8(8), 2305-2309.

[19] Sundberg, M., Bunk, R., Albet-Torres, N., Kvennefors, A., Persson, F., Montelius, L., ... \& Månsson, A. (2006). Actin filament guidance on a chip: toward high-throughput assays and lab-on-a-chip applications. Langmuir, 22(17), 7286-7295.

[20] Alberts, B., Johnson, A., Lewis, J., Raff, M., Roberts, K., Walter, P. (2002) Molecular biology of the cell.

[21] Monthioux, M., \& Kuznetsov, V. L. (2006). Who should be given the credit for the discovery of carbon nanotubes?. Carbon, 44(9), 1621-1623.

[22] Popov, V. N. (2004). Carbon nanotubes: properties and application. Materials Science and Engineering: R: Reports, 43(3), 61-102.

[23] Kalavagunta, A. Modeling Carbon Nanotube FET Physics in COMSOL-Multiphysics.

[24] Katz, E., \& Willner, I. (2004). Biomolecule-functionalized carbon nanotubes: applications in nanobioelectronics. ChemPhysChem, 5(8), 1084-1104.

[25] Avouris, P., Freitag, M., \& Perebeinos, V. (2008). Carbon-nanotube photonics and optoelectronics. Nature photonics, 2(6), 341-350.

[26] C. Jacobs, M. Peairs, and B. Venton - "Review: Carbon nanotube based electrochemical sensors for biomolecules" - Analytica Chimica Acta, 2010, 105-127.

[27] Allen, B. L., Kichambare, P. D., \& Star, A. (2007). Carbon Nanotube Field-Effect-Transistor-Based Biosensors. Advanced Materials, 19(11), 1439-1451.

[28] S. Wang, G. Zhang, R. Wang, and S. Yoon - " A novel multi-walled carbon nanotube-based biosensor for glucose detection" - Biochemical and Biophysical Research Communicaions, 2003, 572-576.

[29] Wang, J. (2005). Carbon-nanotube based electrochemical biosensors: A review. Electroanalysis, 17(1), 7-14.

[30] Cai, H., Cao, X., Jiang, Y., He, P., \& Fang, Y. (2003). Carbon nanotube-enhanced electrochemical DNA biosensor for DNA hybridization detection. Analytical and bioanalytical chemistry, 375(2), 287-293.

[31] Liu, Z., Chen, K., Davis, C., Sherlock, S., Cao, Q., Chen, X., \& Dai, H. (2008). Drug delivery with carbon nanotubes for in vivo cancer treatment. Cancer research, 68(16), 6652-6660.

[32] Bianco, A., Kostarelos, K., \& Prato, M. (2005). Applications of carbon nanotubes in drug delivery. Current opinion in chemical biology, 9(6), 674-679.

[33] Harrison, B. S., \& Atala, A. (2007). Carbon nanotube applications for tissue engineering. Biomaterials, 28(2), 344-353.

[34] Stevens, R. M., Frederick, N. A., Smith, B. L., Morse, D. E., Stucky, G. D., \& Hansma, P. K. (2000). Carbon nanotubes as probes for atomic force microscopy. Nanotechnology, 11(1), 1.

[35] Cherukuri, P., Bachilo, S. M., Litovsky, S. H., \& Weisman, R. B. (2004). Near-infrared fluorescence microscopy of single-walled carbon nanotubes in phagocytic cells. Journal of the American Chemical Society, 126(48), 15638-15639.

[36] Lin, Y., Taylor, S., Li, H., Fernando, K. S., Qu, L., Wang, W., \& Sun, Y. P. (2004). Advances toward bioapplications of carbon nanotubes. J. Mater. Chem., 14(4), 527-541. 
[37] Kostarelos, K., Bianco, A., \& Prato, M. (2009). Promises, facts and challenges for carbon nanotubes in imaging and therapeutics. Nature Nanotechnology, 4(10), 627-633.

[38] Ajayan, P., \& Zhou, O. (2001). Applications of carbon nanotubes. Carbon Nanotubes, 391-425.

[39] Yang, W., Thordarson, P., Gooding, J. J., Ringer, S. P., \& Braet, F. (2007). Carbon nanotubes for biological and biomedical applications. Nanotechnology, 18(41), 412001.

[40] Zhao, Y. L., \& Stoddart, J. F. (2009). Noncovalent functionalization of single-walled carbon nanotubes. Accounts of chemical research, 42(8), 1161-1171.

[41] Kam, N. W. S., O'Connell, M., Wisdom, J. A., \& Dai, H. (2005). Carbon nanotubes as multifunctional biological transporters and near-infrared agents for selective cancer cell destruction. Proceedings of the National Academy of Sciences of the United States of America, 102(33), 11600-11605.

[42] Lu, F., Gu, L., Meziani, M. J., Wang, X., Luo, P. G., Veca, L. M., ... \& Sun, Y. P. (2008). Advances in bioapplications of carbon nanotubes. Advanced Materials, 21(2), 139-152.

[43] Tasis, D., Tagmatarchis, N., Bianco, A., \& Prato, M. (2006). Chemistry of carbon nanotubes. Chemical Reviews-Columbus, 106(3), 1105.

[44] Pastorin, G. (2009). Crucial functionalizations of carbon nanotubes for improved drug delivery: a valuable option?. Pharmaceutical research, 26(4), 746-769.

[45] Gogotsi, Y., Libera, J. A., Guvenc-Yazicioglu, A., \& Megaridis, C. M. (2001). In situ multiphase fluid experiments in hydrothermal carbon nanotubes. Applied physics letters, 79(7), 1021-1023.

[46] Ito, T., Sun, L., \& Crooks, R. M. (2003). Observation of DNA transport through a single carbon nanotube channel using fluorescence microscopy. Chemical Communications, (13), 1482-1483.

[47] Davis, J. J., Green, M. L., Allen O Hill, H., Leung, Y. C., Sadler, P. J., Sloan, J., ... \& Chi Tsang, S. (1998). The immobilisation of proteins in carbon nanotubes. Inorganica Chimica Acta, 272(1), 261-266.

[48] Monthioux, M., Smith, B. W., Burteaux, B., Claye, A., Fischer, J. E., \& Luzzi, D. E. (2001). Sensitivity of single-wall carbon nanotubes to chemical processing: an electron microscopy investigation. Carbon, 39(8), 12511272.

[49] Dujardin, E., Ebbesen, T. W., Hiura, H., \& Tanigaki, K. (1994). Capillarity and wetting of carbon nanotubes. Science, 265(5180), 1850-1852.

[50] Hampel, S., Kunze, D., Haase, D., Krämer, K., Rauschenbach, M., Ritschel, M., ... \& Büchner, B. (2008). Carbon nanotubes filled with a chemotherapeutic agent: a nanocarrier mediates inhibition of tumor cell growth. Nanomedicine, 3(2), 175-182.

[51] Lodish, H., Berk, A., Zipursky, S. L., Matsudaira, P., Baltimore, D., \& Darnell, J. (2000). Molecular cell biology. New York.

[52] http://www.cytoskeleton.com/mh01

[53] Guo, B., \& Guilford, W. H. (2004). The tail of myosin reduces actin filament velocity in the in vitro motility assay. Cell motility and the cytoskeleton, 59(4), 264-272.

[54] Janeway, C. A., Travers, P., Walport, M., \& Shlomchik, M. J. (2001). Immunobiology.

[55] http://www.pierce-antibodies.com/products/secondary-antibodies/ 
[56] Weber, P. C., Ohlendorf, D. H., Wendoloski, J. J., \& Salemme, F. R. (1989). Structural origins of high-affinity biotin binding to streptavidin. Science, 243(4887), 85-88.

[57] Diamandis, E. P., \& Christopoulos, T. K. (1991). The biotin-(strept) avidin system: principles and applications in biotechnology. Clinical chemistry, 37(5), 625-636.

[58] Dinu, C. Z., Bale, S. S., Zhu, G., \& Dordick, J. S. (2009). Tubulin encapsulation of carbon nanotubes into functional hybrid assemblies. Small, 5(3), 310-315.

[59] Dinu, C. Z., Bale, S. S., Chrisey, D. B., \& Dordick, J. S. (2009). Manipulation of individual carbon nanotubes by reconstructing the intracellular transport of a living cell. Advanced Materials, 21(10-11), 1182-1186.

[60] Månsson, A., Sundberg, M., Balaz, M., Bunk, R., Nicholls, I. A., Omling, P., ... \& Montelius, L. (2004). In vitro sliding of actin filaments labelled with single quantum dots. Biochemical and biophysical research communications, 314(2), 529-534.

[61] Takatsuki, H., Rice, K. M., Asano, S., Day, B. S., Hino, M., Oiwa, K., ... \& Blough, E. R. (2010). Utilization of myosin and actin bundles for the transport of molecular cargo. Small, 6(3), 452-457.

[62] Takatsuki, H., Tanaka, H., Rice, K. M., Kolli, M. B., Nalabotu, S. K., Kohama, K., ... \& Blough, E. R. (2011). Transport of single cells using an actin bundle-myosin bionanomotor transport system. Nanotechnology, 22(24), 245101.

[63] Iwabuchi, S., Takahashi, T., \& Hatori, K. (2012). Transport of actin-decorated liposomes along myosin molecules $<\mathrm{i}>$ in vitro $</ \mathrm{i}>$. Biochemical and Biophysical Research Communications.

[64] Howard, J. (2001). Mechanics of motor proteins and the cytoskeleton.

[65] Spudich, J. A., \& Watt, S. (1971). The regulation of rabbit skeletal muscle contraction I. Biochemical studies of the interaction of the tropomyosin-troponin complex with actin and the proteolytic fragments of myosin. Journal of Biological Chemistry, 246(15), 4866-4871.

[66] Wong, I., \& Ho, C. M. (2009). Surface molecular property modifications for poly (dimethylsiloxane)(PDMS) based microfluidic devices. Microfluidics and nanofluidics, 7(3), 291-306.

[67] Gittes, F., Mickey, B., Nettleton, J., \& Howard, J. (1993). Flexural rigidity of microtubules and actin filaments measured from thermal fluctuations in shape. The Journal of cell biology, 120(4), 923-934.

[68] W. Zhao, C. Song, and PE. Pehrsson, "Water-Soluble and Optically pH-Sensitive Single-Walled Carbon Nanotubes from Surface Modification", Journal of the American Chemical Society, pp. 12418- 12419 (2002)

[69] Shieh, Y. T., Liu, G. L., Wu, H. H., \& Lee, C. C. (2007). Effects of polarity and pH on the solubility of acidtreated carbon nanotubes in different media. Carbon, 45(9), 1880-1890.

[70] Schutt, C. E., Myslik, J. C., Rozycki, M. D., Goonesekere, N. C., \& Lindberg, U. (1993). The structure of crystalline profilin- $\beta$-actin. Nature, 365, 810-816.

[71] Sheetz, M. P., Chasan, R., \& Spudich, J. A. (1984). ATP-dependent movement of myosin in vitro: characterization of a quantitative assay. The Journal of cell biology, 99(5), 1867-1871.

[72] Persson, M., Gullberg, M., Tolf, C., Lindberg, A. M., Månsson, A., \& Kocer, A. (2013). Transportation of Nanoscale Cargoes by Myosin Propelled Actin Filaments. PloS one, 8(2), e55931. 
[73] Finer, J. T., Simmons, R. M., \& Spudich, J. A. (1994). Single myosin molecule mechanics: piconewton forces and nanometre steps. Nature, 368(6467), 113-119.

[74] Bachand, M., Trent, A. M., Bunker, B. C., \& Bachand, G. D. (2005). Physical factors affecting kinesin-based transport of synthetic nanoparticle cargo. Journal of nanoscience and nanotechnology, 5(5), 718-722.

[75] ToYOSHIMA, Y. Y., Kron, S. J., \& Spudich, J. A. (1990). The myosin step size: measurement of the unit displacement per ATP hydrolyzed in an in vitro assay. Proceedings of the National Academy of Sciences, 87(18), 7130-7134.

[76] Ishikawa, R., Sakamoto, T., Ando, T., Higashi-Fujime, S., \& Kohama, K. (2003). Polarized actin bundles formed by human fascin-1: their sliding and disassembly on myosin II and myosin V in vitro. Journal of neurochemistry, 87(3), 676-685. 